\title{
Dynamic interactions during ribosome targeting to the membrane
}

\author{
Dissertation \\ for the award of the degree \\ "Doctor rerum naturalium" (Dr. rer. nat.) \\ Division of Mathematics and Natural Sciences of \\ the Georg-August-Universität Göttingen \\ within the doctoral program (Biomolecules) \\ of the Georg-August University School of Science (GAUSS)
}

\author{
Submitted by \\ Sejeong Lee \\ from Seoul, Korea
}

Göttingen 2014 


\section{Members of the Thesis Committee:}

Prof. Dr. Wolfgang Wintermeyer

Research Group of Ribosome Dynamics, Max Planck Institute for Biophysical Chemistry

Prof. Dr. Ralf Ficner

Department of Molecular Structural Biology, Göttingen Center for Molecular Biosciences

Prof. Dr. Marina Bennati

Research Group of EPR spectroscopy, Max Planck Institute for Biophysical Chemistry

\section{Members of the Examination Board}

Refree: Prof. Dr. Wolfgang Wintermeyer

Research Group of Ribosome Dynamics, Max Planck Institute for Biophysical Chemistry

2nd Refree:Prof. Dr. Ralf Ficner

Department of Molecular Structural Biology, Göttingen Center for Molecular Biosciences

\section{Further Members of the Examination Board}

Prof. Dr. Marina Bennati,

Research Group of EPR spectroscopy, Max Planck Institute for Biophysical Chemistry

Prof. Dr. Marina V. Rodnina

Department of Physical Biochemistry, Max Planck Institute for Biophysical Chemistry

Prof. Dr. Manfred Konrad

Research Group of Enzyme Biochemistry, Max Planck Institute for Biophysical Chemistry

Prof. Dr. Holger Stark

Research Group of 3D Electron Cryo-Microscopy, Max Planck Institute for Biophysical Chemistry

Date of oral examination : May 19th, 2014 


\section{Affidavit}

I hereby declare that I prepared the dissertation "Dynamic interactions during ribosome targeting to the membrane" on my own and with no other sources and aids than quoted.

Sejeong Lee,

Göttingen, March 2014 


\section{TABLE OF CONTENTS}

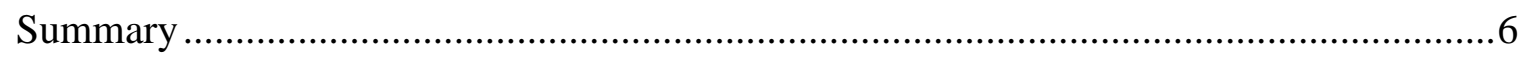

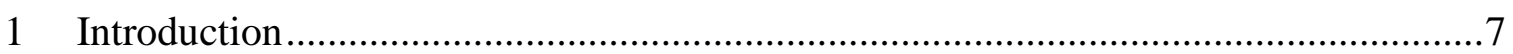

1.1 Targeting translating ribosomes to the membrane ...........................................

1.2 The bacterial signal recognition particle pathway.........................................

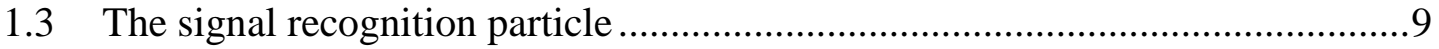

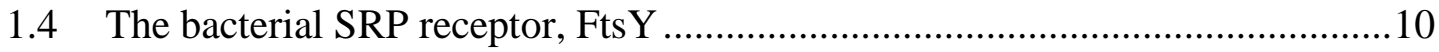

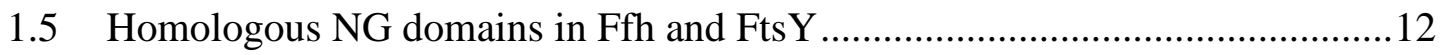

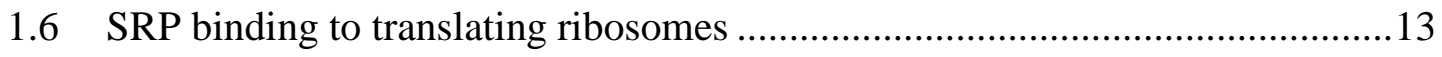

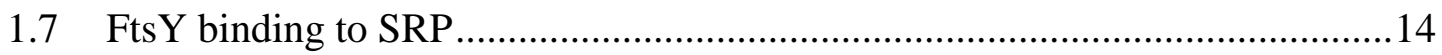

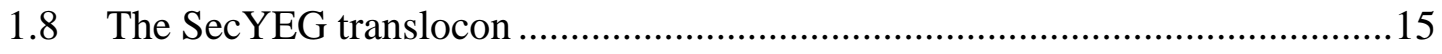

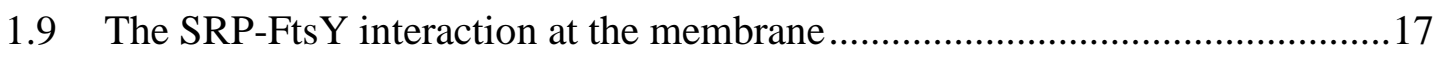

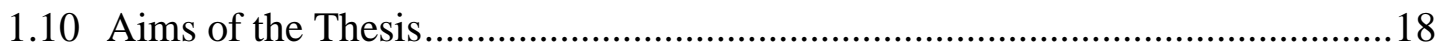

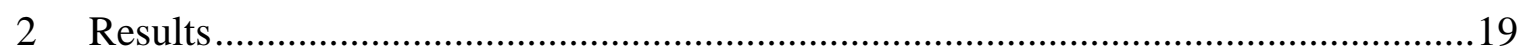

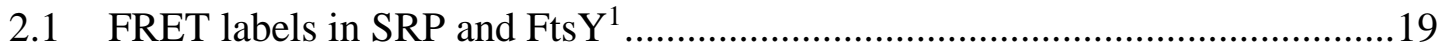

2.2 Affinity of FtsY binding to SRP-ribosome complexes .................................20

2.3 Kinetic stability of FtsY complexes with SRP and ribosome-bound SRP .......21

2.4 Binding of FtsY to SRP and SRP-ribosome complexes................................23

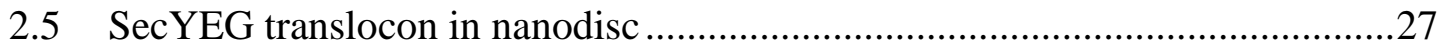

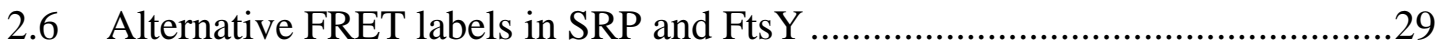

2.7 Stabilization of the SRP-FtsY complex at the translocon ..............................30

2.8 The effect of the translocon on the ribosome-SRP-FtsY complex ....................32

2.9 Partial competitive binding to the ribosome of SRP-FtsY and translocon.........35

2.10 The influence of 4.5S RNA on targeting complex formation ..........................37

2.11 The role of 4.5S RNA in stabilizing the targeting complex .............................39

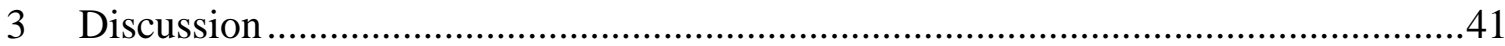




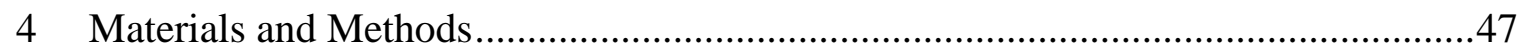

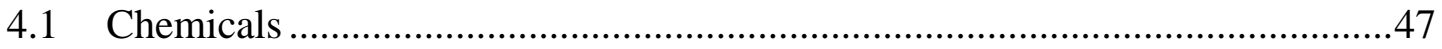

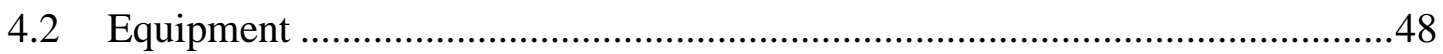

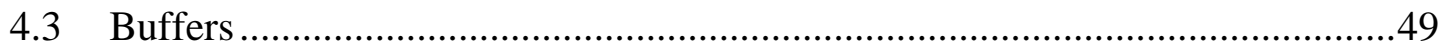

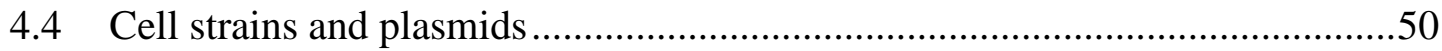

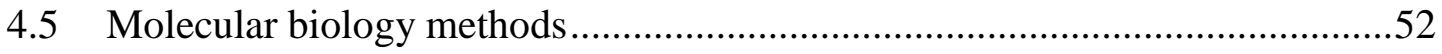

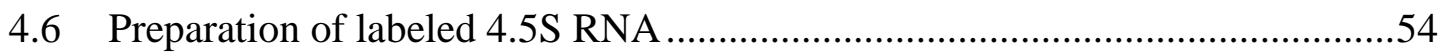

4.7 Preparation of fluorescence-labeled Ffh and FtsY ......................................57

4.8 Preparation of SecYEG embedded in nanodiscs ............................................59

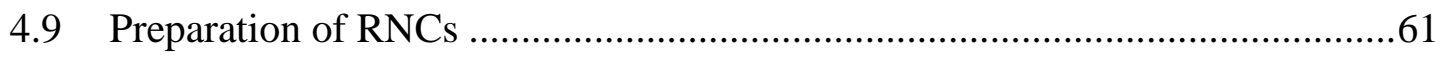

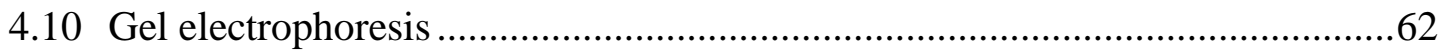

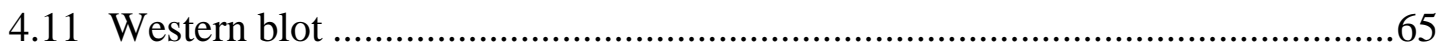

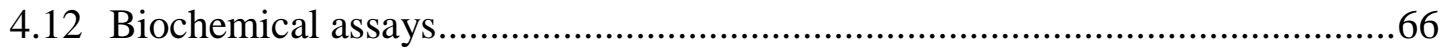

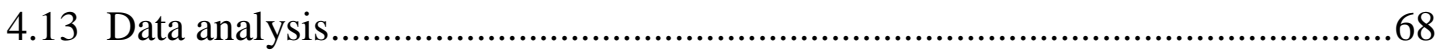

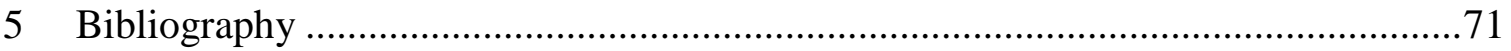

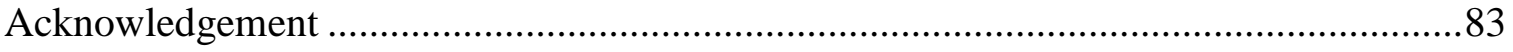

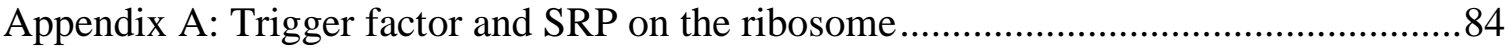

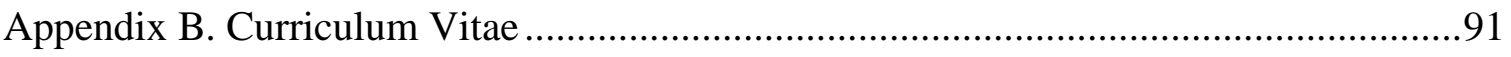




\section{Summary}

The signal recognition particle (SRP) and its receptor are the main components of the cotranslational protein targeting pathway by which membrane proteins are targeted to the membrane. The co-translational targeting pathway is conserved in all organisms. For targeting to the membrane, the membrane proteins contain short hydrophobic patches (about 20 amino acids) at the N-terminus, so called a signal-anchor sequence (SAS). In the bacterial SRP pathway, SRP recognizes a ribosome-nascent chain (RNC) complex by binding to an SAS and forms a targeting complex with its receptor, FtsY. FtsY interacts with SRP and associates with the translocon at the membrane. Thus, from the targeting complex, nascent membrane proteins are transferred to the translocon at the membrane. The targeting complex is formed with high affinity. However, mechanistic details of targeting complex formation and RNC transfer to the translocon are not understood. In this work, the dynamic interactions between SRP and FtsY were analyzed by equilibrium titrations and pre-steadystate kinetics, monitoring FRET between labels introduced in the components of the targeting complex.

We present a mechanism of how the formation of the targeting complex is regulated by the nature of the nascent chain presented on RNCs and how diassembly of the targeting complex and RNC transfer to the translocon is influenced by the nascent chain. The rapid kinetic analysis of targeting complex formation reveals that it takes place in two steps, a bimolecular binding step followed by a conformational change. The conformational change is accelerated on RNCs presenting SAS-containing nascent chains which are about to emerge from the ribosome or already exposed outside the ribosome. Equilibrium studies show that the interaction with the translocon influences binding of FtsY to SRP. In the absence of the RNC, the translocon stabilizes the SRP-FtsY complex. In the presence of ribosomes, the effect is not seen. Instead, the translocon interacts with the ribosome and destabilizes the targeting complex, when the SAS-containing nascent chain reaches a critical length. These observations indicate that the formation and the stability of the targeting complex is regulated by the length of the nascent chain and interaction of the nascent chain containing an SAS with the translocon. 


\section{Introduction}

\subsection{Targeting translating ribosomes to the membrane}

The localization of proteins to the respective destination is essential in cellular activity. Membrane proteins, which comprise about one-third of proteome in every cell, need to be inserted into the eukaryotic endoplasmic reticulum or the bacterial plasma membrane (Driessen and Nouwen, 2008; Rapoport, 2007; Rapoport, 2008). In bacteria, secretory and integral membrane proteins are targeted to the membrane by two distinctive pathways (Beck et al., 2000; Koch and Muller, 2000). Whereas the former are completely translated and then translocated in a post-translational manner, the latter are co-translationally inserted into the membrane. Co-translational targeting is mediated by a ribonucleoprotein complex, signal recognition particle (SRP), and its receptor (SR) (Gilmore et al., 1982; Walter and Blobel, 1981). Co-translational targeting prevents the hydrophobic parts of membrane proteins from misfolding or aggregation in the cytoplasm. Post-translational targeting is conferred by SecB, which is a secretion-dedicated chaperone, and SecA, an ATP-driven motor protein responsible for protein translocation (Huber et al., 2011). Additional proteins at the membrane assist the insertion of mature proteins into the membrane. Co- and posttranslational pathways converge at the translocation machinery, the Sec translocase, in the membrane (Valent et al., 1998).

The targeting of secretory or membrane proteins from ribosomes to the membrane involves interactions between SRP and SR. To be destined to the membrane, the proteins contain an intrinsic signal, which is composed of a specific sequence of 15-20 amino acids at the Nterminus of inner membrane proteins or in the folded proteins (Blobel et al., 1979; Lingappa et al., 1980). The signal sequence consists of three parts, a few positively charged amino acids at the N-terminus, a hydrophobic core, usually in the form of an alpha helix, and the C-terminus. Signal sequences of secretory proteins are cleaved off by signal peptidases (Paetzel et al., 2002), whereas signal sequences of integral membrane proteins are not cleaved and form the first transmembrane helix of the membrane protein, hence the designation signal anchor sequence (SAS) (Robinson et al., 2012; Sakaguchi et al., 1992; Ulmschneider and Sansom, 2001). 


\subsection{The bacterial signal recognition particle pathway}

The SRP-dependent pathway is conserved not only in euaryotes but also in prokaryotes (Bibi, 2011; Grudnik et al., 2009; Luirink et al., 2005). The SAS is co-translationally recognized by SRP. Binding of SRP to the ribosome-nascent chain (RNC) complex arrests translational elongation in eukaryotes (Chang et al., 1997), but not in bacteria. The SASbound SRP forms a targeting complex with the SR (FtsY in bacteria) in a GTP-dependent manner (Powers and Walter, 1995). The targeting complex interacts with the proteinconducting membrane channel (translocon) at the membrane. Nascent chains are transferred to the translocon and then secreted across the membrane or laterally inserted in the membrane. SRP and FtsY are dissociated by GTP hydrolysis, which thereby are recycled for the next targeting cycle.

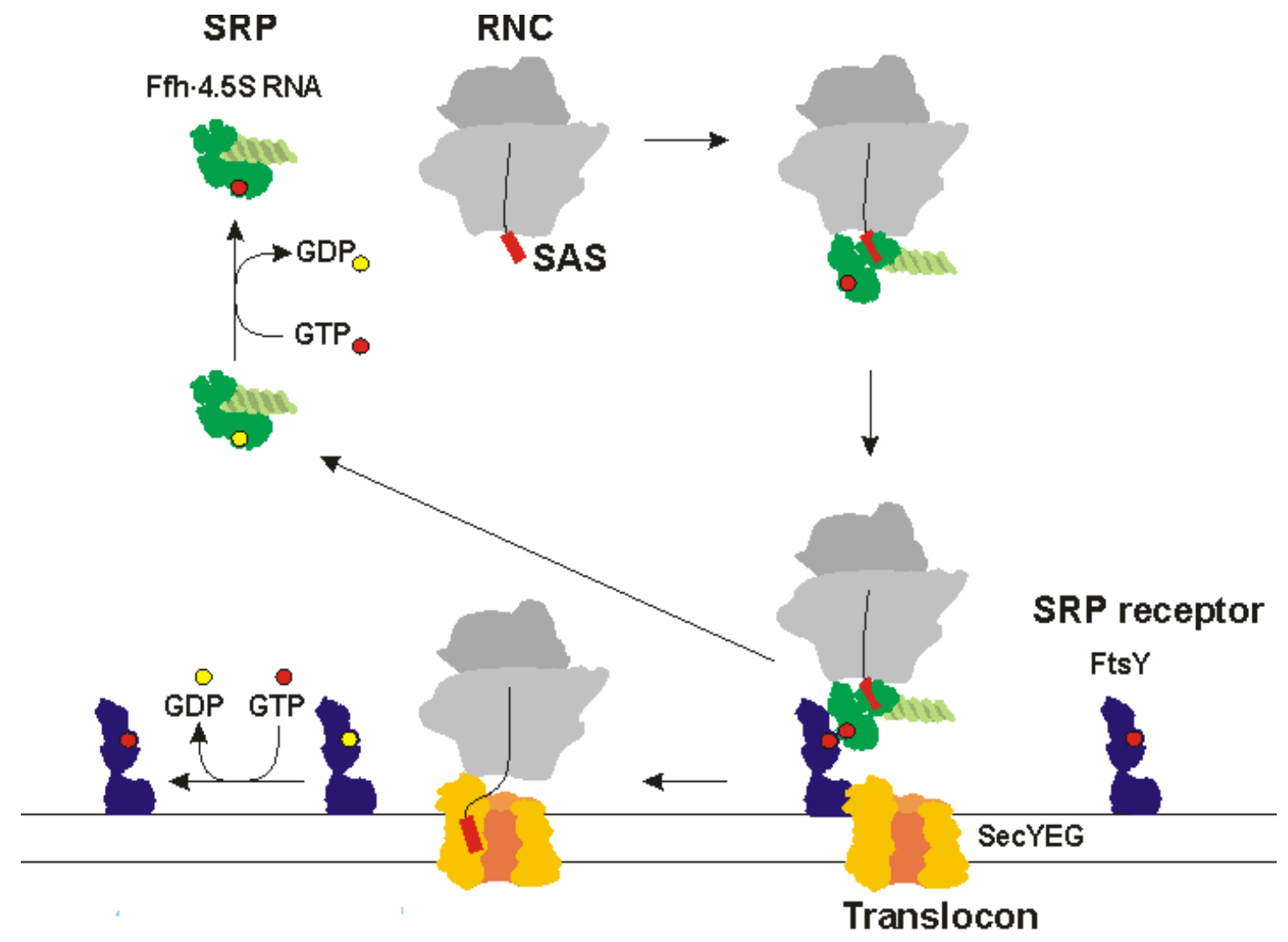

Figure 1 SRP-dependent protein targeting pathway in E.coli

Inner membrane proteins are recruited by the SRP. The RNC-SRP complex is targeted to the translocon with the help of FtsY. Inner membrane proteins are inserted through the lateral gate of the translocon. Finally, SRP and FtsY are recycled after GTP hydrolysis. 


\subsection{The signal recognition particle}

SRP is a universally conserved ribonucleoprotein found in all three kingdoms of life. The depletion of SRP disrupts the insertion and assembly of membrane proteins (Yosef et al., 2010). The composition of the SRP in bacteria is relatively simple compared to the eukaryotic and archaeal SRP. Eukaryotic SRP is composed of six proteins (SRP9, SRP14, SRP19, SRP54, SRP68, SRP72) and 7SL RNA (Gundelfinger et al., 1983). Archaeal SRP consists of SRP19, SRP54, and 7SL RNA. Archaeal 7SL RNA forms a similar secondary structure to higher eukaryotic 7SL RNA (Zwieb and Eichler, 2002). Bacterial SRP is composed of only one protein, Ffh (fifty-four homolog), which is homologous to SRP54 in eukaryotes, and a short 4.5S RNA (114 nucleotides) (Jensen and Pedersen, 1994; Poritz et al., 1990). SRP54 or Ffh recognizes and binds the SAS (Keenan et al., 2001). 4.5S RNA comprises the conserved part of the S domain of the 7SL RNA (Lentzen et al., 1996), which consists of two domains, a large (S) domain and a small (Alu) domain. The $\mathrm{S}$ domain is responsible for SRP assembly with SRP19, SRP54, SRP68, and SRP72. The Alu domain in conjunction with SRP9/14 involves translation arrest by interfering with elongation factor binding to the ribosome (Chang et al., 1997, Mason et al., 2000), while the bacterial SRP does not arrest translation elongation.

Ffh consists of an $\mathrm{N}$ domain, a G domain, which contains the GTP-binding site, and the methionine-rich $\mathrm{M}$ domain (Figure 2). The $\mathrm{N}$ domain is composed of a four-helix bundle and forms a rigid frame with the $G$ domain. The $G$ domain contains the classical four conserved sequence motifs around the GTP binding site and an insertion (IBD domain) that is characteristic for the SRP-related GTPases that belong to the class of SIMIBI GTPases (Verstraeten et al., 2011). The M domain consists of four amphipathic helices. The first two antiparallel helices form a hydrophobic groove which binds the signal sequence and the third helix is part of a highly conserved RNA binding motif (Batey et al., 2000; Janda et al., 2010; Keenan et al., 1998). The NG domain and the $\mathrm{M}$ domain are connected by a linker, called GM linker. The GM linker is disordered therefore the orientation of $\mathrm{M}$ domain to $\mathrm{NG}$ domain could vary depending on the environment and functional state of SRP (Hainzl et al., 2011). 
Free Ffh represents a tightly packed conformation occluding the 4.5S RNA binding site as indicated by the high affinity of the interaction between NG and M domains ( $\mathrm{K}_{\mathrm{d}}$ of 40-90 nM) (Buskiewicz et al., 2005b). However, upon binding of the domain IV of 4.5S RNA to the SRP RNA binding motif in the M domain (Keenan et al., 1998), the M domains opens a little by moving away from the NG domain as indicated by the loss of the crosslinking between the residue 231 of the NG domain and the residue 377 of the $M$ domain (Buskiewicz et al., 2005a). Thus, the structure of $E$. coli SRP resembles the crystal structure of the core of archaeal SRP (Hainzl et al., 2007) (Figure 2).

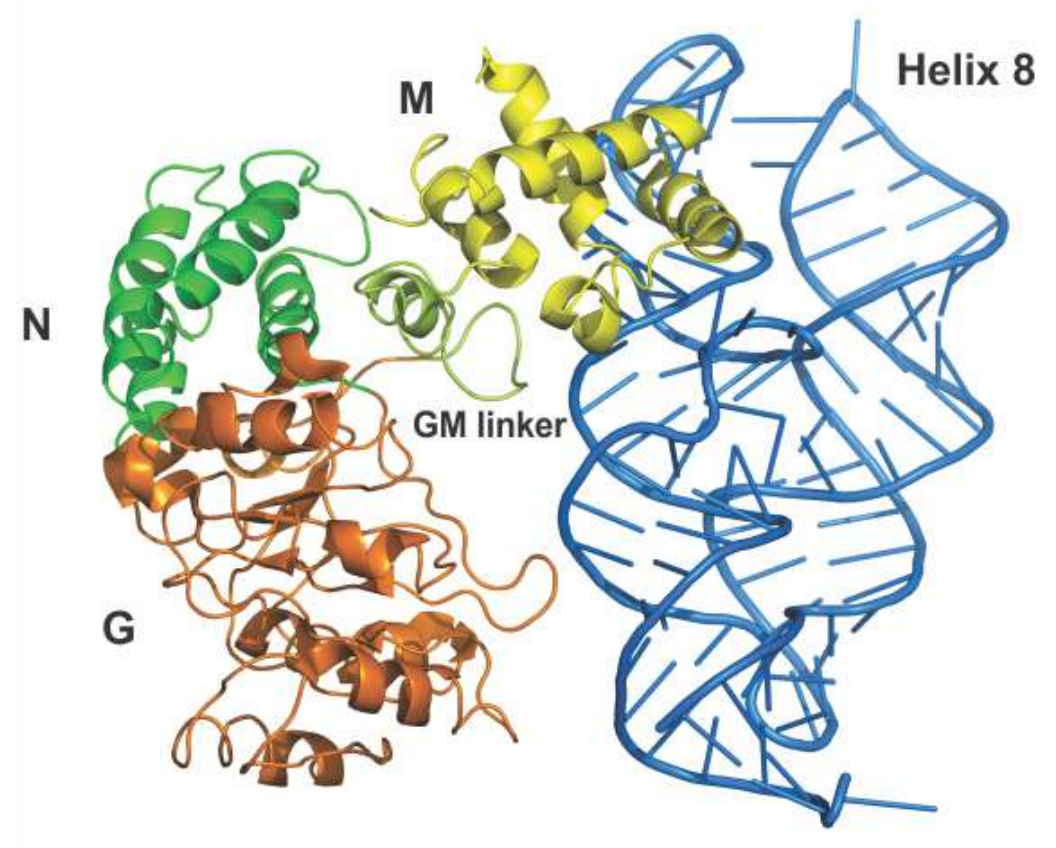

Figure 2 Structure of SRP

Crystal structure of the archaeal SRP core. The core consists of SRP54 and helix 8 of 7SL RNA, which are homologous to Ffh and 4.5S RNA in E.coli. The three domains of Ffh, the $\mathrm{N}$ (green), $\mathrm{G}$ (orange), and $\mathrm{M}$ (yellow) domains are shown. $\mathrm{G}$ and $\mathrm{M}$ domains are connected by the GM linker (lemon). Helix 8 of the S domain of 7SL RNA (blue) is bound to the $\mathrm{M}$ domain. The image was modified from the PDB file 2V3C (Hainzl et al., 2007).

\subsection{The bacterial SRP receptor, FtsY}

The SR recruits the RNC-bound SRP to the membrane due to the amphipathic features. Therefore the SR comprises two subunits, one for binding of SRP and the other for membrane association. The SR in eukaryotes consists of two functional subunits, SR $\alpha$ and 
SR $\beta$, while bacterial and archaeal SR consists of a single protein, Fts Y. SR $\alpha$ (homolog to FtsY) forms a heterodimer with SRP54 and hydrolyzes GTP as SR $\beta$ (Gilmore et al., 1982). $\mathrm{SR} \beta$ is responsible for the membrane association of SR $\alpha$ (Miller et al., 1995; Osborne and Rapoport, 2007). Although FtsY lacks a separate membrane association domain (SR $\beta$ ), it plays a key role in the translocation of membrane proteins, as indicated by in vivo depletion assays (Luirink et al., 1994; Seluanov and Bibi, 1997).

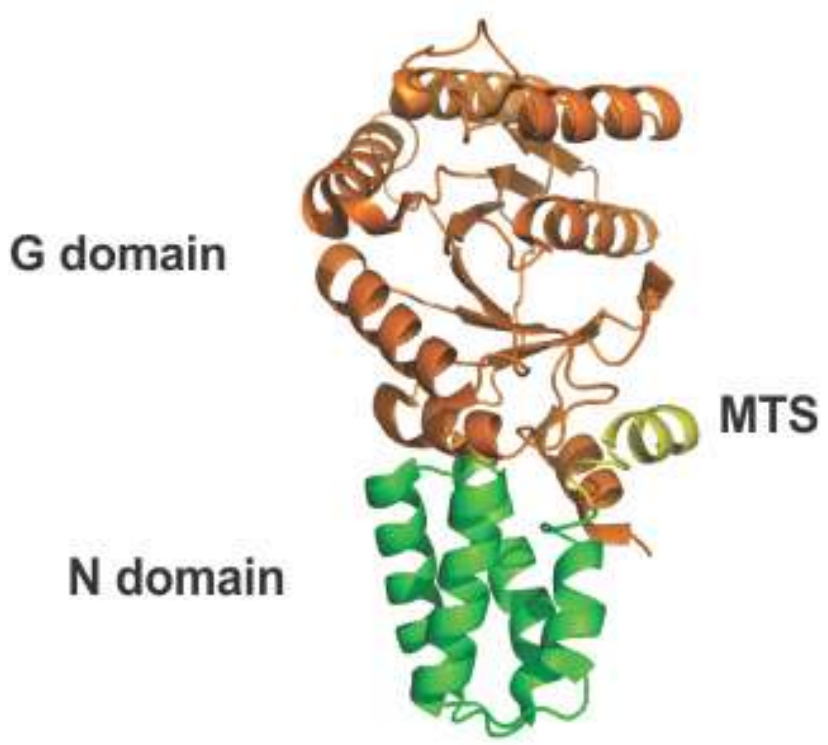

\section{Figure 3 Structure of FtsY-NG+1}

Crystal structure of bacterial SR, FtsY. The N and G domains of Fts $\mathrm{Y}$ are shown in green and orange, respectively. The membrane targeting sequence (MTS), which is responsible for membrane association, is shown in yellow. The image was modified from the PDB file 2QY9 (Parlitz et al., 2007).

FtsY consists of the N-terminal A domain and the NG domain. The FtsY-NG domain is homologous to the NG domain of Ffh and responsible for binding to the Ffh-NG domain in a GTP dependent manner (Montoya et al., 1997) (Figure 4). Presumably, the A domain is responsible for the association with the membrane. Positively charged residues are thought to contribute to the interaction with anionic phospholipid (Bahari et al., 2007; de Leeuw et al., 2000; Millman et al., 2001). In particular, an amphipathic $\alpha$-helix at the N-terminus of the $\mathrm{N}$ domain of FtsY (termed membrane targeting sequence, MTS) downstream the A domain seems to play a key role in lipid binding (Parlitz et al., 2007), as its $\alpha$-helical structure changes in the presence of anionic phospholipids as indicated by circular dichroism (CD) spectra (Stjepanovic et al., 2011). 


\subsection{Homologous NG domains in Ffh and FtsY}

As mentioned above, Ffh and FtsY share homologous NG domains, which form a large interaction interface in the Ffh-FtsY heterodimer (Egea et al., 2004; Eitan and Bibi, 2004; Focia et al., 2004). The heterodimer of the Ffh NG domain and the FtsY NG domain forms a quasi-twofold symmetric complex with three distinctive features (Figure 4). These are inserted-box-domain (IBD) helices, a nucleotide binding cleft, and the triangular-shape interface (Focia et al., 2004).

a

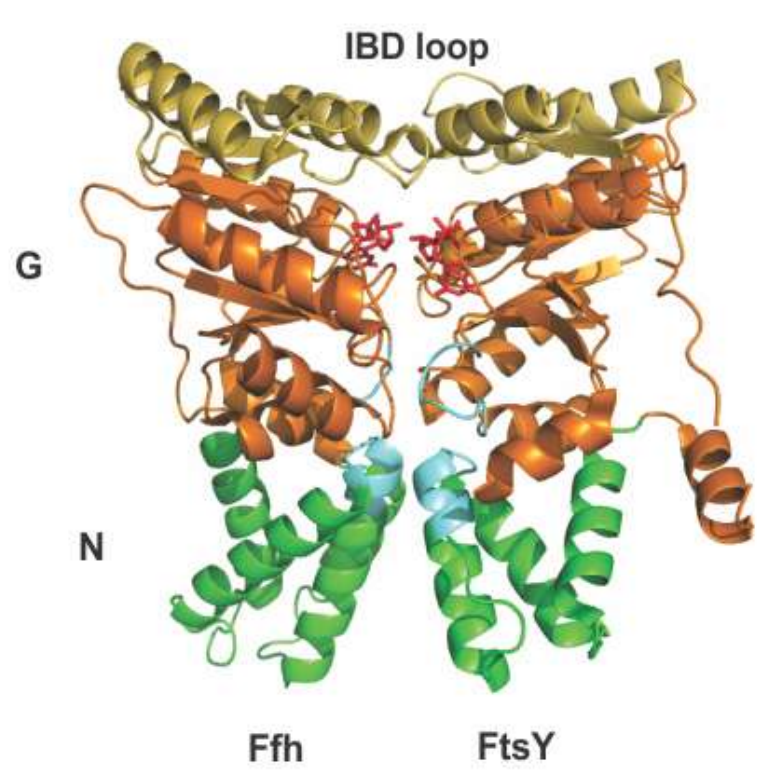

b

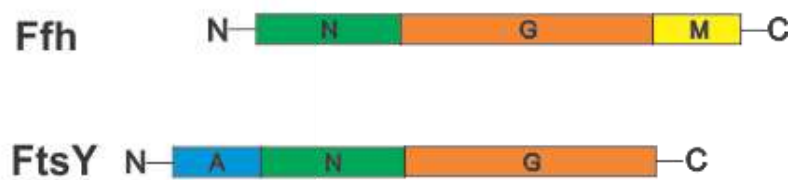

Figure 4 Heterodimer of Ffh(NG) and FtsY(NG)

(a) NG domains of SRP54 (left) and FtsY(right) from Thermus aquaticus are shown as cartoon. Their $\mathrm{N}$ domain and $\mathrm{G}$ domain are shown in green and orange. Two GMPPNP are shown as spheres (red). IBD is in yellow. Conserved motives (ALLEADV and DARGG) are in cyan. The image was modified from the PDB file 2CNW(Focia et al., 2004). (b) Domains of Ffh and FtsY. $\mathrm{N}$ and $\mathrm{C}$ describe $\mathrm{N}$-termini and $\mathrm{C}$-termini, respectively. $\mathrm{NG}$ domains are in same colors as in (a).

The IBD, which is an insertion in motif II in the G domain, is unique for the SRP subfamily of GTPases (Freymann et al., 1997; Montoya et al., 1997). In addition, the conserved residues in the Ffh NG domain such as DARGG or ALLEADV imply hydrophobic interactions which stabilize the heterodimer, the Ffh-FtsY complex (Egea et al., 2004). For the SRP superfamily of GTPases, no GTPase activating protein (GAP) or guanine nucleotide exchange factor (GEF) were found. Accordingly, the dissociation of guanine nucleotides 
from both Ffh and FtsY is rapid intrinsically (Jagath et al., 1998). The triangular shape interface provides a large area of van der Waals interactions and hydrogen bonds, mostly in the G domains (about $2500 \AA^{2}$ ), which are three quarters of the total interface of the FfhFts Y heterodimer (3200 $\left.\AA^{2}\right)$ (Egea et al., 2004).

\subsection{SRP binding to translating ribosomes}

SRP cotranslationally recognizes the SAS on ribosomes at the vicinity of the ribosome tunnel exit. The ribosome tunnel exit is surrounded by four ribosomal proteins, uL22, uL23, uL24 and uL29 (previous name L22 and so on; for the new nomenclature, see (Ban et al., 2014)). The $\mathrm{N}$ domain of Ffh forms crosslinks to uL23 independently of the absence or presence of an SAS (Gu et al., 2003), as supported by cryo-EM structures of the complex which show that SRP interacts with uL23 via the Ffh $\mathrm{N}$ domain (Halic et al., 2006; Schaffitzel et al., 2006). The hydrophobic groove of the M domain in Ffh serves as the SAS binding pocket (Keenan et al., 1998). The M domain of Ffh also interacts with uL24 and binds the SAS. On the translating ribosome, SRP undergoes a conformational rearrangement which changes the relative position of its domains. The GM linker forms a helix and accordingly the $\mathrm{G}$ domain moves in between the $\mathrm{N}$ domain and the $\mathrm{M}$ domain (Hainzl et al., 2011). 4.5S RNA from a bent conformation switches to an extended conformation, to form an open conformation of SRP (Buskiewicz et al., 2009). The cryo-EM structure of bacterial SRP bound to the RNC shows a detailed view (Figure 5), where 4.5S RNA is in contact with the RNC via its C loop and protein bL17 (Halic et al., 2006), supporting the open conformation. The high resolution crystal structure also shows that the SAS-bound SRP core in $M$. janaschii undergoes a similar conformational change, in that the NG domain flips away from 4.5S RNA by 180 degrees (Hainzl et al., 2011). 


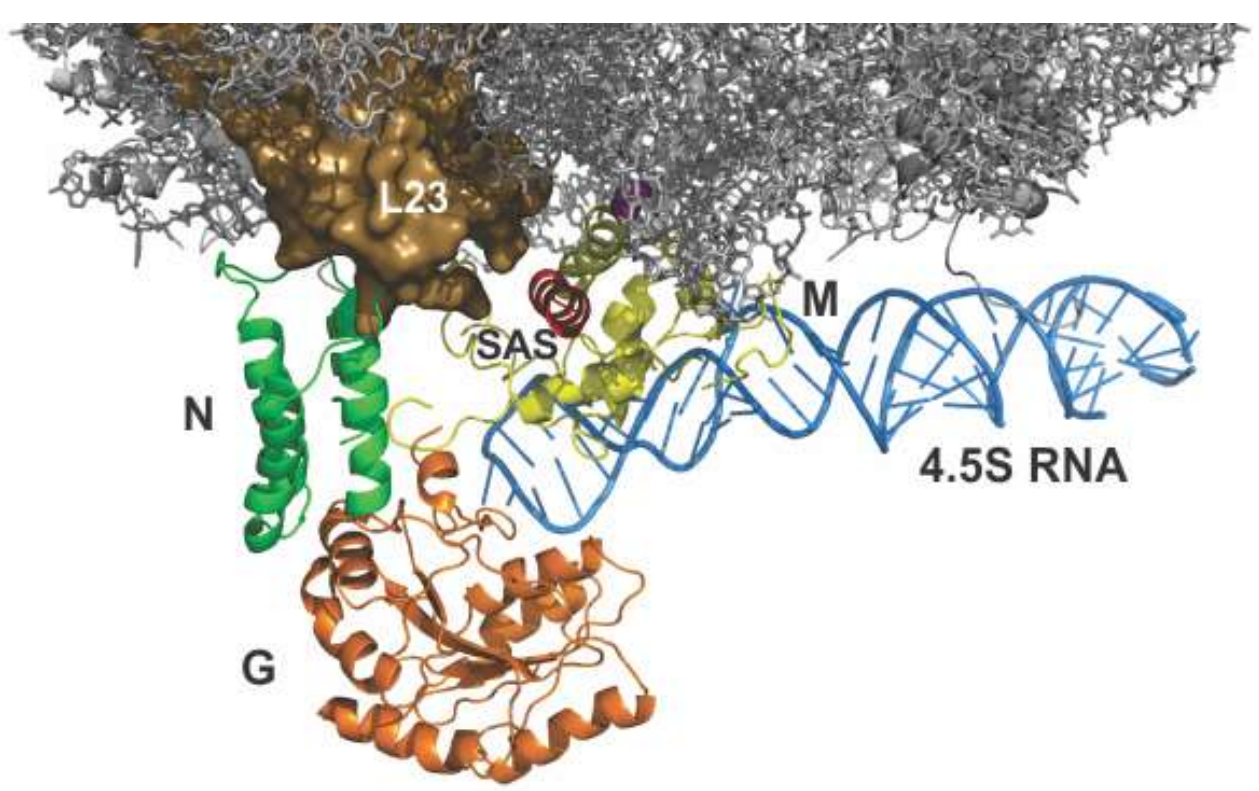

Figure 5 Conformation of SRP on the translating ribosome

The crystal structure of the SRP bound to the RNC in E.coli. The N, G, and M domains of Ffh are shown in green, orange, and yellow color, respectively. The signal peptide is depicted in red. The tetraloop of 4.5S RNA (blue) associates with the G domain of Ffh. The contact of the N domain of Ffh is made with uL23 (brown) of the ribosome. The image was modified from the PDB file 2J28 (Halic et al., 2006).

\subsection{FtsY binding to SRP}

Interactions between SRP and FtsY are involved in ribosome targeting to the membrane. The SRP-FtsY complex is formed in a GTP-dependent manner with moderate affinity $\left(\mathrm{K}_{\mathrm{d}}\right.$ 0.2-0.6 $\mu \mathrm{M}$ ) (Jagath et al., 2001). The GGAA tetraloop of 4.5S RNA at the apex of domain IV is involved in SRP-FtsY complex formation (Jagath et al., 2001)(Spanggord et al., 2005), which may involve a transient tether between the tetraloop and residue K399 of FtsY (Shen and Shan, 2010). Crystal structures of the SRP-FtsY complex show that 4.5S RNA interacts with both Ffh and FtsY via the M domain of Ffh and the NG domains of the Ffh-Fts Y heterodimer (Ataide et al., 2011; Voigts-Hoffmann et al., 2013). A single-molecule FRET study supports the conformation as indicated by increased FRET between the distal end of 4.5S RNA and the G domains of Ffh and FtsY (Shen et al., 2012). Bases at the distal end of 4.5S RNA seem to play an important role in the stimulation of GTP hydrolysis (Akopian et al., 2013). 
The RNC-bound SRP is stable as indicated by 10 to 100 -fold lower dissociation rate compared to the vacant ribosome-bound SRP (Holtkamp et al., 2012), reflecting 10 to 100 fold higher affinity $\left(\mathrm{K}_{\mathrm{d}} \sim 1 \mathrm{nM}\right)$ (Bornemann et al., 2008). The SRP on the RNC is present in an open conformation, which is different from the conformation of free SRP (Buskiewicz et al., 2009). In keeping with a more accessible NG domain, the RNC-SRP complex forms a high-affinity targeting complex with FtsY $\left(\mathrm{K}_{\mathrm{d}} \sim 3 \mathrm{nM}\right)$, with an about 20-fold higher affinity, compared to the complex with vacant ribosomes (Bornemann et al., 2008; Buskiewicz et al., 2009). In addition, Zhang et al. suggests another point of view that the targeting complex is less stable than the SRP-FtsY complex as indicated by four-fold lower affinity $\left(\mathrm{K}_{\mathrm{d}} 40 \mathrm{nM}\right)$ and targeting complex formation is accelerated in the absence of GMPPNP by the RNC (Zhang et al., 2009). Since current cryo-EM structures show that both substrate and GTP are necessary for correct targeting complex formation, this model is not well understood. The complex (RNC-SRP-FtsY) exposing the non-SRP substrate does not form a quasi-twofold symmetric structure between Ffh- and FtsY-NG domains, but forms a so-called 'false' complex (von Loeffelholz et al., 2013). The targeting complex in the absence of GMPPNP contains only a transient contact between Fts Y and the tetraloop of 4.5S RNA (Estrozi et al., 2011).

Upon targeting complex formation, the RNC-SRP complex undergoes a limited conformational change as shown by FRET distance measurements (Buskiewicz et al., 2009). In parallel to this, the mammalian targeting complex undergoes a slight conformational change whereby the heterodimer of SRP54 and SR $\alpha$ (homolog to the Ffh-FtsY heterodimer) swings a little from L23e and bL35 (homolog to L23 in E.coli) (Halic et al., 2006b). However, dynamics of targeting complex formation are poorly understood.

\subsection{The SecYEG translocon}

Secretory and membrane proteins, which are targeted to the membrane by SRP and SR, are exported across or inserted into the bacterial cytoplasmic membrane via a proteinconducting channel, the Sec translocon that is found in all three kingdoms of life (Simon and Blobel, 1991). The Sec translocon is a trans-membrane protein complex, consisting of three different subunits, which are homologous and called Sec61 $\alpha \beta \gamma$ in eukarya, SecYE $\beta$ in 
archaea, and SecYEG in bacteria (Matlack et al., 1998). The bacterial SecYEG translocon is composed of SecY, SecE, and SecG proteins. SecY (48 kD) consists of ten transmembrane helices (TM helices) which form two domains in a clamshell shape (Figure 6). The two pseudo-symmetric halves are formed of TM helices1-5 and 6-10 and are connected by a hinge between helix 5 and 6 (Van den Berg et al., 2004). SecE (14 kD) consists of two TM domains, of which one traverses the translocase complex making extensive contacts with SecY, and the other is amphipathic (Van den Berg et al., 2004). SecG (12 kD) is homologous to $\operatorname{Sec} \beta$ of $M$. janaschii, which is known as non-essential for translocation (Flower, 2001). SecG makes only limited contacts with SecY. The cytosolic loops 6/7 and 8/9 of SecY contact uL23, uL24 and uL29 (Frauenfeld et al., 2011). Therefore, mutations in the cytosolic loop 8/9 cause a defect of translocation activity (Baba et al., 1990). For instance, residue R357 is essential for the function of SecY in translocation (Akopian et al., 2013; Mori and Ito, 2001), and the mutation of the residue R357 of SecY causes the loss of the interaction of SecY with the ribosome, as indicated by a cryo-EM structure (Menetret et al., 2007). In eukaryotes, point mutations in the loops homologous to loops 6/7 and loop 8/9 of E. coli SecY inhibit the co-translational translocation, as indicated by a decrease in growth rate (Cheng et al., 2005).

Upon recognition of the signal sequence, the plug domain is relocated and the pore ring widens up (Harris and Silhavy, 1999; Park et al., 2013; Tam et al., 2005) (Figure 6). Transmembrane segments of membrane proteins inserted into the channel then move to the lipid bilayer through the 'lateral gate'. Reversible lateral gate opening (Bonardi et al., 2010) is closely involved in translocation activity as indicated by the observation that chemical crosslinking between TM2b and TM7 abolishes translocation (du Plessis et al., 2009). A cryo-EM structure shows the signal peptide associated with the partially opened lateral gate (TM2b and TM7 of the SecY) at the periphery of the translocon (Park et al., 2013).

Whether the functional SecYEG translocon is in a monomeric or higher oligomeric state has been under debate. A dimer was observed by cryo-EM, native gel and cross-linking, (Bessonneau et al., 2002; Breyton et al., 2002; Mitra et al., 2005), which can aid each other when one of them is defective in translocation (Osborne and Rapoport, 2007). Since a new technique called nanodisc made it possible to study integral proteins in phospholipid-protein 
complexes assuming the native structure (Bayburt and Sligar, 2002), a functional single copy of SecYEG translocon is biochemically defined (Alami et al., 2007; Kedrov et al., 2011). Monomeric structures in bacterial SecYEG complex (Frauenfeld et al., 2011) and yeast and mammalian Sec61 complexes (Becker et al., 2009) are also recently shown by cryo-EM. It was not excluded that the SecYEG translocon may assemble and form oligomers in cell. However, it seems likely that translating ribosomes interact with a single SecYEG translocon, whereas the functional complex with SecA may be the SecYEG dimer (Wu et al., 2012).
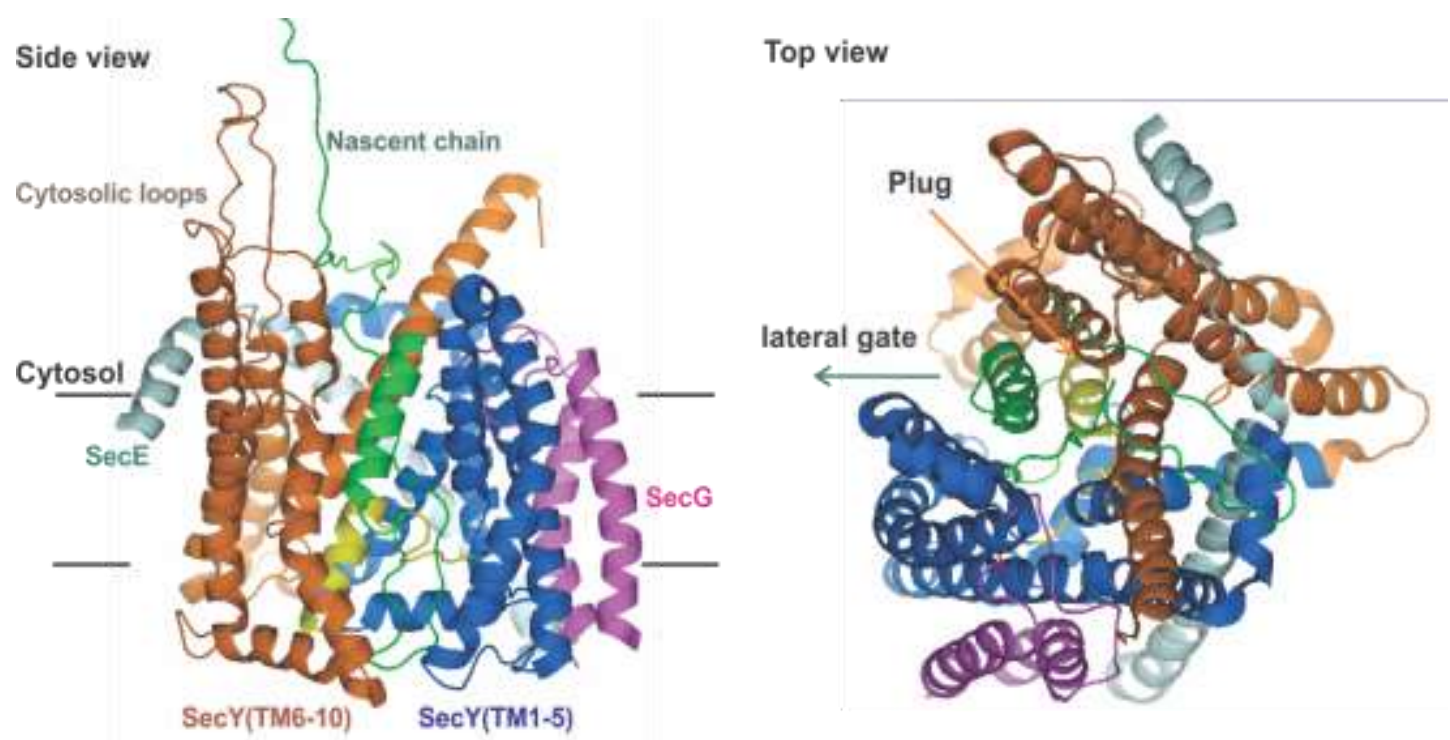

\section{Figure 6 Structure of SecYEG translocon}

Crystal structure of bacterial SecYEG complex. (Left: side view) SecY is arranged in ten TM helices, TM1-5 (blue) and TM6-10 (brown) that are connected by a hinge between TM5 and TM6. The plug domain is shown in yellow, the SecE helices in pale green, SecG in violet, and the nascent peptide in bright green. (Right: top view) Nascent chains (green) are next to the lateral gate, which creates an opening between TM2b and TM7. Plug domain (yellow) is moved away from the pore. The structure illustrates how the SecYEG complex opens the pore upon translocation. The image was modified from the PDB file 3J46 (Park et al., 2013).

\subsection{The SRP-FtsY interaction at the membrane}

FtsY has been reported to be about equally distributed in between cytoplasm and membrane (Luirink et al., 1994). In the resulting targeting model, FtsY forms a targeting complex with the RNC-SRP complex in the cytosol and transfers the RNC on to the translocon. However, according to recent results obtained by fluorescence microscopy in vivo, FtsY seems to be 
mainly localized at the plasma membrane, (Mircheva et al., 2009), where it probably interacts with both lipids and the translocon.

FtsY seems to bind to the SecYEG translocon via its two domains, NG and A domains, as indicated by protease protection and resistance against carbonate extraction, respectively (Angelini et al., 2006). The observation of co-purification of an FtsY-SecY complex also indicates direct interactions between FtsY and the translocon (Bahari et al., 2007). Recent studies report that SRP binding to FtsY in the presence of phospholipids is facilitated and undergoes a conformational change as shown by gel analysis (Braig et al., 2011). However, the interaction between SRP and FtsY in the presence of the translocon at the membrane is not well understood. Also, the effect of the SecYEG translocon on the targeting complex has been studied. The SecYEG translocon solubilized by adding the detergent DDM enhanced the low GTPase activity of the RNC-SRP-FtsY complex (Akopian et al., 2013). However, it is unclear whether or not the intact targeting complex, consisting of RNC, SR, and FtsY interacts with the translocon to form a quaternary complex at the membrane.

\subsection{Aims of the Thesis}

The interaction between SRP and FtsY is dynamic for the targeting of integral membrane proteins to the membrane. So far the steady-state kinetic agrees with the higher thermodynamic stability of the targeting complex (RNC-SRP-FtsY), compared to the complex with vacant ribosomes. The stable targeting complex interacts with the translocon at the membrane and facilitates the docking of the RNC to the translocon. However, by which mechanism the targeting complex is formed and how the targeting complex is disassembled at the translocon are unclear. In the present work, we aimed to elucidate (i) the mechanism of targeting complex formation and dissociation in a time-resolved manner and (ii) to understand how the thermodynamic stability of the targeting complex changes at the translocon. This involved the use of pre-steady-state kinetics and steady-state titration experiments. Using fluorescence change and FRET between SRP and FtsY, the targeting complex was monitored. For comparison, various functional states of ribosomes were used. A few kinetic experiments with a ribosome-associated chaperone, trigger factor, that influences the interaction of SRP with ribosomes are presented in an Appendix. 


\section{Results}

\subsection{FRET labels in SRP and Fts $\mathrm{Y}^{1}$}

The SRP-FtsY complex formation was studied by fluorescence resonance energy transfer (FRET) between fluorescence labels introduced into SRP(Ffh) and FtsY. To obtain selectively labeled Ffh, the residue at the position 406 was mutated into Ser (C406S). C406S is well tolerated as shown by NTCB cleavage assay (Cleverley and Gierasch, 2002). To determine rate constants of FtsY interaction with SRP and SRP bound to ribosomes, the G domains of Ffh and Fts $\mathrm{Y}$ were chosen as labeling targets, because the primary binding between Ffh and FtsY is via their G domains (Egea et al., 2004). Therefore, residue A152 in Ffh and residue V342 in FtsY located in the helical region of the G domains were exchanged with Cys. The Cys residues in Ffh and FtsY were labeled with Alexa-555 (donor) and QSY9 (non-fluorescent acceptor), respectively. In addition, the Cys residue in FtsY was labeled with BPY (Fts Y342BPY) (Figure 7).

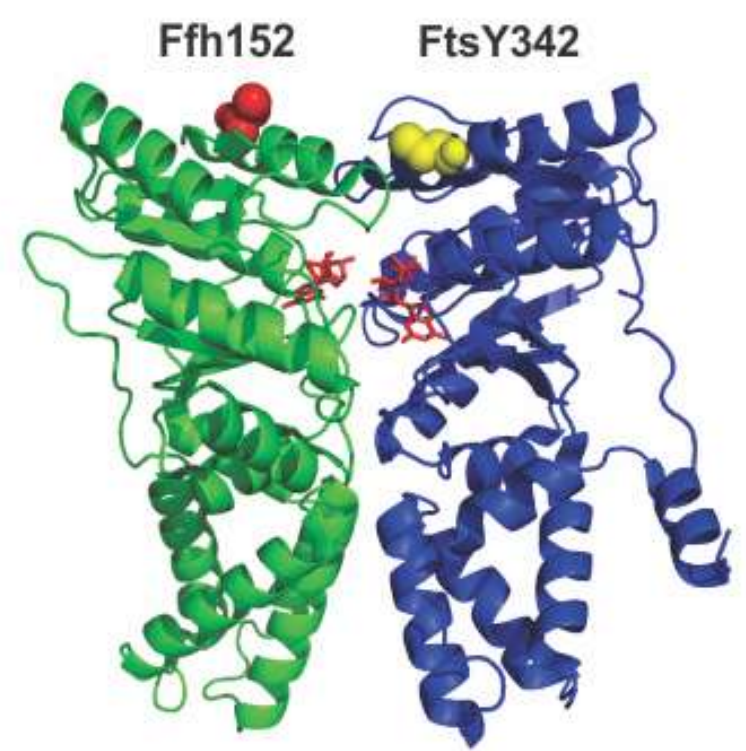

Figure 7 Positions of fluorophores in Ffh (left) and FtsY (right)

Crystal structure of the Ffh-FtsY NG domain heterodimer from T.aquaticus. Residue 152 in Ffh (red) and residue 342 in FtsY (yellow) are shown above the GTP binding pocket. The color code is the same as in Figure 1. The image was modified from the PDB file 2CNW (Focia et al., 2004).

\footnotetext{
${ }^{1}$ Parts of this work are published in the following article: Holtkamp, W., Lee, S., Bornemann, T., Senyushkina, T., Rodnina, M. V. and Wintermeyer, W. (2012). Dynamic switch of the signal recognition particle from scanning to targeting. Nat Struct Mol Biol 19, 1332-7.
} 


\subsection{Affinity of FtsY binding to SRP-ribosome complexes}

As mentioned above, it has been shown that affinities of FtsY binding to ribosome-bound SRP complex increase in the presence of nascent chains (Bornemann et al., 2008). To verify that our labeled components behave as the unlabeled ones, we have measured the affinities of the SRP-FtsY complex formation by monitoring FRET between SRP(ALX) and FtsY(QSY) (Figure 7).

In the absence of ribosomes, the affinity of the SRP-FtsY complex was observed as $K_{d}=$ $700 \pm 100 \mathrm{nM}$ (Figure 9a), consistent with the published values $\left(\mathrm{K}_{\mathrm{d}}=200-600 \mathrm{nM}\right)(\mathrm{Jagath}$ et al., 2000). The affinity of the ribosome-SRP-FtsY complex was determined as $250 \pm 50$ $\mathrm{nM}$ (Figure 9b), comparable to a previous value $\left(\mathrm{K}_{\mathrm{d}} \sim 70 \mathrm{nM}\right)$ determined with 3'-end truncated 4.5S RNA (61mer; (Bornemann et al., 2008; Buskiewicz et al., 2009)). To examine the influence of an SAS on the ribosome-SRP-FtsY complex, the isolated SAS of an inner-membrane protein, Leader peptidase (de Gier et al., 1996), was used as a model substrate. To improve the solubility of the hydrophobic peptide, Lys residues were introduced into the peptide (Figure 8). In the presence of the Lep-peptide, the affinity of the ribosome-SRP-FtsY complex increased $\left(\mathrm{K}_{\mathrm{d}}=20 \pm 5 \mathrm{nM}\right)$ (Figure 9c). The ten-fold increased affinity indicates that the presence of the SAS stabilizes the ribosome-SRP-FtsY complex.

\section{MKK MFALILVIATLVTGILWCVD KKKK}

\section{Figure 8 Lep27 peptide}

Lep peptide containing the SAS of leader peptidase (red) and additional Lys residues (blue).

For the next step, the affinity of the RNC-SRP-FtsY complex was determined using RNCs prepared by in vitro translation of 3'-truncated Lep-mRNA (Method 4.9). RNCs carrying the N-terminal 35 and 50 amino acids of leader peptidase, Lep35- and Lep50-RNC were prepared. In Lep35-RNC, the exit tunnel of the ribosome presumably is just filled, whereas in Lep50-RNC the SAS of leader peptidase will be exposed (Bornemann et al., 2008). SRP in complex with Lep35-RNC and Lep50-RNC bound FtsY with high affinity, $\mathrm{K}_{\mathrm{d}}=7 \pm 2 \mathrm{nM}$ 
and $5 \pm 1 \mathrm{nM}$, respectively (Figure 9d), as observed with the 3'-end truncated 4.5S RNA previously (Bornemann et al., 2008). Therefore, we monitored the kinetics of targeting complex formation using labeled Ffh(ALX) and FtsY(QSY).

a

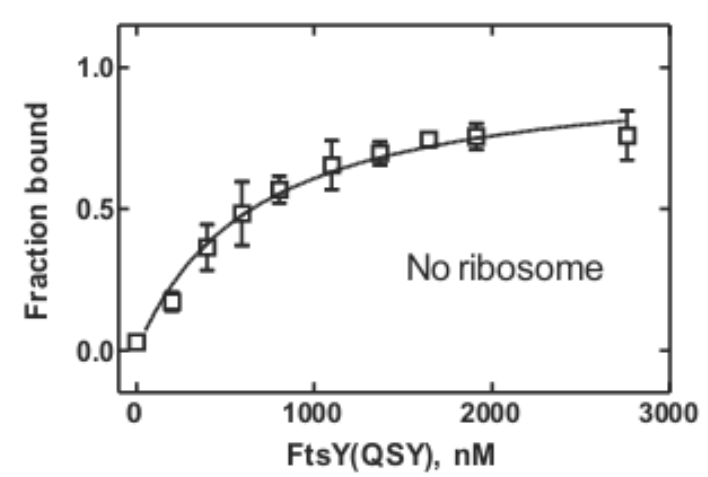

C

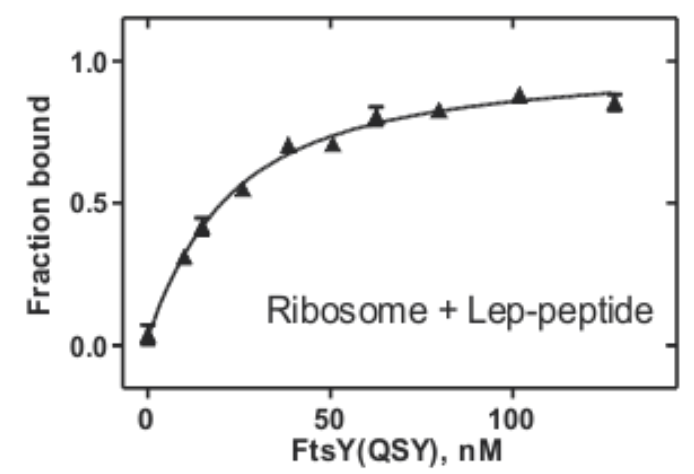

b

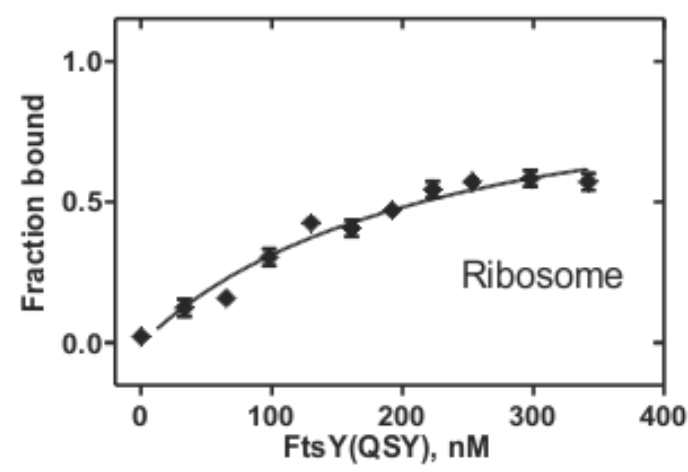

d

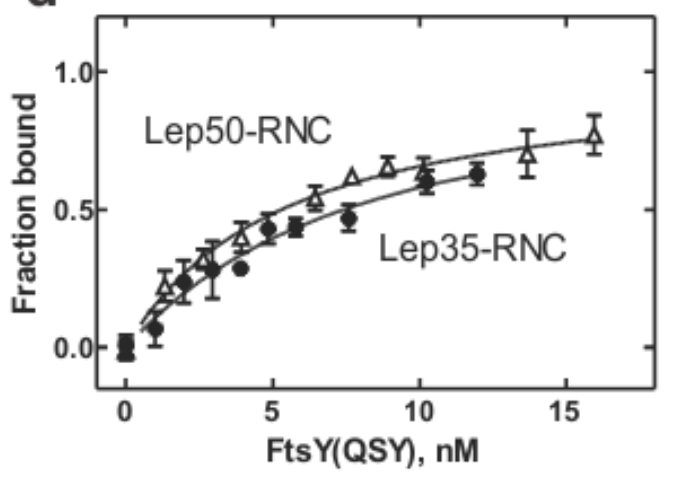

Figure 9 Equilibrium titrations of FtsY binding to SRP

Equilibrium titrations of SRP and SRP bound to ribosomes with FtsY. (a) FtsY binding to SRP. (b) FtsY binding to SRP bound to vacant ribosomes. (c) FtsY binding to ribosomebound SRP in the presence of Lep-peptide. (d) FtsY binding to SRP bound to Lep35-RNC or to SRP bound to Lep50-RNC. Titration data were evaluated by fitting to a quadratic equation assuming a 1:1 binding stoichiometry. Points depicted are averages from two to three measurements.

\subsection{Kinetic stability of FtsY complexes with SRP and ribosome-bound SRP}

To find out whether the stabilization effect comes from the kinetic stability of the targeting complex, the dissociation experiment was performed by mixing the SRP(ALX)-FtsY(QSY) complex in a various functional states of ribosomes with an excess $(5 \sim 10 \mu \mathrm{M})$ of nonlabeled FtsY in the stopped-flow apparatus. Upon dissociation of the complex, the increase in donor fluorescence was monitored (Figure 10). The time course of the donor fluorescence 
was fitted to a double-exponential equation which implies a two-step mechanism. Dissociation rate constants $\left(\mathrm{k}_{-1}, \mathrm{k}_{-2}\right)$ were determined by global fitting the combined set of dissociation and association experiments (Methods 4.13.4).

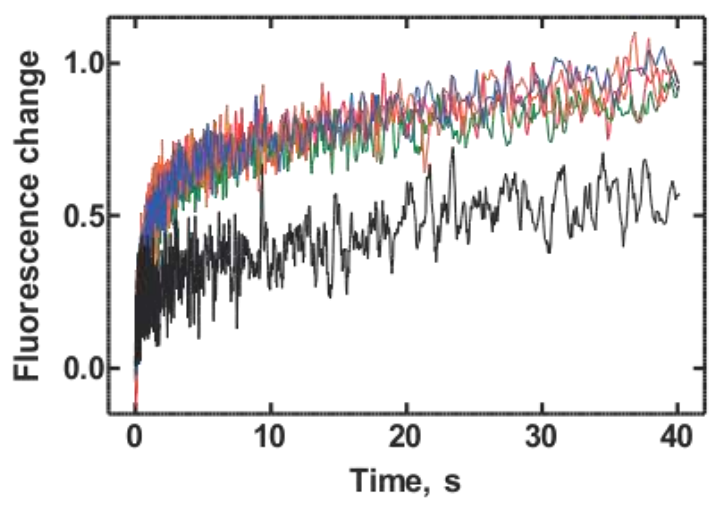

Figure 10 Dissociation of the SRP-FtsY complex in different functional states of ribosomes

Dissociation of FtsY from SRP alone (black); ribosome-bound SRP (blue); ribosome-bound SRP with Lep-peptide (orange); Lep35-RNC-bound SRP (green); Lep50-RNC-bound SRP (red). SRP-ribosome-FtsY complexes $(0.1 \mu \mathrm{M}$ SRP, $0.5 \mu \mathrm{M}$ non-translating ribosomes, 1 $\mu \mathrm{M}$ FtsY) or SRP-RNC-FtsY complexes $(0.1 \mu \mathrm{M}$ SRP, $0.085 \mu \mathrm{M}$ RNC, $1 \mu \mathrm{M}$ FtsY) were rapidly mixed with non-labeled FtsY $(5 \mu \mathrm{M})$. The decrease in donor fluorescence of Ffh(ALX) was detected with an excitation at $520 \mathrm{~nm}$ through a KV550 cut off filter (Schott). The dissociation rate constants are presented in Table 1.

Table 1 Rate constants of FtsY dissociation from SRP and SRP-ribosome complexes

\begin{tabular}{|l|c|c|c|c|c|}
\hline \multirow{2}{*}{} & \multicolumn{5}{|c|}{ FtsY dissociation from } \\
\cline { 2 - 6 } & SRP & $\begin{array}{c}\text { Ribosome- } \\
\text { SRP }\end{array}$ & $\begin{array}{c}\text { Ribosome- } \\
\text { SRP + Lep }\end{array}$ & $\begin{array}{c}\text { Lep35-RNC- } \\
\text { SRP }\end{array}$ & $\begin{array}{c}\text { Lep50-RNC- } \\
\text { SRP }\end{array}$ \\
\hline $\mathrm{k}_{-1}, \mathrm{~s}^{-1}$ & $8 \pm 2$ & $1.6 \pm 0.3$ & $1.4 \pm 0.2$ & $1.5 \pm 0.3$ & $1.6 \pm 0.3$ \\
\hline $\mathrm{k}_{-2}, \mathrm{~s}^{-1}$ & $0.05 \pm 0.02$ & $0.05 \pm 0.02$ & $0.2 \pm 0.05$ & $0.1 \pm 0.03$ & $0.07 \pm 0.02$ \\
\hline
\end{tabular}

The five-fold smaller dissociation rate $\left(\mathrm{k}_{-1} 8 \mathrm{~s}^{-1}\right.$ to $\left.1.6 \mathrm{~s}^{-1}\right)$ in the presence of ribosomes suggests that the ribosome contributes to the stabilization of the SRP-FtsY complex, in line with three-fold higher affinity. The comparable dissociation rates of the SRP-FtsY complex on vacant and translating ribosome indicate that SRP binding to the nascent chain does not increase the kinetic stability of the SRP-FtsY complex. This implies that the increased 
affinity of SRP-FtsY interaction on Lep-RNCs must be due to an effect on the binding step. This is examined in the following.

\subsection{Binding of FtsY to SRP and SRP-ribosome complexes}

To explain the high affinity of the targeting complex and determine the kinetic model of SRP-FtsY complex formation, FtsY(QSY) binding to SRP(ALX) was measured by FRET in stopped-flow experiments, monitoring the decrease of donor fluorescence upon complex formation (Figure 11a). Complex formation was monitored over time at increasing concentrations of FtsY(QSY). Time courses were fitted by a double-exponential function ( $\mathrm{k}_{\mathrm{app} 1}$ and $\mathrm{k}_{\mathrm{app} 2}$ ), indicating a two-step association mechanism, as expected from the two-step dissociation described above (Figure 13). The apparent rate constant of the first step $\left(\mathrm{k}_{\mathrm{app} 1}\right)$ increased linearly as the concentration of FtsY(QSY) increased (Figure 11b), indicating that the rapid phase of FtsY binding to SRP is due to the bimolecular association. From the linear fitting, an analytic solution of the elemental rate constants $\mathrm{k}_{1}$ and $\mathrm{k}_{-1}$ was obtained. The quality of the signal was good enough to guess $k_{a p p 2}$ but not enough to get an elemental rate constant $\left(\mathrm{k}_{\mathrm{app} 2}\right.$ 0.04 0.2 $\left.\mathrm{s}^{-1}\right)$. Therefore, the association experiment was repeated with different labels.

To determine the elemental rate constant in the second step of association, FtsY labeled with BPY at position 342 was used. FtsY(342BPY) reported complex formation with SRP only in the presence of GMPPNP (Figure 11c), i.e. did not report initial binding, which does not require the nucleotide. It is likely, therefore, that FtsY(342BPY) reports a conformational change of the complex following the binding step. The time course of the BPY fluorescence was fitted to a single exponential function. The apparent rate constants $\left(\mathrm{k}_{\mathrm{app} 2}\right)$ increased in a hyperbolic fashion with the concentration of SRP (Figure 11d). At the highest SRP concentration $(5 \mu \mathrm{M}) \mathrm{k}_{\mathrm{app} 2}$ of $0.19 \mathrm{~s}^{-1}$ was obtained (data not shown), which is in the same range as the $k_{\text {app2 }}$ observed by FRET in the saturating conditions. This indicates that the signal change in BPY fluorescence reports the second step of association, a conformational change.

From the concentration dependence of the apparent rate constants, elemental rate constants were obtained. Global fitting of the combined data set of association and dissociation 
experiments based on the elemental rate constants yielded rate constants (Method 4.13.4). As a result, association rate constants of the SRP-FtsY complex were determined as $\mathrm{k}_{1}$ of 5 $\pm 1 \mu \mathrm{M}^{-1} \mathrm{~s}^{-1}$ and $\mathrm{k}_{2}$ of $0.14 \pm 0.05 \mathrm{~s}^{-1}$.

a

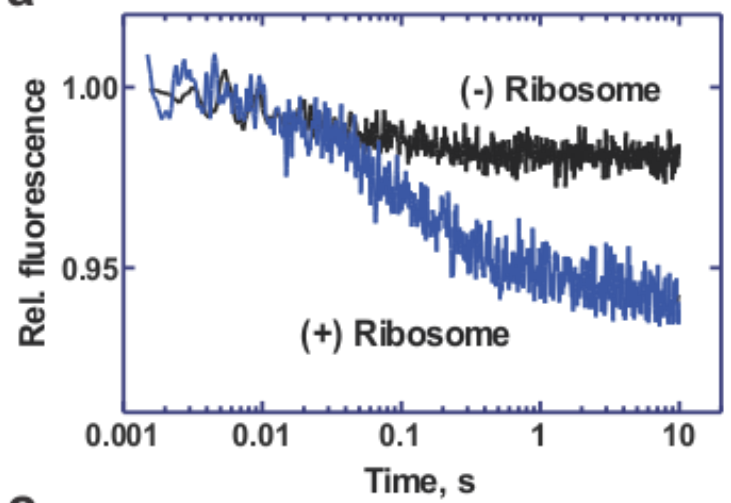

C

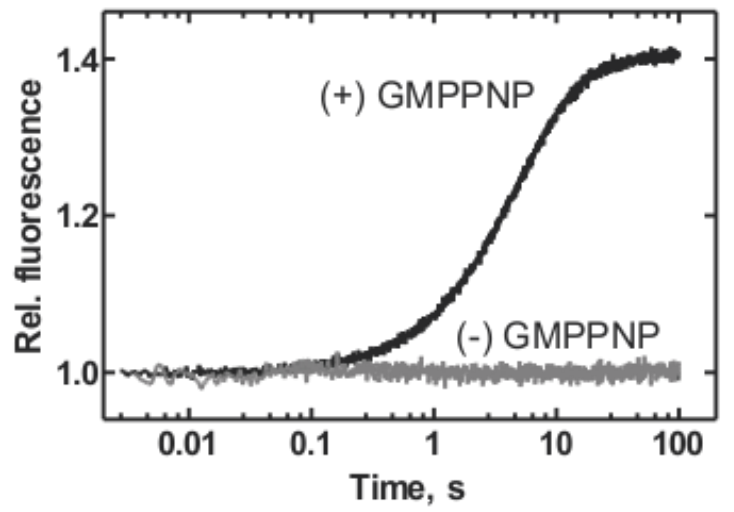

b
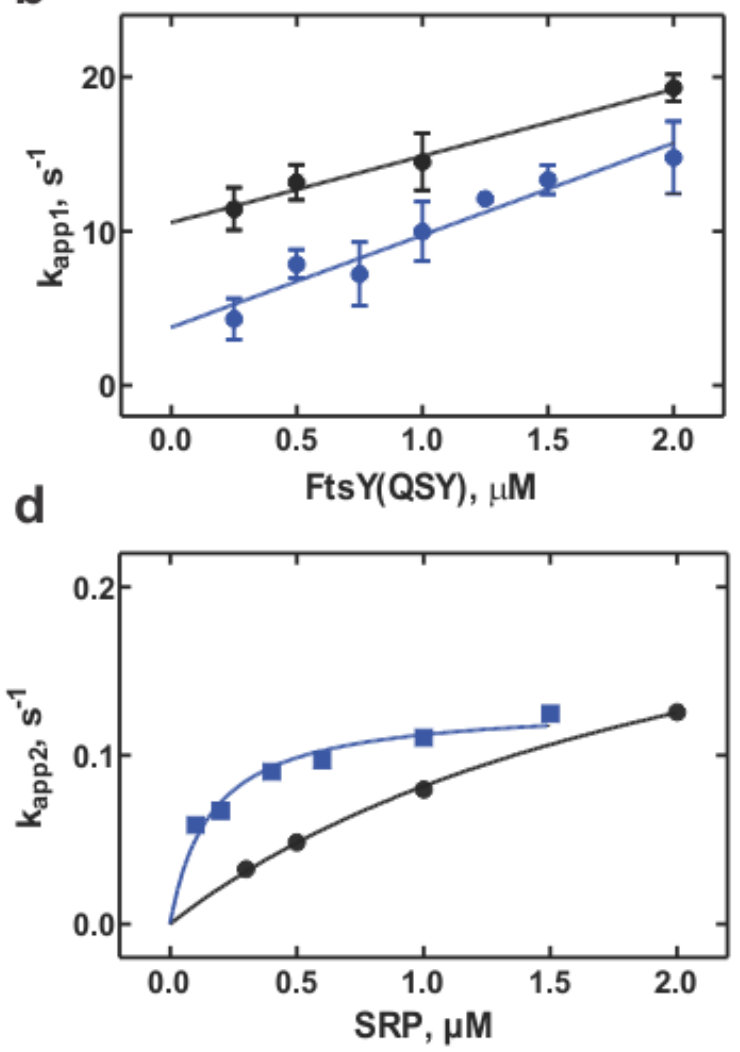

Figure 11 Association of FtsY with SRP in the presence and absence of the ribosome

Association experiments were performed by rapidly mixing labeled FtsY $(0.2-2 \mu \mathrm{M})$ with either labeled SRP alone $(0.1 \mu \mathrm{M})$ or SRP-ribosome complexes $(0.1 \mu \mathrm{M}$ SRP, $0.5 \mu \mathrm{M}$ nontranslating ribosomes). (a) Complex formation between SRP(ALX) alone (black trace) or SRP(ALX)-ribosome complex (blue trace) and $1 \mu \mathrm{M}$ FtsY(QSY). (b) Concentration dependence of $\mathrm{k}_{\mathrm{app} 1}$. Colors as in (a). (c) Interaction between $0.2 \mu \mathrm{M}$ of FtsY (BPY) and 5 $\mu \mathrm{M}$ SRP in the absence (grey) and in the presence (black trace) of the GTP analog, GMPPNP. (d) Concentration dependence of $k_{\text {app2 }}$. Color as in (a).

To determine the effect of the vacant ribosome on the SRP-FtsY complex, association of FtsY to SRP bound to the vacant ribosome was examined. The ribosome-bound SRP forms a rather stable complex with FtsY $\left(\mathrm{K}_{\mathrm{d}} \sim 200 \mathrm{nM}\right)$. Previous dissociation experiments in the presence of ribosomes showed that the SRP-FtsY complex on ribosomes is more stable compared to the binary SRP-FtsY complex, as indicated by a five-fold decreased dissociation rate constant $\left(\mathrm{k}_{-1}=8 \mu \mathrm{M}^{-1} \mathrm{~s}^{-1}\right.$ to $\left.1.6 \mu \mathrm{M}^{-1} \mathrm{~s}^{-1}\right)$. Upon complex formation between 
SRP and FtsY on the ribosome, again a biphasic signal change was observed (Figure 11a) which was fitted by a double-exponential function, and the value of $\mathrm{k}_{\mathrm{app} 1}$ increased linearly with the concentration of FtsY (Figure 11b). To obtain elemental rate constants, the second step of association was measured with FtsY(342BPY) and, again, a hyperbolic dependence of kapp 2 was observed (Figure 11d). Global fitting of the combined data set yielded forward rate constants of $\mathrm{k}_{1}$ of $8 \pm 1 \mu \mathrm{M}^{-1} \mathrm{~s}^{-1}$ and $\mathrm{k}_{2}$ of $0.12 \pm 0.05 \mathrm{~s}^{-1}$. Comparable association rates of the SRP-FtsY complex in the presence and absence of the vacant ribosome indicate that the vacant ribosome does not influence the association of FtsY with SRP.

In equilibrium, high-affinity targeting complex (RNC-SRP-FtsY or Rib-SRP-FtsY with Leppeptide) was observed ( $\mathrm{K}_{\mathrm{d}} \sim 5$ to $\left.20 \mathrm{nM}\right)$. However, the increased affinity was not due to a higher kinetic stability, as dissociation rates were similar. Therefore, the association of Fts Y with SRP in the presence of the RNC and the ribosome with the Lep-peptide was examined.

To see the effect of the SAS of the Lep-peptide, the association of FtsY(QSY) to SRP(ALX) on the vacant ribosome with the Lep-peptide was monitored. Upon complex formation, a biphasic decrease in donor fluorescence was observed (Figure 12a). Double-exponential terms were used to fit the time courses $\left(k_{a p p 1}\right.$ and $\left.k_{a p p 2}\right)$. $k_{a p p 1}$ increased linearly as the concentrations of FtsY(QSY) increased (Figure 12b) and $\mathrm{k}_{\mathrm{app} 2}$ saturated independently of the concentration of FtsY(QSY) (Figure 12c). Elemental rate constant in each step was determined by fitting the linear and hyperbolic titrations, respectively. Elemental rate constants were obtained by global fitting of the combined data sets of association and dissociation. The rate constants of the SRP-FtsY complex on the vacant ribosome with the Lep-peptide were $\mathrm{k}_{1}=9 \pm 2 \mu \mathrm{M}^{-1} \mathrm{~s}^{-1}$ and $\mathrm{k}_{2}=0.9 \pm 0.2 \mathrm{~s}^{-1}$. Compared to the association of FtsY with SRP on the vacant ribosome, the first step of association is similar but the second step of association is seven-fold faster as shown by seven-fold increased association rate in the presence of the Lep-peptide $\left(\mathrm{k}_{2}=0.12 \mathrm{~s}^{-1}\right.$ to $\left.0.9 \mathrm{~s}^{-1}\right)$. This indicates that Lep-peptide binding to SRP on the ribosome facilitates targeting complex formation during the second step of association, which is a conformational change.

FtsY binding to RNC-SRP complexes was monitored with Lep35-RNC and Lep50-RNC. Experiment and analysis were performed as above (Figure 12). The rate constants were 
similar to the rate constants of FtsY binding to SRP on the vacant ribosome with the Leppeptide. Since Lep35-RNC does not expose its N-terminal SAS outside the ribosome, this observation implies that FtsY binding to SRP is facilitated on the translating ribosome independently of whether an SAS is exposed on the ribosome, in accordance with previous equilibrium data (Bornemann et al., 2008).
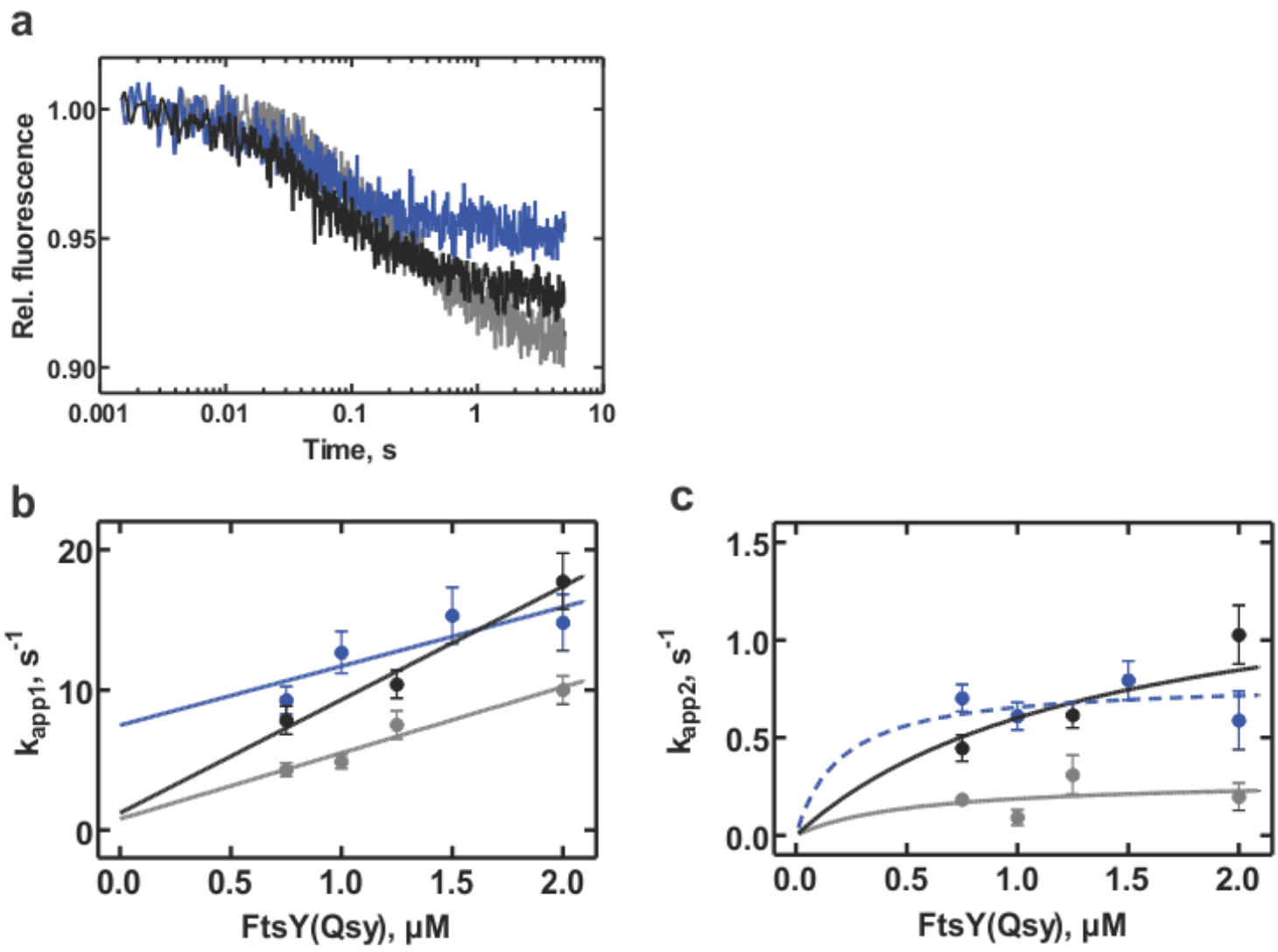

Figure 12 Association of FtsY with SRP bound to translating ribosomes

Association experiments were performed by rapidly mixing labeled FtsY $(0.75-2 \mu \mathrm{M})$ with either labeled SRP-ribosome-Lep-peptide complex $(0.1 \mu \mathrm{M}$ SRP, $0.5 \mu \mathrm{M}$ ribosome, $5 \mu \mathrm{M}$ Lep-peptide) or SRP-RNC complexes (0.1 $\mu \mathrm{M}$ SRP, $0.085 \mu \mathrm{M}$ RNC). (a) Interaction between the SRP(ALX)-ribosome-Lep-peptide complex (grey trace), SRP(ALX)-Lep35RNC complex (blue trace), or SRP(ALX)-Lep50-RNC complex (black trace) and $0.75 \mu \mathrm{M}$ FtsY(QSY). (b) Concentration dependence of $k_{a p p 1}$. Colors as in (a). (c) Concentration dependence of $\mathrm{k}_{\mathrm{app} 2}$. Colors as in (a)

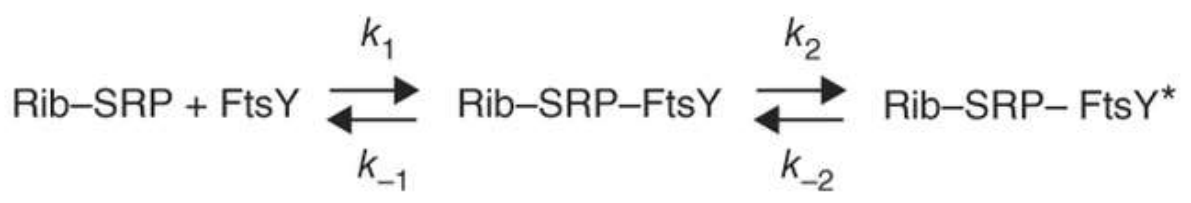

Figure 13 Two-step scheme of FtsY-SRP complex formation.

Rib, ribosome. Rate constants are summarized in Table 2. 
Table 2 Kinetic parameters of SRP-FtsY complex formation and dissociation.

\begin{tabular}{|c|c|c|c|c|c|}
\hline \multirow{2}{*}{} & \multicolumn{5}{|c|}{ FtsY binding to } \\
\cline { 2 - 6 } & SRP & $\begin{array}{c}\text { Ribosome- } \\
\text { bound SRP }\end{array}$ & $\begin{array}{c}\text { Ribosome- } \\
\text { bound SRP } \\
\text { + Lep }\end{array}$ & $\begin{array}{c}\text { Lep35-RNC } \\
\text { bound SRP }\end{array}$ & $\begin{array}{c}\text { Lep50-RNC } \\
\text { bound SRP }\end{array}$ \\
\hline $\mathrm{k}_{1}, \mu \mathrm{M}^{-1} \mathrm{~s}^{-1}$ & $5 \pm 1$ & $8 \pm 1$ & $9 \pm 2$ & $9 \pm 2$ & $8 \pm 1$ \\
\hline $\mathrm{k}_{2}, \mathrm{~s}^{-1}$ & $0.14 \pm 0.05$ & $0.12 \pm 0.05$ & $0.9 \pm 0.2$ & $0.7 \pm 0.2$ & $0.7 \pm 0.2$ \\
\hline $\mathrm{k}_{-1}, \mathrm{~s}^{-1}$ & $8 \pm 2$ & $1.6 \pm 0.3$ & $1.4 \pm 0.2$ & $1.5 \pm 0.3$ & $1.6 \pm 0.3$ \\
\hline $\mathrm{k}_{-2}, \mathrm{~s}^{-1}$ & $0.05 \pm 0.02$ & $0.05 \pm 0.02$ & $0.2 \pm 0.05$ & $0.1 \pm 0.03$ & $0.07 \pm 0.02$ \\
\hline $\mathrm{K}_{\mathrm{d}}, \mathrm{nM}^{*}$ & $700 \pm 100$ & $250 \pm 50$ & $20 \pm 5$ & $7 \pm 2$ & $5 \pm 1$ \\
\hline
\end{tabular}

$* K_{d}$ values determined by titration (Figure 9). $K_{d}$ values calculated from the rate constants match the values determined by titration within a factor of 3-4.

\subsection{SecYEG translocon in nanodisc}

At the membrane, the targeting complex RNC-SRP-FtsY interacts with the translocon until the complex is disassembled and the RNC is transferred to the translocon. Thus, the question arises whether the contact with the translocon already destabilizes the targeting complex to facilitate the following steps. To monitor the effect of the translocon, the equilibrium constants of the targeting complex was determined in the presence of the translocon.

As a membrane protein complex, SecYEG exposes hydrophobic residues at its outside, making it aggregation-prone in aqueous solution. Aggregation can be avoided by adding detergent (such as DDM) or by incorporating the translocon into phospholipid bilayers, as in proteoliposomes or nanodiscs (Alami et al., 2007; Bayburt and Sligar, 2002; Kalmbach et al., 2007; Klammt et al., 2005). A recent report shows that integral membrane proteins embedded in nanodisc resembles a native folded structure better than that in DDM (Lyukmanova et al., 2012). A surface plasmon resonance study shows that the interaction 
between SecYEG proteins, SecA, and ribosomes is affected by the presence of DDM (Wu et al., 2012). This shows that the environment of SecYEG is critical for measuring interactions between SecYEG proteins and ligands. Thus, in the present work we employed SecYEG proteins embedded in nanodisc (SecYEG-ND) containing lipids from E. coli membranes.

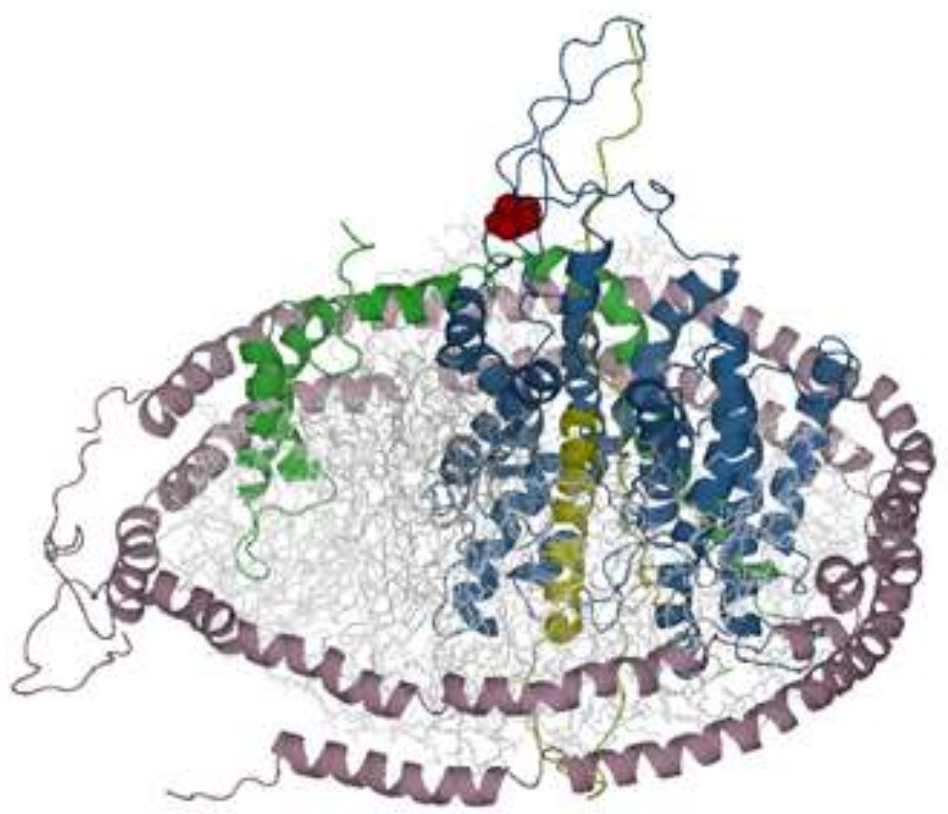

Figure 14 Structural model of SecYEG in nanodiscs.

SecY(blue)-E(yellow)-G(green) is located in the middle and E.coli lipids (grey lines) are wrapped in multi scaffold protein (MSP) (violet). Arginine 357 is shown in red sphere at C5 loop. The image was modified from the PDB file 3J00/3J01 (Frauenfeld et al., 2011).

Nanodiscs, discoidal lipid bilayers encircled by a membrane scaffold protein derived from apolipoprotein A1, have proven to be effective in solubilizing membrane proteins. (Alami et al., 2007; Bayburt and Sligar, 2002) (Figure 14). Thus, to obtain the translocon in a biochemically well-defined form, we have used the nanodisc technology. To see the effect of the translocon, a single copy of SecYEG embedded in nanodisc (SecYEG-ND) was prepared (Method 4.8). As a control, empty nanodiscs without translocon were used. In addition, a mutant translocon (mtSecYEG-ND) which was impaired in ribosome binding was used. The mutant translocon was prepared by exchanging Arg 357 of SecY to His $(\mathrm{R} 357 \mathrm{H})$ located in the cytosolic loop $(8 / 9)$, which is directly involved in ribosome binding (Menetret et al., 2007). 


\subsection{Alternative FRET labels in SRP and FtsY}

To monitor a conformational change of the targeting complex, the C-termini of the $\mathrm{G}$ domains were chosen as FRET labeling targets. Residues A235 in Ffh and D487 in FtsY were exchanged to Cys residues and labeled with MDCC (donor) and BPY(acceptor), respectively (Figure 15).

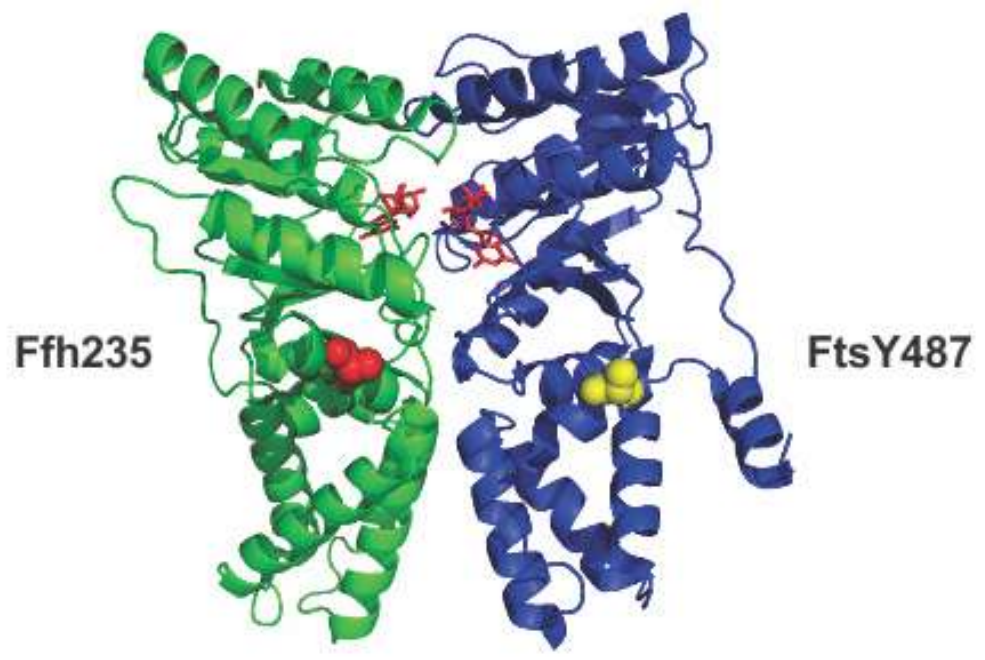

Figure 15 Positions of fluorophores in Ffh(left) and FtsY(right)

Crystal structure of the heterodimer of Ffh-NG and FtsY-NG from $T$.aquaticus. Residue 235 in Ffh (red) and residue 487 in FtsY (yellow) are shown in the middle. The image was modified by PDB file 2CNW (Focia et al., 2004).

To determine if the FRET between Ffh(MDCC) and FtsY(BPY) reports targeting complex formation in the same way as the Ffh(ALX) and FtsY(QSY) pair used above, the affinities of FtsY(BPY) binding to SRP(MDCC) and to SRP(MDCC) bound to ribosomes in various functional states were determined by equilibrium titrations. Complex formation was monitored by the decrease of donor fluorescence (Figure 16).

The titration data were fitted to the quadratic equation (Method 4.13.1) According to these data, Fts Y binding to SRP $\left(K_{d}=210 \mathrm{nM}\right)$ and the ribosome-SRP complex $\left(K_{d}=55 \mathrm{nM}\right)$ was comparable, if slightly (three-fold) better, compared to the previously determined affinities. With the Lep-RNC with chain lengths of 35, 50, 75, and 94 amino acids, five to ten-fold increased affinities of the SRP-FtsY complex compared to the affinity with the vacant ribosome were observed $\left(\mathrm{K}_{\mathrm{d}}=12 \mathrm{nM}, 6 \mathrm{nM}, 6 \mathrm{nM}\right.$, and $15 \mathrm{nM}$, respectively). This is in a 
good agreement with affinities determined previously (Figure 9c-d), again indicating a stabilization of the SRP-FtsY complex on translating ribosomes (Bornemann et al., 2008). Therefore, the FRET between SRP(MDCC) and FtsY(BPY) was considered suitable for further experiments.

a

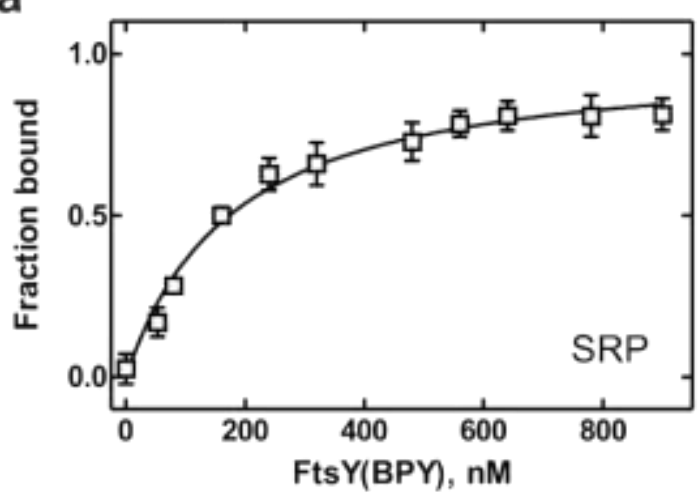

C

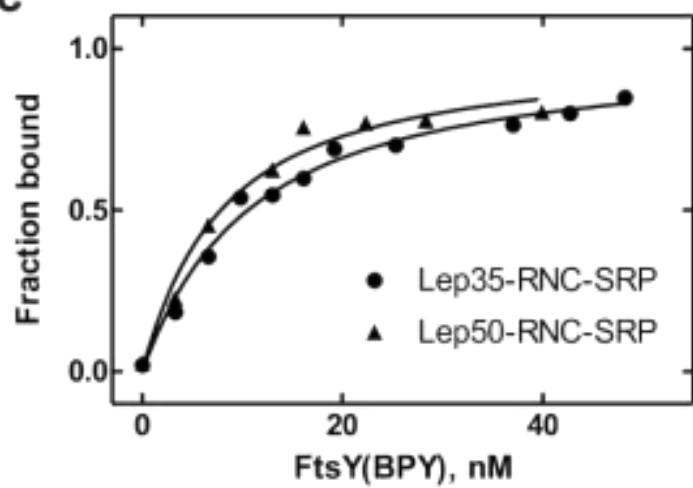

b

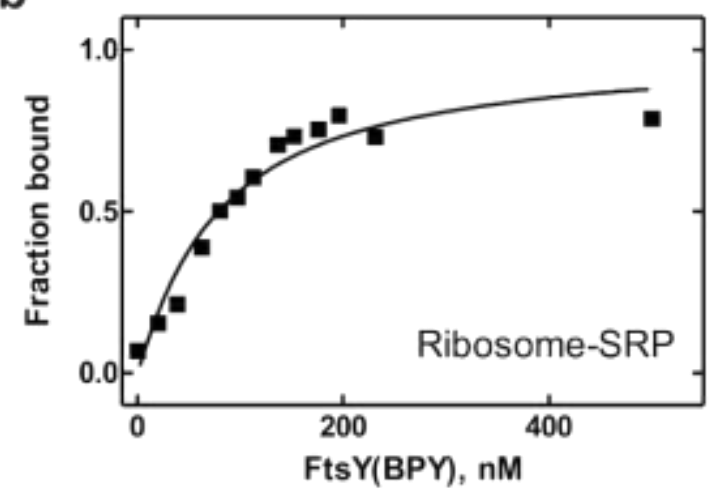

d

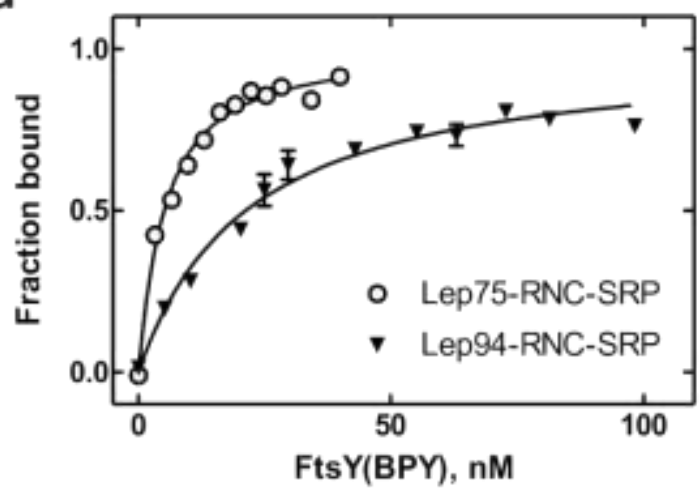

Figure 16 Affinities of FtsY binding to SRP monitored by alterative FRET pair

Equilibrium titrations of Fts (BPY) to SRPMDCC) and SRP(MDCC) bound to ribosomes monitoring FRET. (a) FtsY binding to SRP. (b) FtsY binding to SRP-ribosomes. (c) FtsY binding to SRP-Lep35-RNC and to SRP-Lep50-RNC. (d) FtsY binding to SRP-Lep75-RNC and to SRP-Lep94-RNC. Data are averages of two to three experiments.

\subsection{Stabilization of the SRP-FtsY complex at the translocon}

Using the FRET between SRP(MDCC) and FtsY(BPY), the interaction of the SRP-FtsY complex with the translocon embedded in nanodisc (SecYEG-ND) was monitored. For this, the affinity of the SRP-FtsY complex in the presence and absence of SecYEG-ND was determined by equilibrium titration. 
SRP(MDCC) was titrated with FtsY(BPY) in the presence of SecYEG-ND or, for comparison, solubilized by the addition of the detergent DDM. To saturate FtsY with SecYEG-ND, excess amount of SecYEG-ND (300 nM) was added. Control measurements were performed with empty nanodisc and mtSecYEG-ND. The titration curves were fitted to the quadratic equation assuming 1:1 binding stoichiometry (Figure 17).

a

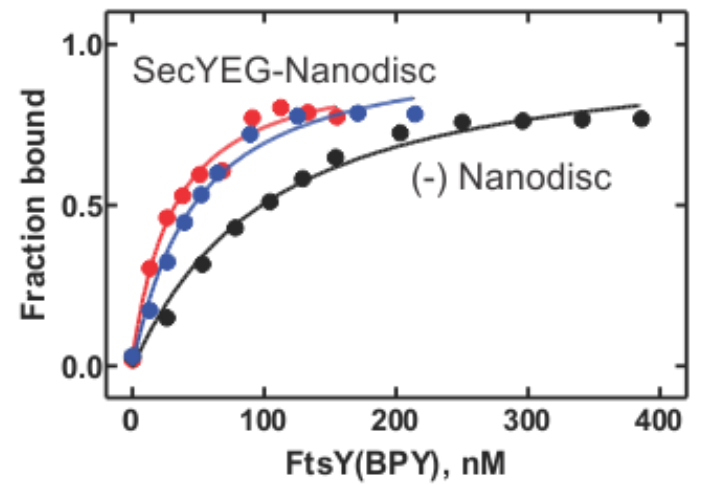

b

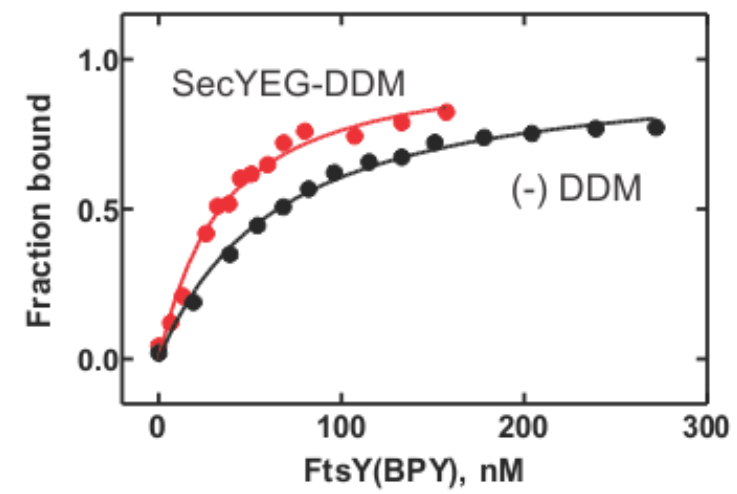

Figure 17 Binding of FtsY to SRP in the presence of the translocon

(a) FtsY binding to SRP with empty nanodisc (black), SecYEG-ND (red), with mtSecYEGND (blue). (b) FtsY binding to SRP in the presence (red) and absence (black) of SecYEG in DDM containing buffer. Controls (-) were performed with empty nanodiscs or DDMcontaining buffer without translocon. Data points are averages from two to three experiments. The fluorescence change due to FRET is normalized to give fraction bound.

In the presence of SecYEG-ND, a ten-fold higher affinity $\left(K_{d}=23 \pm 5 n M\right)$ of Fts Y binding to SRP compared to that observed in the absence of SecYEG-ND was observed (Figure 17a). This indicates that SecYEG-ND stabilizes the SRP-FtsY complex, presumably via an interaction of Fts Y with the translocon (Angelini et al., 2005; Kedrov et al., 2011). In the presence of mtSecYEG-ND a similar affinity of FtsY to SRP $\left(K_{d}=37 \pm 2 \mathrm{nM}\right)$ was observed. This indicates that the mutation $\mathrm{R} 357 \mathrm{H}$ of $\mathrm{SecY}$, which impairs ribosome binding, does not influence the interaction between the translocon and the SRP-FtsY complex.

To clarify whether the stabilizing effect is due to interactions with the SecYEG translocon or with lipids in the nanodisc, the analogous titration was performed in the presence of empty nanodisc (Figure 17a). As a result, a slightly higher affinity of FtsY binding to SRP $\left(\mathrm{K}_{d}=\right.$ $100 \pm 20 \mathrm{nM})$ compared to that in the absence of nanodisc $\left(\mathrm{K}_{\mathrm{d}}=215 \mathrm{nM}\right)$ was observed; 
however, this affinity was less than that observed with SecYEG-ND. This indicates that the empty nanodisc has a minor effect on the stabilization of the SRP-FtsY complex.

Another control was performed with SecYEG solubilized by adding DDM, rather than embedding in nanodisc. Under these conditions, the affinity of FtsY binding to SRP was about as high as above $\left(\mathrm{K}_{\mathrm{d}}=30 \pm 7 \mathrm{nM}\right)$ (Figure 17b). This indicates that mainly the SecYEG proteins are responsible for the stabilization of the SRP-FtsY complex. In the absence of SecYEG proteins, the affinity of the SRP-FtsY complex was lower $\left(\mathrm{K}_{\mathrm{d}}=65 \pm 10\right.$ $\mathrm{nM}$ ) in buffer containing DDM (Figure 17b). This indicates that DDM also somewhat stabilizes the SRP-FtsY complex compared to the control without DDM ( $\left.\mathrm{K}_{d}=215 \mathrm{nM}\right)$. The following experiments were performed with SecYEG embedded in nanodiscs.

\subsection{The effect of the translocon on the ribosome-SRP-FtsY complex}

To monitor targeting complex formation at the translocon in the membrane, the interaction between SRP and FtsY on ribosomes in various functional states was studied in the presence of SecYEG-ND. Accordingly, the same sets of equilibrium titrations in the presence of SecYEG-ND were performed. To exclude the influence of the translocon on ribosomes and to see only the effect of the translocon on the SRP-FtsY complex, mtSecYEG-ND which is impaired in ribosome binding was used as a control. Empty nanodiscs, lacking the translocon, were used as a negative control.

In the presence of SecYEG-ND, FtsY(BPY) binding to SRP(MDCC) bound to vacant ribosome had a $\mathrm{K}_{\mathrm{d}}$ of $85 \mathrm{nM}$ (Figure 18a). In the presence of mtSecYEG-ND or empty nanodisc, the $\mathrm{K}_{\mathrm{d}}$ was about $50 \mathrm{nM}$ (Figure 18a), the same as the affinity observed in the absence of the translocon $\left(\mathrm{K}_{\mathrm{d}}=55 \mathrm{nM}\right)$. This indicates that the translocon did not further stabilize the SRP-FtsY complex when it was bound to vacant ribosomes. One explanation would be that the stabilization effect induced by the translocon on the SRP-FtsY complex becomes small when SRP is already stabilized on the ribosome, because both effects have the same structural basis. 
a

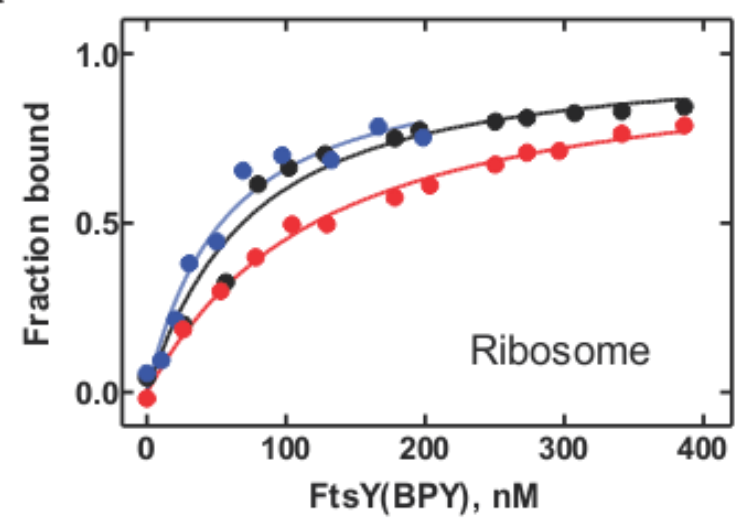

C

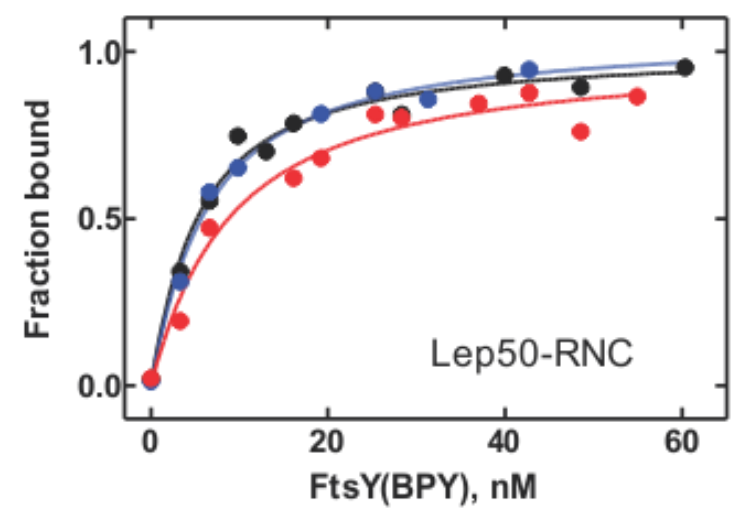

e

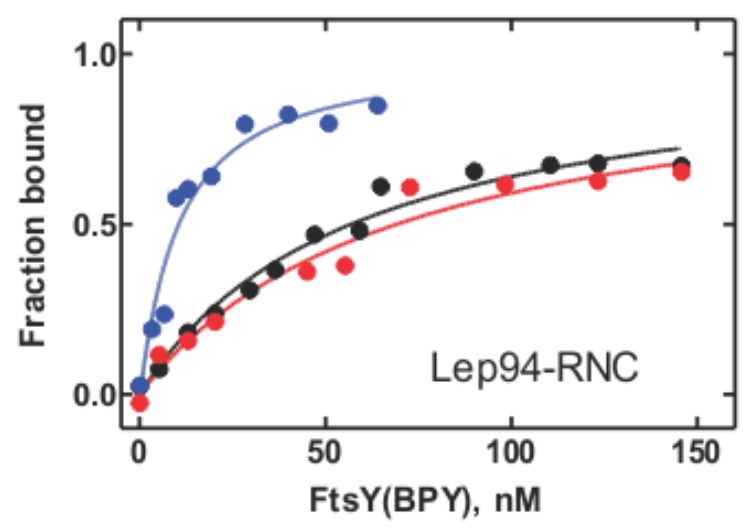

b

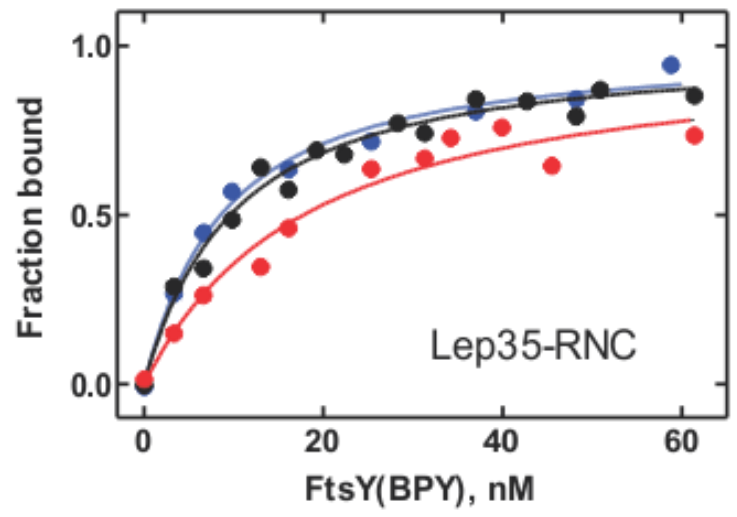

d

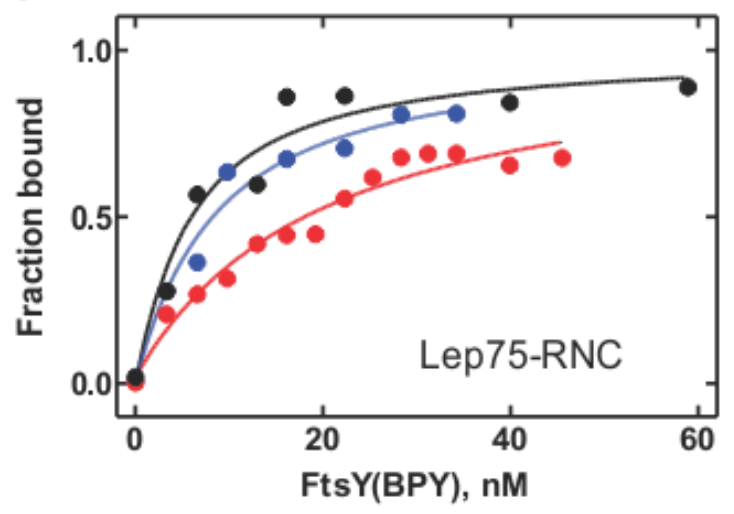

Figure 18 Equilibrium titrations in the presence of SecYEG-ND

Equilibrium titrations of FtsY binding to SRP bound to ribosomes in various functional states in the presence of wild-type SecYEG-ND (red), mtSecYEG-ND (blue), or empty nanodisc (black). (a) FtsY binding to SRP bound to ribosomes. (b-e) FtsY binding to SRP bound to Lep-RNCs of the indicated length of the Lep nascent chain. Data points are averages from two to three experiments.

Next, the affinity of the SRP-FtsY interaction on the Lep-RNC-SRP-FtsY complex was determined in the presence of SecYEG-ND. In the presence of Lep35-RNC or Lep50-RNC, 
affinities of FtsY binding to SRP had $\mathrm{K}_{\mathrm{d}}$ values of $16 \mathrm{nM}$ and $8 \mathrm{nM}$, respectively (Figure $18 \mathrm{~b}-\mathrm{c})$. These values are slightly higher than the $\mathrm{K}_{\mathrm{d}}$ values of Fts $\mathrm{Y}$ binding to SRP bound to Lep35-RNC or Lep50-RNC observed in the presence of mtSecYEG-ND or empty nanodiscs $\left(\mathrm{K}_{\mathrm{d}}\right.$ around 6-9 $\left.\mathrm{nM}\right)$. This indicates that the SecYEG-ND has very little influence on the affinity of the SRP-FtsY complex bound to Lep35-RNC or Lep50-RNC.

To monitor targeting complex formation with RNCs fully exposing an SAS at the translocon, SRP(MDCC) bound to Lep-RNCs harboring longer nascent chains (75 and 94 amino acids) was titrated with FtsY(BPY) in the presence of SecYEG-ND (Figure 18d-e). The affinities of Fts Y binding to the Lep75-RNC-SRP and Lep94-RNC-SRP complexes were about the same ( $\mathrm{K}_{\mathrm{d}}$ values of $36 \mathrm{nM}$ and $42 \mathrm{nM}$, respectively), i.e., three- to six-fold lower than in the absence of the translocon or in the presence of mtSecYEG-ND $\left(\mathrm{K}_{\mathrm{d}}\right.$ values of $\sim 6 \mathrm{nM}$ or $\sim 10$ $\mathrm{nM}$, respectively). These results indicate that SecYEG-ND in fact weakens the interaction of SRP with FtsY on Lep75/94-RNCs. The affinity of the SRP-FtsY complex on the Lep75/94RNC in the presence of mtSecYEG-ND was almost the same as that in the absence of SecYEG-ND. This suggests that the destabilization of the targeting complex observed in the presence of SecYEG-ND is caused by interactions between SecYEG-ND and the Lep75/94RNCs.

Table 3 Summary of equilibrium constants of FtsY binding to SRP and SRP- ribosome complexes in the presence and absence of the translocon

\begin{tabular}{|c|c|c|c|c|c|}
\hline \multirow{2}{*}{ Addition } & \multicolumn{5}{|c|}{ Affinity of FtsY binding to SRP-ribosome complexes $\left(\mathrm{K}_{\mathrm{d}}, \mathrm{nM}\right)$} \\
\cline { 2 - 6 } & $\begin{array}{c}\text { Vacant } \\
\text { ribosome }\end{array}$ & $\begin{array}{c}\text { Lep35- } \\
\text { RNC }\end{array}$ & $\begin{array}{c}\text { Lep50- } \\
\text { RNC }\end{array}$ & $\begin{array}{c}\text { Lep75- } \\
\text { RNC }\end{array}$ & $\begin{array}{r}\text { Lep94- } \\
\text { RNC }\end{array}$ \\
\hline None & $55 \pm 10$ & $12 \pm 2$ & $6 \pm 4$ & $6 \pm 2$ & $15 \pm 5$ \\
\hline $\begin{array}{c}\text { Empty nanodisc } \\
\text { Translocon } \\
\text { (SecYEG-ND) }\end{array}$ & $86 \pm 13$ & $9 \pm 2$ & $8 \pm 3$ & $5 \pm 1$ & $33 \pm 20$ \\
\hline $\begin{array}{c}\text { Mutant translocon } \\
\text { (mtSecYEG-ND) }\end{array}$ & $51 \pm 18$ & $9 \pm 1$ & $6 \pm 2$ & $7 \pm 2$ & $8 \pm 2$ \\
\hline
\end{tabular}




\subsection{Partial competitive binding to the ribosome of SRP-FtsY and translocon}

To investigate the $K_{d}$ effect of SecYEG-ND on the targeting complex (Lep75-RNC-SRPFtsY) in more detail (Figure 18d), FtsY(BPY) binding to Lep75-RNC-bound SRP(MDCC) was examined in the presence of increasing amounts of SecYEG-ND (Figure 19a).

a

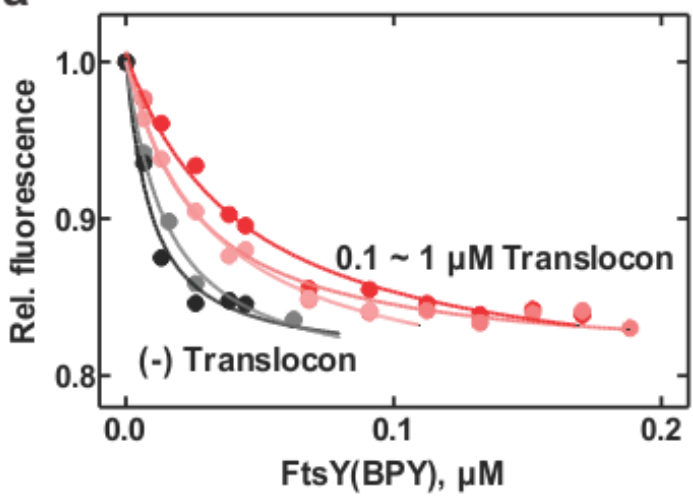

b

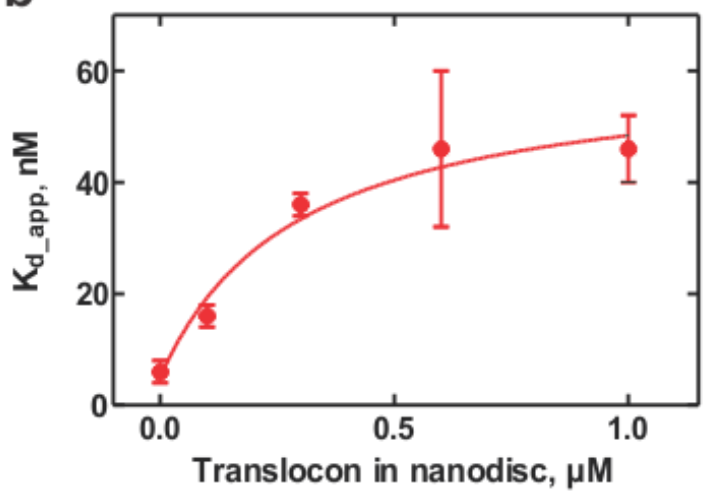

Figure 19 Effect of the translocon on the targeting complex

(a) Equilibrium titrations of Fts Y(BPY) to the Lep75-RNC bound SRP(MDCC) using $2 \mathrm{nM}$ SRP(MDCC), $5 \mathrm{nM}$ Lep75-RNC, and $500 \mu \mathrm{M}$ GMPPNP with FtsY(BPY) at increasing concentrations of the translocon ranging from $0 \mu \mathrm{M}$ (black), $0.1 \mu \mathrm{M}$ (grey), $0.3 \mu \mathrm{M}$ (pale pink), $0.6 \mu \mathrm{M}$ (pink), to $1 \mu \mathrm{M}$ (red). (b) Apparent $\mathrm{K}_{\mathrm{d}}$ values are shown with increasing concentrations of SecYEG-ND.

Upon binding of FtsY to the SRP-Lep75-RNC complex in the presence of SecYEG-ND, about $20 \%$ of signal change in donor fluorescence (MDCC) was observed (Figure 19a), independent on the concentration of SecYEG-ND. This indicates that there is competition between translocon and one component of the targeting complex, presumably the RNC, resulting in weaker binding of FtsY to SRP. Apparent $\mathrm{K}_{\mathrm{d}}$ values (Lep75-RNC-SRP-FtsY) were determined as before (Method 4.13.1). The apparent $K_{d}$ increased from $6 \mathrm{nM}$ to $46 \mathrm{nM}$ in a hyperbolic fashion with increasing concentration of SecYEG-ND and reached saturation at around $1 \mu \mathrm{M}$ SecYEG-ND (Figure 19b). Thus, the binding competition is only partial, because otherwise the apparent $\mathrm{K}_{\mathrm{d}}$ would increase linearly. To evaluate the partial competition quantitatively, the apparent $\mathrm{K}_{\mathrm{d}}$ plot versus the concentration of the translocon was fitted to a model of partial competitive binding (Method 4.13.1). The observed apparent $K_{d}$ at saturation with the translocon differs from the intrinsic $K_{d}$ by a factor of $\alpha=12 \pm 5$. 
The $\mathrm{K}_{\mathrm{d}}$ of FtsY binding to the Lep75-RNC-SRP was $5 \pm 2 \mathrm{nM}$. Hence, the maximum apparent $\mathrm{K}_{\mathrm{d}}$ approaches $60 \mathrm{nM}$, which indicates that at the membrane the targeting complex is weakened. The intrinsic $\mathrm{K}_{\mathrm{d}}$ of SecYEG-ND binding to the Lep75-RNC-SRP complex was $20 \pm 10 \mathrm{nM}$.

To investigate targeting complex formation with FtsY associated with the translocon at the membrane, analogous titrations were performed with mtSecYEG-ND. Since the mutant translocon is impaired in ribosome binding, this represents targeting complex formation at the membrane without further conformational change for translocation via the interaction between the RNC and the translocon. Upon FtsY binding to the Lep75-RNC-SRP complex in the presence of increasing concentration of mtSecYEG-ND, the signal change decreased from $20 \%$ to $10 \%$ (Figure 20a). Assuming 1:1 binding stoichiometry, apparent $\mathrm{K}_{\mathrm{d}}$ values were determined (Method 4.13.1). The apparent $\mathrm{K}_{d}$ values were not affected by the presence of mtSecYEG-ND (Figure 20b). This indicates that mtSecYEG-ND does not compete for ribosome binding, suggesting that in the experiments with wild-type translocon, the competition was, in fact, due to translocon binding to the ribosome.
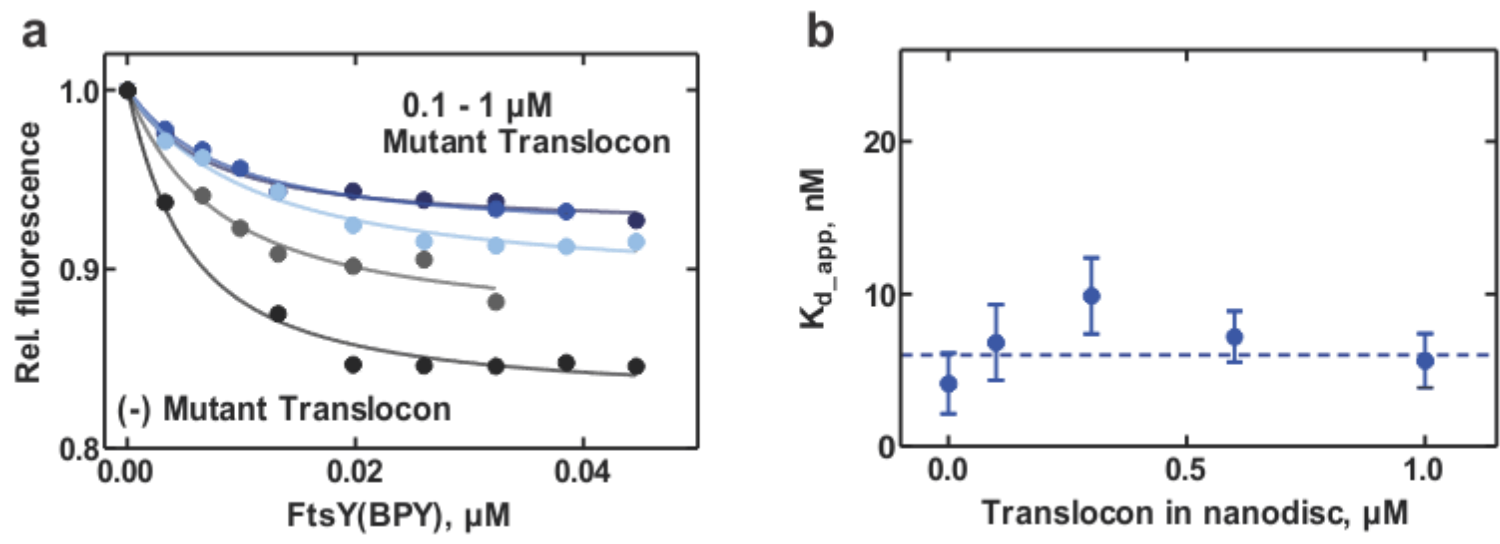

Figure 20 Effect of the mutant translocon on the targeting complex

(a) Equilibrium titrations of Fts Y(BPY) to the Lep75-RNC bound SRP(MDCC) using $2 \mathrm{nM}$ SRP(MDCC), $5 \mathrm{nM}$ Lep75-RNC, and $500 \mu \mathrm{M}$ GMPPNP with FtsY(BPY) at increasing concentrations of the mutant translocon ranging from $0 \mu \mathrm{M}$ (black), $0.1 \mu \mathrm{M}$ (light blue), 0.3 $\mu \mathrm{M}$ (sky blue), $0.6 \mu \mathrm{M}$ (blue), to $1 \mu \mathrm{M}$ (dark blue). (b) Apparent $\mathrm{K}_{\mathrm{d}}$ values are shown with increasing concentration of mutant translocon. 


\subsection{The influence of 4.5S RNA on targeting complex formation}

It has been reported that the distal end of 4.5S RNA involves the GTPase activation, which leads the completion of the targeting process (Shen et al., 2013). Thus, the question if the distal end of 4.5S RNA involves the destabilization of the targeting complex was addressed. To monitor the effect of the distal end on the targeting complex, the truncated 4.5S RNA constructs were prepared. The tetraloop and domain IV region of $4.5 \mathrm{~S}$ RNA, which is responsible for SRP assembly and binding to FtsY, remain unchanged. In the shortest construct, the D and E loops of 4.5S RNA were deleted (4.5S RNA21-81, or 61mer). As an intermediate, 4.5S RNA7-91 (83mer) lacking E loop was prepared (Figure 21).

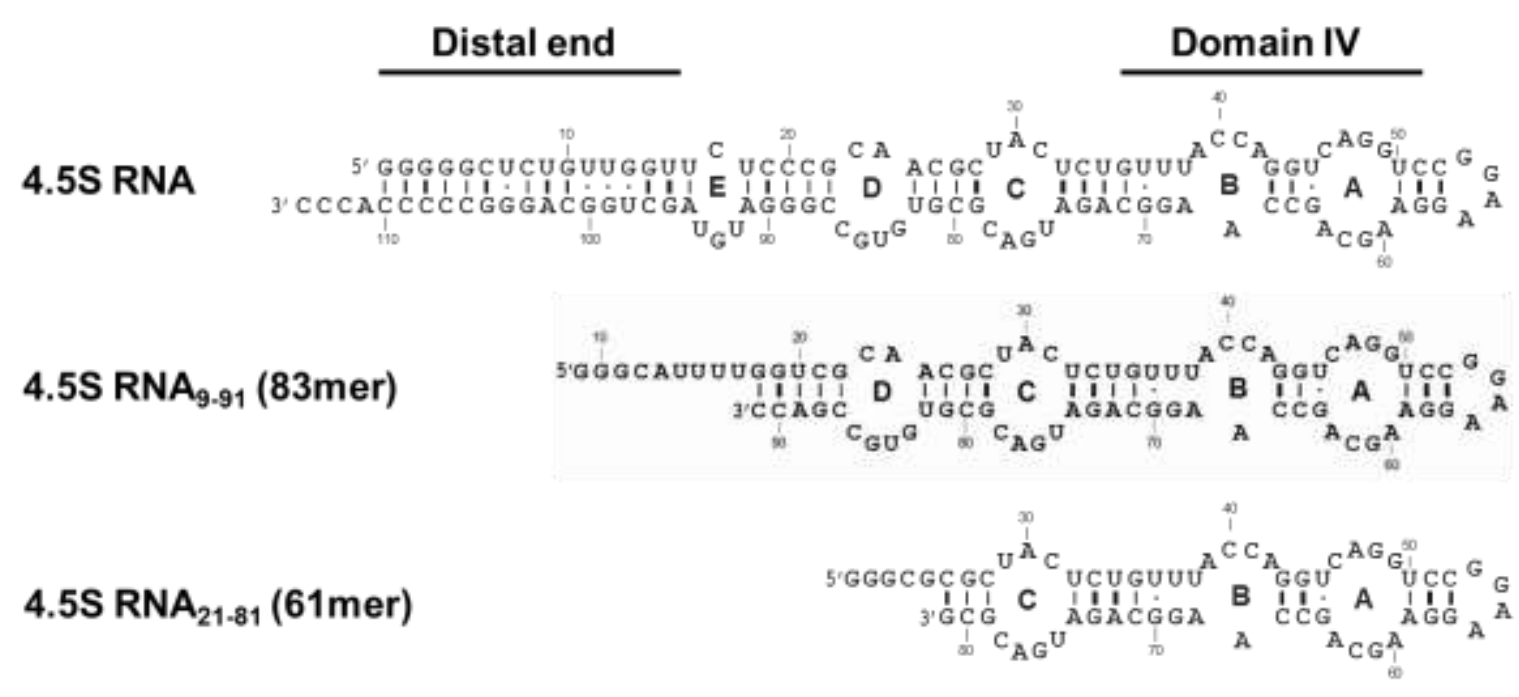

Figure 21 Truncated 4.5S RNA constructs

The secondary structure of full-length and truncated 4.5S RNA constructs are depicted as predicted by mfold.

Recently, it has been reported that $3^{\prime}$ truncations of 4.5S RNA impaired the GTPase activity of the binary SRP-FtsY complex (Ataide et al., 2011; Voigts-Hoffmann et al., 2013). As the observation had the potential of providing means to arrest the disassembly of the targeting complex, we have repeated these experiments and have confirmed the basic findings. Accordingly, the GTPase activity of the Ffh-FtsY heterodimer was examined in the presence of the full-length and the truncated 4.5S RNA constructs. The amount of hydrolyzed phosphate (Pi) was plotted against time (Figure 22a). The GTP hydrolysis rate was determined by linear fitting the initial velocity (Figure 22b). 
The GTPase activities of free Ffh and the Ffh-FtsY heterodimer were $0.9 \pm 0.8$ and $1.2 \pm 0.2$ $\mathrm{min}^{-1}$, respectively (Figure 22). The similar GTPase activity of Ffh alone and the Ffh-FtsY heterodimer shows that the addition of Fts $\mathrm{Y}$ to Ffh does not promote GTP hydrolysis significantly. In the presence of 4.5S RNA, the GTPase activity of the Ffh-Fts Y heterodimer increased tenfold to $13 \pm 2 \mathrm{~min}^{-1}$ (Figure 22), confirming the stimulatory effect of 4.5S RNA on the GTPase activity of the Ffh-FtsY heterodimer (Peluso et al., 2000).

a

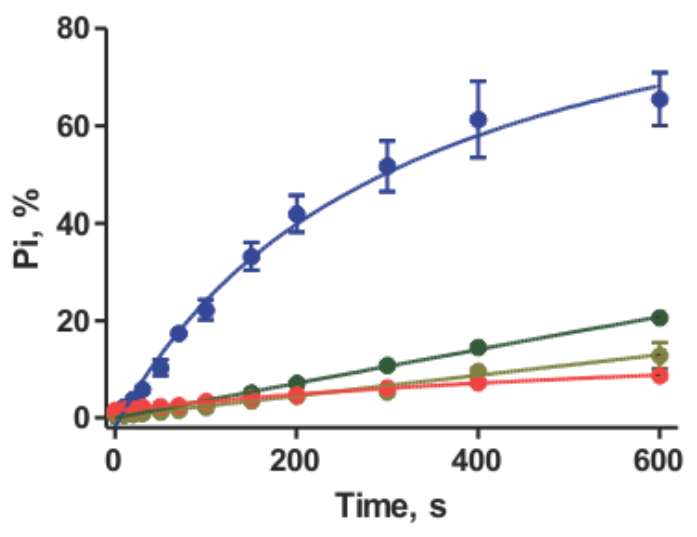

b

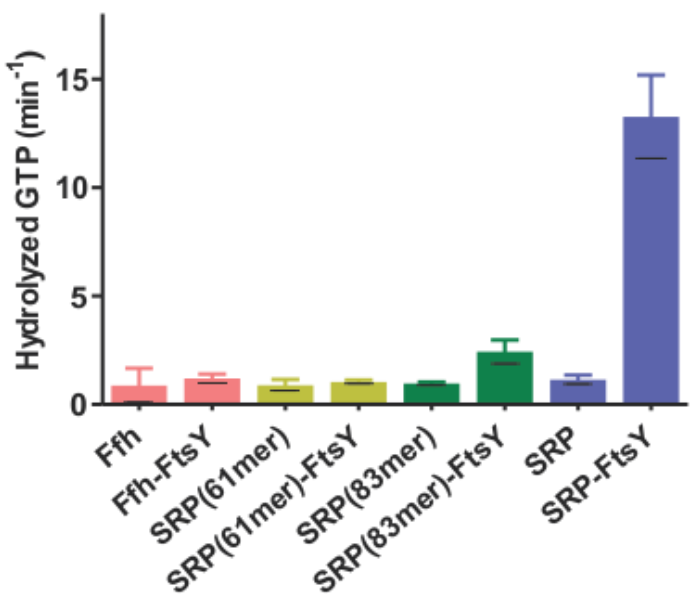

Figure 22 GTPase activities of Ffh and the Ffh-FtsY complexes with different $4.5 \mathrm{~S}$ RNA constructs

(a) Time courses of the GTP hydrolysis. GTP (\% of total) hydrolyzed by the Ffh-FtsY heterodimer in the absence of 4.5S RNA (pink), in the presence of 4.5S RNA $21-81$ (yellow), 4.5S RNA9-91 (green), and 4.5S RNA (blue). (b) GTPase rate constant. GTP molecules hydrolyzed are shown in the presence and absence of FtsY with the same color code. Represented activity is the average of triplicates $( \pm \mathrm{SD})$.

To verify the stimulatory effect of the distal end on the GTPase activity of the Ffh-FtsY heterodimer, the GTPase assay was performed with the truncated 4.5S RNA constructs. The GTPase activity of SRP with 61mer and 83mer (SRP61 and SRP83) was $1.0 \pm 0.1$ and $0.9 \pm$ $0.3 \mathrm{~min}^{-1}$, respectively (Figure 22), indicating that the basal GTPase activity of SRP is not influenced by the truncation of the 3'-end of 4.5S RNA. However, in the presence of $4.5 \mathrm{~S}$ RNA $_{7-91}$ (83mer), the GTPase activity of the heterodimer increased only twofold, to $2.4 \pm 0.5$ $\min ^{-1}$ (Figure 22b). In the presence of $4.5 \mathrm{~S} \mathrm{RNA} 21-81(61 \mathrm{mer})$, the GTPase activity of the heterodimer did not change. This confirms that the 3'-end in the region of the $\mathrm{D}$ and $\mathrm{E}$ loops of 4.5S RNA plays a key role in the stimulation of GTP hydrolysis in the targeting complex (Ataide et al., 2011). 


\subsection{The role of 4.5S RNA in stabilizing the targeting complex}

To determine if the stimulated GTPase activity in the presence of the distal end of 4.5S RNA is due to the stability of the SRP-FtsY complex, SRP containing truncated 4.5S RNA constructs was titrated with FtsY, monitoring FRET signals between the 3'-end of $4.5 \mathrm{~S}$ RNA(3'-ALX) and FtsY(QSY) (Figure 23). All the titrations were repeated monitoring FRET between Ffh(MDCC) and FtsY(BPY) (Figure 15), which gave a somewhat better signal.
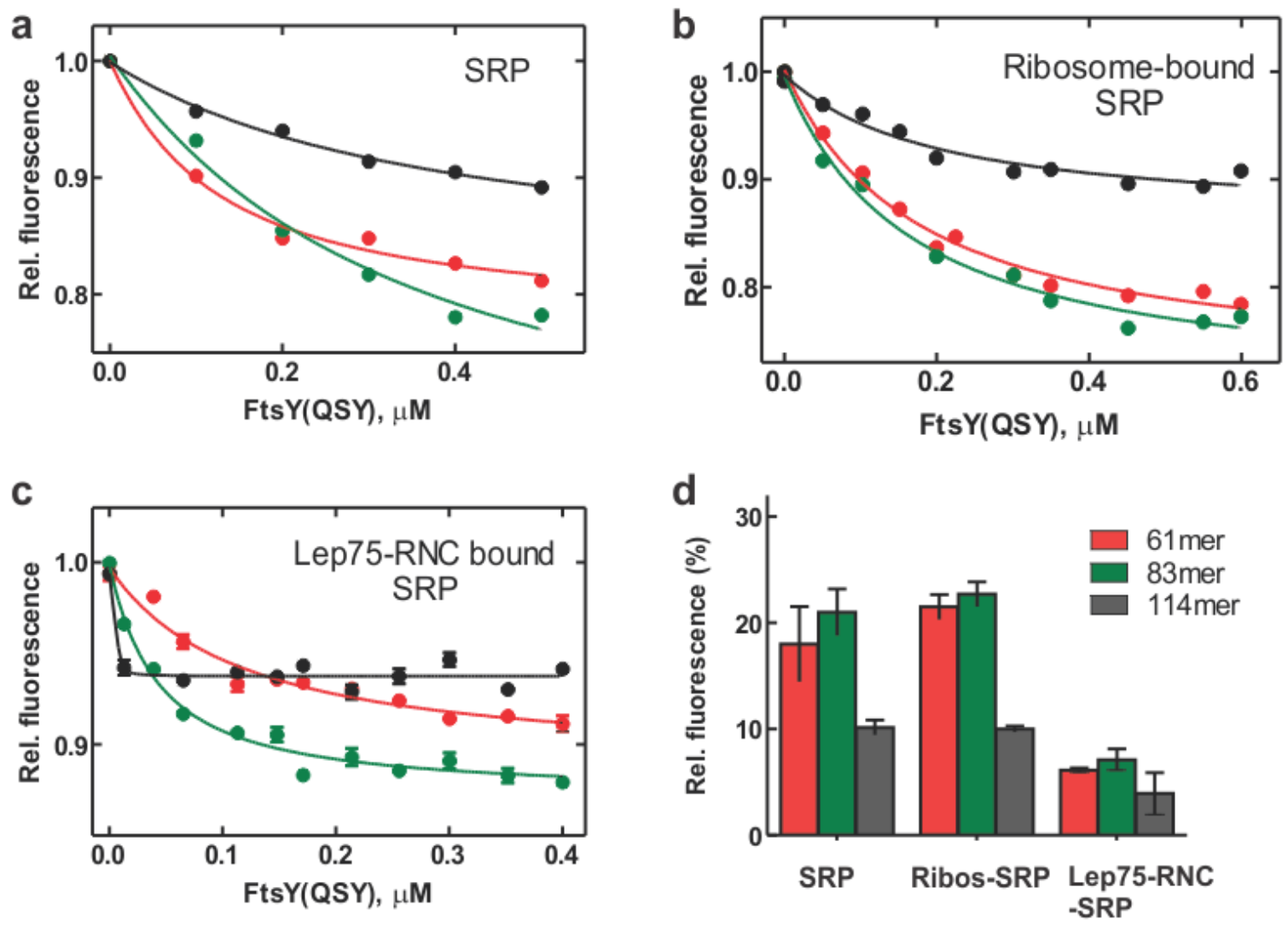

\section{Figure 23 FtsY binding to SRP and SRP-ribosome complexes}

Increasing amounts of FtsY(QSY) were added to SRP(3'-ALX) and SRP(3'-ALX) bound to ribosomes with different RNA constructs. Full-length 4.5S RNA (black) and 3'-end truncated 4.5S RNA (83mer in green and $61 \mathrm{mer}$ in red) constructs were used. (a) FtsY binding to SRP. (b) FtsY binding to SRP bound to ribosomes. (c) FtsY binding to the SRPLep75-RNC complex. (d) FRET amplitudes from panels (a) to (c) FRET amplitudes were estimated by evaluating the titration curves with a quadratic equation to yield binding constants and final fluorescence levels. Data are averages from two to three experiments. 
As a result, four-fold higher affinity of the SRP-FtsY complex with 83 mer and 61 mer $\left(\mathrm{K}_{\mathrm{d}}\right.$ values $50 \pm 10 \mathrm{nM}$ and $60 \pm 15 \mathrm{nM}$, respectively) than that of the SRP-FtsY complex $\left(\mathrm{K}_{\mathrm{d}}\right.$ $200 \pm 50 \mathrm{nM}$ ) was observed. This indicates that the SRP-FtsY complex is of lower affinity when the SRP contains full-length 4.5S RNA. When FRET changes were compared to the full-length and the 3'-end truncated 4.5S RNA constructs at saturation with FtsY(QSY), about two-fold larger signal change was observed with the truncated 4.5S RNA (Figure 23a) which may be related to the effect on affinity.

In the presence of the vacant ribosome, the affinities of FtsY binding to SRP containing different 4.5S RNA constructs were similar $\left(\mathrm{K}_{\mathrm{d}} 60-80 \mathrm{nM}\right)$ (Figure 23b), comparable to the published values (Bornemann et al., 2008). A two-fold larger signal change with the truncated 4.5S RNA constructs at saturation with FtsY(QSY) than that with the full-length 4.5S RNA was observed as before. In the presence of the Lep75-RNC, the three- to five-fold lower affinity of the SRP-FtsY complex with 61mer $\left(\mathrm{K}_{\mathrm{d}} 25 \pm 11 \mathrm{nM}\right)$ than that of the complex with 83 mer and full-length $4.5 \mathrm{~S}$ RNA ( $\mathrm{K}_{\mathrm{d}} 8 \pm 1 \mathrm{nM}$ and $5 \pm 2 \mathrm{nM}$, respectively) was observed (Figure 23c). This indicates that, as the binary SRP-FtsY complex, the targeting complex with the truncated $4.5 \mathrm{~S} \mathrm{RNA}(61 \mathrm{mer})$ is of lower affinity than the targeting complex with 83 mer or full-length $4.5 \mathrm{~S}$ RNA. At saturation with FtsY(QSY), signal changes of the Lep75-RNC-SRP-FtsY complex decreased slightly compared to that of the vacant ribosome-SRP-FtsY complex. This probably indicates a change of the distance between the two labels, the 3'-end of 4.5S RNA and the G domain of FtsY. 


\section{Discussion}

The process of co-translational targeting of membrane proteins to the membrane is important for cellular membrane function. In bacteria, the process is governed by SRP and FtsY. The timely formation of the targeting complex (RNC-SRP-FtsY) and its interaction with the translocon at the membrane are required for the localization of membrane proteins to the membrane. However, it is not understood when targeting complex formation occurs and how the stability of the targeting complex is regulated by the translocon. Monitoring FRET between labeled SRP and FtsY we studied thermodynamics and kinetics of targeting complex formation and interaction of the targeting complex with the translocon.

\section{Kinetics of targeting complex formation}

Inner membrane proteins harbor non-cleavable signal-anchor sequences (SAS) at their Ntermini which are recognized by SRP as they emerge from the ribosome, initiating membrane targeting via interaction with FtsY. The binding of SRP to the ribosome is already enhanced by any nascent chain within the peptide exit tunnel of the ribosome, or by an SAS exposed outside the ribosome (Bornemann et al., 2008; Holtkamp et al., 2012). Upon binding to the ribosome, and enforced by binding an SAS, the SRP undergoes a global conformational change toward an open conformation of SRP54 (Janda et al., 2010). In yeast and bacteria, the open structure of SRP was reported as well, in which the M domain becomes distant from the G domain by the helix formation of GM linker (Buskiewicz et al., 2009; Hainzl et al., 2011; Halic et al., 2006). The SRP bound to the RNC interacts with FtsY more strongly (about 10-fold) than the SRP on ribosomes (Bornemann et al., 2008). The present kinetic analysis shows that the increased affinity of the RNC-SRP-FtsY complex is due to the accelerated rearrangement of the RNC-SRP-FtsY complex following initial binding. The acceleration is observed when Fts $\mathrm{Y}$ binds to SRP bound to translating ribosomes, such as Lep35-RNC, Lep50-RNC, and the vacant ribosome with the SAScontaining Lep-peptide added in trans. Notably, in the ribosome complexes SRP is present in a conformation where the NG domain of Ffh is exposed (Buskiewicz et al., 2009; Halic et al., 2006), thereby facilitating the binding of the NG domain of FtsY (Egea et al., 2004; Focia et al., 2004). Such a conformation has been observed directly in the cryo-EM reconstruction of the RNC-SRP-FtsY complex (Estrozi et al., 2011). 
The rates of initial binding of FtsY to SRP alone or SRP-ribosome complexes are similar. With the Lep-RNCs FtsY binding to SRP increases slightly $\left(5-8 \mu \mathrm{M}^{-1} \mathrm{~s}^{-1}\right)$. This is comparable to the 'early' complex proposed by Shan and her colleagues $\left(\sim 10 \mu \mathrm{M}^{-1} \mathrm{~s}^{-1}\right)$ when FtsY binds to SRP bound to RNCs exposing the SAS of FtsQ without GTP (Zhang et al., 2008). However, the second step of targeting complex formation which forms the 'closed' complex in their model is different from our second step. We measured the backward rate constant $\left(\mathrm{k}_{-2}\right)$ of the targeting complex as $\sim 0.05 \mathrm{~s}^{-1}$, which is more than ten-fold slower than the previously reported value for $\mathrm{k}_{\text {off }}\left(\sim 1 \mathrm{~s}^{-1}\right)$ (Zhang et al., 2009), consistent with the higher affinity of our targeting complex $\left(\mathrm{K}_{\mathrm{d}} \sim 5 \mathrm{nM}\right)$. In the absence of the RNC, the dissociation of the SRP-FtsY complex is 20-fold slower $\left(\sim 0.0026 \mathrm{~s}^{-1}\right)$ (Zhang et al., 2009) compared to that of our study $\left(\mathrm{k}_{-2} \sim 0.05\right)$. The different rate constants are reflected in different affinities of complexes, in that the affinity of the SRP-FtsY complex $\left(\mathrm{K}_{\mathrm{d}}=10 \mathrm{nM}\right)$ is higher than that of the targeting complex $\left(\mathrm{K}_{\mathrm{d}}=40 \mathrm{nM}\right)$ (Zhang et al., 2009). Another remarkable difference is observed when the affinity of FtsY binding to SRP bound to the non-translating ribosome (5.2 $\mu \mathrm{M}$, (Shen et al., 2011)) is compared to submicromolar affinities in the present work or from our previous study (Bornemann et al., 2008). The differences in kinetic parameters between our data and the data of Zhang et al. (Zhang et al., 2009) can arise from different experimental setup and analysis. For instance, when we studied the concentration dependence of the kinetics of targeting complex formation we titrated to concentrations up to seven-fold $K_{d}$ whereas the titrations from Shan's group did not reach saturation. In addition, to obtain kinetic parameters we performed global fitting of combined data sets of dissociation and association, whereas Shan and colleagues (Zhang et al., 2009) used linear extrapolation of data points measured far from saturation.

In summary, the kinetic analysis reveals that targeting complex formation is facilitated on ribosomes presenting nascent chains that are either contained inside the exit tunnel or exposed outside the ribosome. Interestingly, the kinetic effect is an increase of the forward rate constants of a rearrangement following the initial binding step. We note that, in the cell, binding of FtsY to the SRP-ribosome complexes may be influenced by memrbane lipids or the translocon (Angelini et al., 2006; Braig et al., 2011). The influence of the translocon on the targeting complex is discussed below. 


\section{The influence of translocon binding on the targeting complex}

The targeting complex formed between FtsY and the RNC-bound SRP transfers the membrane proteins to the translocon at the membrane. The translocon interacts with both FtsY (Angelini et al., 2006; Kedrov et al., 2011) and the RNC (Frauenfeld et al., 2011; Park et al., 2013; Wu et al., 2012), and one important question is whether these interactions can take place in parallel. Recently, it was reported that FtsY is mainly located at the membrane (Mircheva et al., 2009). The A domain and the membrane targeting sequence (MTS), a short amphiphilic helix located at the interface between the A and the NG domain of FtsY, are required for the associations with anionic phospholipids (de Leeuw et al., 2000; Parlitz et al., 2007; Stjepanovic et al., 2011). FtsY also interact with the translocon via the A and the NG domain (Angelini et al., 2006; Kedrov et al., 2011). It has been suggested that these interactions may require a conformational change of FtsY, influencing the SRP-FtsY complex (Braig et al., 2011; Lam et al., 2010). The present thermodynamic analysis shows that the SRP-FtsY complex is stabilized in the presence of the translocon. The binding of the translating ribosome to the translocon is seen by cryo-EM (Frauenfeld et al., 2011; Park et al., 2013) and the interaction seems to be inhanced by nascent chains (Wu et al., 2012). Our results indicate that the targeting complex is destabilized at a certain critical length of the nascent chain in the presence of the translocon.

The stabilization is observed in the presence of the wild-type translocon embedded in nanodisc (SecYEG-ND), mutant translocon embedded in nanodisc (mtSecYEG-ND), impaired in ribosome binding, and SecYEG proteins solubilized in DDM by a factor of upto ten $\left(\mathrm{K}_{\mathrm{d}} 220 \mathrm{nM}\right.$ to 20 30 nM). Apparently, FtsY, which is bound to the translocon (Angelini et al., 2006; Kedrov et al., 2011), becomes readily accessible for the interaction with SRP presumably due to a conformational change of the A domain of FtsY. The Ffh (NG)-FtsY (NG) heterodimer seen in crystal structure (Egea et al., 2004; Focia et al., 2004) does not contain the A domain and the MTS, without which SRP-FtsY complex formation is facilitated, resulting in the increased basal GTPase activity (Neher et al., 2008). The interaction between the translocon and only the SRP-FtsY complex is probably not relevant in vivo, since all the SRP might be bound to the translating ribosome. However, this observation suggests that a structural rearrangement accompanies the ineraction of the targeting complex with the translocon. In addition, we observe the effect of DDM (Wu et al., 
2012) on the interaction between SRP and FtsY. The four-fold increased affinity of the SRPFtsY complex in the presence of DDM compared to that in the absence of DDM (K 220 vs. $60 \mathrm{nM}$ ) in the present work may imply that the environment of SecYEG is critical for interactions between SRP and FtsY. Therefore, we note that the direct comparison of the study using SecYEG proteins embedded in nanodisc with the study using SecYEG solubilized in DDM (SecYEG-DDM) is difficult.

The final step of ribosome targeting to the membrane is the disassembly of the targeting complex that precedes or accompanies the transfer of the RNC to the translocon. Thus, we investigated the effect of the lengths of nascent chains on the stability of the targeting complex at the translocon. Our results indicate that the targeting complex formed on RNCs harboring nascent chains of 75 amino acids or longer is weakened at the translocon as indicated by the six-fold decreased affinity ( $\mathrm{K}_{\mathrm{d}} 6 \mathrm{nM}$ vs. $\left.36 \mathrm{nM}\right)$. A destabilization of the targeting complex at the translocon would not be unexpected. However, the destabilization does not occur with a targeting complex with less than 75 amino acids. Considering membrane-localized FtsY (Mircheva et al., 2009), this may imply that the translocon does not contribute significantly to the targeting of the SRP-RNC complex when nascent chains are less than 75 amino acids long. Using mtSecYEG-ND, we show that the destabilization of the targeting complex is due to the interaction between the translocon and longer nascent chains emerging from the RNC (Figure 18). According to cryo-EM structures and SPR measurements using SecYEG-ND (Frauenfeld et al., 2011; Park et al., 2013; Wu et al., 2012), the translocon interacts with the ribosome exit near L23, where also SRP binds (Gu et al., 2003; Halic et al., 2006) and signal peptides associates directly with the translocon. Thus, it seems likely that binding of the translocon to ribosomes carrying short nascent chains only slightly affects the targeting complex, whereas the binding of longer nascent chains containing an SAS weakens the targeting complex and may facilitate targeting complex disassembly.

The destabilization of the targeting complex at the translocon can be due to both a conformational change of the targeting complex at the translocon and the disassembly of the targeting complex. Our thermodynamic data shows a partial competition between the targeting complex and the translocon (Figure 19), in which a quaternary complex (the 
targeting complex bound to the translocon) may exist. However, the quaternary complex is expected to be labile ( $\mathrm{K}_{\mathrm{d}}$ up to $60 \mathrm{nM}$ ) at saturation with SecYEG-ND. Alternatively, mtSecYEG-ND stabilizes the targeting complex, suggesting a formation of pre-translocation complex which mediates to the peptide transfer. Since the interaction between the ribosome and the translocon is impaired, the pre-translocation complex would be formed via interaction between Fts $\mathrm{Y}$ and the translocon. Otherwise, the conformation of the targeting complex at the translocon is not clear. It was recently suggested that the Ffh(NG)-FtsY(NG) heterodimer relocates from the apical to the distal end of 4.5S RNA, and that this relocation leads to GTP hydrolysis and complex disassembly (Ataide et al., 2011; Shen et al., 2012; Shen et al., 2013). The role of the distal end on the GTP hydrolysis was verifieid in the present work. As these data were obtained with translocon preparations stabilized by detergent (DDM), the comparison with the present data is difficult. However, nascent chaindependent weakening of the targeting complex at the translocon may reflect a rearrangement preceding the disassembly of the complex. It remains to be established, at which point in complex disassembly GTP hydrolysis is triggered.

Based on the results of our kinetic and thermodynamic analysis of the bacterial targeting complex, we propose a model (Figure 24), in which the RNC-SRP complex encounters FtsY and followed by the translocon to the membrane in a co-translational manner.
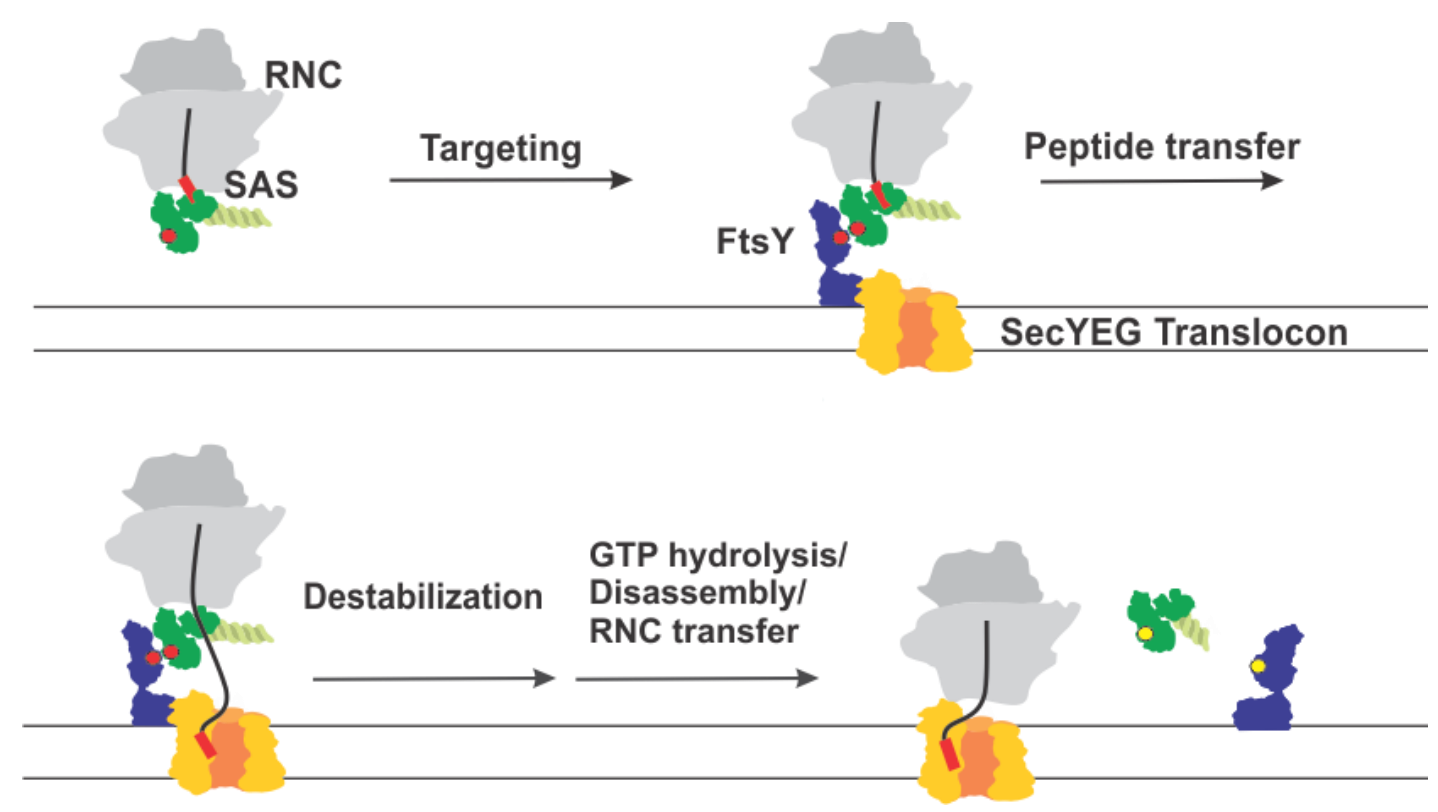

Figure 24 Dynamic model of targeting complex interactions with the translocon at the membrane See text for details. 
First, targeting complex formation is accelerated by rapid conformational change when the RNC-bound SRP exhibits an open conformation, in which the NG domain of Ffh is accessible for the binding of the FtsY-NG domain. Second, as translation proceeds, at a certain lengths of nascent chains (75 amino acids or longer) the targeting complex is destabilized at the translocon, presumably due to the interaction between the nascent chains and the translocon-Complex weakeneing may lead to the following steps, including GTP hydrolysis, and the disassembly of the targeting complex and peptide insertion into the membrane. 


\section{Materials and Methods}

\subsection{Chemicals}

Chemical reagents were purchased from Merck or from other providers, as follows.

HEPES

Ampicillin

Chloramphenicol

Kanamycin

IPTG

DTT

GTP

GDP

GMPPNP

$\left[\gamma^{32} \mathrm{P}\right] \mathrm{GTP}$

Fluorescent dyes

SDS

Ni-NTA agarose

Acrylamide/Bisacrylamide (29:1) and (19:1)

Lysozyme

Phusion polymerase

Dpn1 restriction enzyme

Pyruvate kinase

Smart Ladder Markers

Perfect Protein Marker 15-150kDa

SUMO-Protease
Sigma-Aldrich

Sigma-Aldrich

Sigma-Aldrich

Serva

Roth

Applichem

Jena Bioscience

Jena Bioscience

Jena Bioscience

Hartmann

Molecular Probes, Invitrogen

Serva

Qiagen

Serva

Sigma-Aldrich

Thermo Scientific

Thermo Scientific

Roche

Eurogenetic

Novagen

Invitrogen 


\subsection{Equipment}

Centrifuge Avanti J-26 (Rotors:JLA8.1 JA25.5)

Ultracentrifuge Optima MAX XP (Rotors: TLS-55)

Emulsiflex homogenizer

Supersignal West pico

Western film (Amersham Hyperfilm ECL)

TLC (Polygram CEL 300)

Typhoon FLA-7000 Laser Scanner

Fluorimeter Fluorolog-3

Stopped-Flow SX18MV

DNA preparation kit

Gel running system

FPLC ÄCTA

HPLC
Beckman

Beckman

Avestin

Thermoscientific

GE Healthcare

Macherey-Nagel

GE Healthcare Life Science

Horiba Jobin-Yvon

Applied Photophysics, UK

Machery-Nagel

Peqlab and Biorad

GE Healthcare Life Science

Waters 


\subsection{Buffers}

\begin{tabular}{|c|c|c|}
\hline Buffers & Usage & Composition \\
\hline Buffer A & $\begin{array}{l}\text { Fluorescence } \\
\text { measurements }\end{array}$ & $\begin{array}{l}20 \mathrm{mM} \text { HEPES (pH 7.5), } 30 \mathrm{mM} \mathrm{NH} \mathrm{H}_{4} \mathrm{Cl}, 70 \mathrm{mM} \\
\mathrm{KCl}, 7 \mathrm{mM} \mathrm{MgCl}_{2}, 10 \% \text { glycerol }\end{array}$ \\
\hline Buffer B & Transcription & $\begin{array}{l}40 \mathrm{mM} \text { Tris- } \mathrm{HCl} \text { (pH 7.5), } 1 \mathrm{mM} \text { spermidine, } 10 \\
\mathrm{mM} \text { DTT, } 0.05 \% \text { Tween-20, } 8 \mathrm{mM} \mathrm{MgCl}_{2}\end{array}$ \\
\hline Buffer C & FPLC-HiTrap-Q & $\begin{array}{l}30 \mathrm{mM} \text { Bis-Tris (pH 6.0), } 1 \text { mM EDTA, } 1.5 \mathrm{M} \\
\mathrm{NaCl}, \mathrm{pH} 6.0\end{array}$ \\
\hline Buffer D & HPLC-RP18 & $\begin{array}{l}20 \mathrm{mM} \text { Ammonium acetate ( } \mathrm{pH} 5.0 \text { ), } 10 \mathrm{mM} \\
\mathrm{MgCl}_{2}, 400 \mathrm{mM} \mathrm{NaCl}, 100 \% \text { ethanol }\end{array}$ \\
\hline Buffer E & $50 X$ TAE & $2 \mathrm{M}$ Tris, $1 \mathrm{M}$ acetic acid, $50 \mathrm{mM}$ EDTA (pH 8.0) \\
\hline Buffer F & 10X TBE & $\begin{array}{l}890 \mathrm{mM} \text { Tris, } 890 \mathrm{mM} \text { boric acid, } 30 \mathrm{mM} \text { EDTA } \\
\text { (pH 8.0) }\end{array}$ \\
\hline Buffer G & $\begin{array}{l}\text { 4X Separating } \\
\text { buffer }\end{array}$ & 1.5 M Tris-HCl buffer ( $\mathrm{pH} 8.8$ ), $0.4 \%$ w/v SDS \\
\hline Buffer $\mathrm{H}$ & 4X Stacking buffer & $0.5 \mathrm{M}$ Tris- $\mathrm{HCl}$ buffer ( $\mathrm{pH} 6.8), 0.4 \%$ w/v SDS \\
\hline Buffer I & $\begin{array}{l}\text { Western blot } \\
\text { (upper layer) }\end{array}$ & $\begin{array}{l}25 \mathrm{mM} \text { Tris (pH 9.4), } 40 \mathrm{mM} \text { 6-amino caproic acid, } \\
20 \% \text { methanol }\end{array}$ \\
\hline Buffer J & $\begin{array}{l}\text { Western blot } \\
\text { (middle layer) }\end{array}$ & $25 \mathrm{mM}$ Tris (pH 10.4), $20 \%$ methanol \\
\hline Buffer K & $\begin{array}{l}\text { Western blot } \\
\text { (lower layer) }\end{array}$ & $300 \mathrm{mM}$ Tris (pH 10.4), $20 \%$ methanol \\
\hline Buffer L & $10 \mathrm{X}$ PBS & $\begin{array}{l}80 \mathrm{~g} \mathrm{NaCl}, 2 \mathrm{~g} \mathrm{KCl}, 14.4 \mathrm{~g} \mathrm{Na}_{2} \mathrm{HPO}_{4}, 2.4 \mathrm{~g} \mathrm{KH}_{2} \mathrm{PO}_{4} \\
\text { in } 1 \mathrm{~L} \text { water }(\mathrm{pH} 7.2)\end{array}$ \\
\hline Buffer M & In vitro translation & 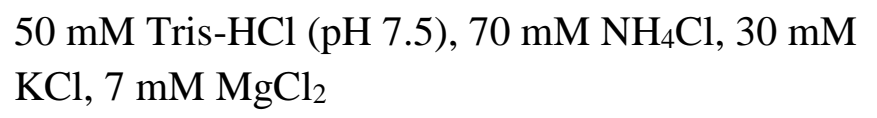 \\
\hline
\end{tabular}




\begin{tabular}{|c|c|c|}
\hline Buffers & Usage & Composition \\
\hline Buffer Ffh-A & Cell opening & 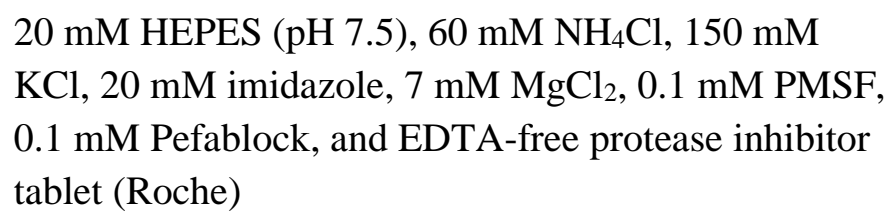 \\
\hline Buffer Ffh-B & Ni-NTA washing & 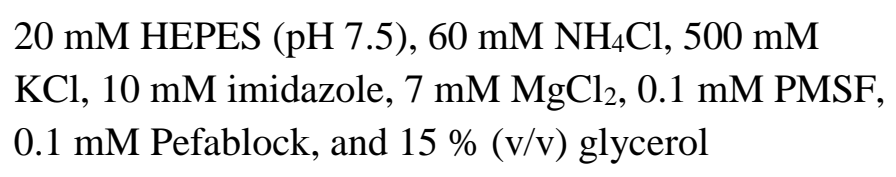 \\
\hline Buffer Ffh-C & Ni-NTA elution & $\begin{array}{l}20 \mathrm{mM} \text { HEPES (pH 7.5), } 60 \mathrm{mM} \mathrm{NH}_{4} \mathrm{Cl}, 100 \mathrm{mM} \\
\mathrm{KCl}, 250 \mathrm{mM} \text { imidazole, } 7 \mathrm{mM} \mathrm{MgCl}_{2} \text {, and } 10 \% \\
\text { (v/v) glycerol }\end{array}$ \\
\hline Buffer Ffh-D & FPLC-HiTrap-SP & $\begin{array}{l}20 \mathrm{mM} \text { HEPES (pH 7.5), } 1 \mathrm{M} \mathrm{KCl,} 7 \mathrm{mM} \mathrm{MgCl}_{2}, \\
10 \% \text { (v/v) glycerol, and } 10 \mathrm{mM} \mathrm{ß-mercaptoethanol}\end{array}$ \\
\hline Buffer FtsY- A & $\begin{array}{l}\text { Cell } \\
\text { resuspension }\end{array}$ & $\begin{array}{l}20 \mathrm{mM} \text { HEPES (pH 7.5), } 2 \mathrm{mM} \text { EDTA, } 150 \mathrm{mM} \\
\mathrm{NaCl}, 0.01 \% \text { Nikkol, } 2 \mathrm{mM} \text { DTT, } 0.1 \mathrm{mM} \text { PMSF, } 0.1 \\
\text { mM Pefabloc, and a pill of EDTA-free proteinase } \\
\text { inhibitor }\end{array}$ \\
\hline Buffer FtsY- B & Ni-NTA binding & 20 mM HEPES (pH 7.5), $150 \mathrm{mM} \mathrm{KCl}$ \\
\hline Buffer FtsY-C & Ni-NTA washing & $20 \mathrm{mM}$ HEPES (pH 7.5), $1 \mathrm{M} \mathrm{KCl}, 10 \mathrm{mM}$ imidazole \\
\hline Buffer FtsY- D & Ni-NTA elution & $\begin{array}{l}20 \mathrm{mM} \text { HEPES (pH 7.5), 150mM KCl, } 200 \mathrm{mM} \\
\text { imidazole }\end{array}$ \\
\hline Buffer FtsY- E & FPLC-Hitrap-Q & $\begin{array}{l}20 \mathrm{mM} \text { HEPES (pH 7.5), } 2 \mathrm{mM} \text { EDTA, } 500 \mathrm{mM} \\
\mathrm{NaCl}, 0.01 \% \text { Nikkol, and } 2 \mathrm{mM} \text { DTT }\end{array}$ \\
\hline $\begin{array}{l}\text { Buffer SecYEG- } \\
\text { A }\end{array}$ & $\begin{array}{l}\text { Cell } \\
\text { resuspension }\end{array}$ & $\begin{array}{l}20 \mathrm{mM} \text { Tris- } \mathrm{HCl} \text { (pH 7.5), } 200 \mathrm{mM} \mathrm{NaCl}, 5 \mathrm{mM} \\
\mathrm{MgCl}_{2}\end{array}$ \\
\hline $\begin{array}{l}\text { Buffer SecYEG- } \\
\qquad \text { B }\end{array}$ & Washing & $\begin{array}{l}20 \mathrm{mM} \text { Tris- } \mathrm{HCl}(\mathrm{pH} 7.5), 1.0 \mathrm{M} \mathrm{NaCl}, 5 \mathrm{mM} \mathrm{MgCl}_{2} \text {, } \\
5 \mathrm{mM} \text { imidazole, } 0.5 \mathrm{mM} \text { phenylmethylsulfonyl } \\
\text { fluoride (PMSF), } 1 \mathrm{mM} \text { dithiothreitol (DTT), and } 1 \% \\
\text { dodecyl- } \beta \text {-D-maltopyranoside (DDM }\end{array}$ \\
\hline $\begin{array}{l}\text { Buffer SecYEG- } \\
\qquad \text { C }\end{array}$ & Ni-NTA washing & $\begin{array}{l}20 \mathrm{mM} \text { Tris- } \mathrm{HCl}(\mathrm{pH} 7.5), 200 \mathrm{mM} \mathrm{NaCl}, 5 \mathrm{mM} \\
\mathrm{MgCl}_{2}, 10 \% \text { glycerol, } 0.03 \% \mathrm{DDM}, 10 \mathrm{mM} \text { imidazole }\end{array}$ \\
\hline $\begin{array}{l}\text { Buffer SecYEG- } \\
\quad \text { D }\end{array}$ & Dialysis & $\begin{array}{l}50 \mathrm{mM} \text { HEPES-HCl (pH 8.0), } 50 \mathrm{mM} \mathrm{NaCl}, 10 \% \\
\text { glycerol, } 0.03 \% \mathrm{DDM}\end{array}$ \\
\hline
\end{tabular}




\subsection{Cell strains and plasmids}

\subsubsection{Cell strains}

E.coli $\mathrm{DH} 5 \alpha$ competent cells were used for heat shock transformation and plasmid DNA preparation. E.coli BL21(DE3) pLysS was used for expression of Ffh protein. E.coli BL21(DE3) was used to express FtsY protein.

\subsubsection{Plasmids}

\begin{tabular}{|c|c|c|c|}
\hline RNA or protein & Vector & Resistance & Reference \\
\hline 4.5S RNA-WT & \multirow{3}{*}{ pT7 } & \multirow{3}{*}{ Ampicillin } & Lentzen, 1994 \\
\hline 4.5S RNA-83mer & & & This study \\
\hline 4.5S RNA-61mer & & & This study \\
\hline Ffh-WT(His6) & \multirow{3}{*}{ pET24 } & \multirow{3}{*}{ Kanamycin } & Jagath, 1998 \\
\hline Ffh-A152C(His6) & & & Buskiewicz, 2005b \\
\hline Ffh-A235C(His6) & & & This study \\
\hline FtsY-WT(His $\left.{ }_{6}\right)$ & pET9a & Kanamycin & Jagath, 1998 \\
\hline FtsY-V342C(His $\left.{ }_{6}\right)$ & pET9a & Kanamycin & Jagath, 1998 \\
\hline FtsY-D487C(His6) & pET9a & Kanamycin & This study \\
\hline Lep-WT & pBSK2 & Amplicillin & This study \\
\hline $\begin{array}{c}\text { SecYEG } \\
\text { SecY-R357H-EG }\end{array}$ & pTRC99a & Ampicillin & $\begin{array}{c}\text { Provided by C. Schaffitzel } \\
\text { This study }\end{array}$ \\
\hline
\end{tabular}




\subsection{Molecular biology methods}

\subsubsection{Plasmid construction}

pET24a and pET9a were used to express Ffh and FtsY proteins, respectively. Both plasmids contain T7 promoter which upon induction by IPTG recruits T7 RNA polymerase. Downstream of the protein sequence of an interest $6 \mathrm{X}$ His were inserted for $\mathrm{Ni}^{2+}$ purification.

\subsubsection{Site-directed mutagenesis}

To introduce a single cysteine at the position of interest, site-directed mutagenesis was used. Double-stranded template DNA is mixed with a pair of complementary primers which have Cys bases at the site of an interest and about 15 bases flanking upstream and downstream of the mutation site. By thermocycling DNA with a desired mutation replicates itself.

\begin{tabular}{|c|c|c|c|}
\hline \multicolumn{2}{|c|}{ Materials } & & Concentration \\
\hline \multicolumn{2}{|c|}{ Template DNA } & & $50 \sim 100 \mathrm{ng}$ \\
\hline \multicolumn{2}{|c|}{ Forward and reverse primer } & & $10 \mu \mathrm{M}$ each \\
\hline \multicolumn{2}{|c|}{ dNTP } & & $10 \mathrm{mM}$ each \\
\hline \multicolumn{2}{|c|}{ Phusion HF buffer } & & $1 \mathrm{X}(5 \mathrm{X}$ stock $)$ \\
\hline \multicolumn{2}{|c|}{ Phusion polymerase } & & $1 \mathrm{U}(2 \mathrm{U} / \mu \mathrm{l})$ \\
\hline \multicolumn{2}{|c|}{ Water } & & Up to $50 \mu \mathrm{l}$ \\
\hline Time & \multicolumn{2}{|c|}{ Temperature } & Duration \\
\hline 1 & \multicolumn{2}{|c|}{$95^{\circ} \mathrm{C}$} & $30 \mathrm{sec}$ \\
\hline \multirow[t]{3}{*}{$2-31$} & \multicolumn{2}{|c|}{ Denaturation $95^{\circ} \mathrm{C}$} & $30 \mathrm{sec}$ \\
\hline & \multicolumn{2}{|c|}{ Annealing $55-65^{\circ} \mathrm{C}$} & $30 \mathrm{sec}$ \\
\hline & \multicolumn{2}{|c|}{ Polymerizing at $72^{\circ} \mathrm{C}$} & $2 \min$ \\
\hline 32 & \multicolumn{2}{|c|}{$72{ }^{\circ} \mathrm{C}$} & $10 \mathrm{~min}$ \\
\hline
\end{tabular}

\subsubsection{Dpn digestion}

Following PCR, methylated parental DNAs are digested by incubating with Dpn1 restriction enzyme (Biolab, NEB) at $37^{\circ} \mathrm{C}$ for 2-3 hours. Only synthesized DNAs by PCR remain. The DNAs with a mutation are analyzed by agarose gel electrophoresis. 


\subsubsection{Primers}

\section{For Cys mutation on Ffh and FtsY}

FfhA235C

Fwd 5'-GCG GCC AAT ACG GCA AAA TGT TTC AAT GAA GCG TTA CCG-3'

Rev 5'- CGG TAA CGC TTC ATT GAA ACA TTT TGC CGT ATT GGC CGC-3'

FtsYD487C

Fwd 5'-CCG TTT AAG GCG GAC TGT TTT ATA GAG GCA CTT TTT G-3'

Rev 5'- CAA AAA GTG CCT CTA TAA AAC AGT CCG CCT TAA ACG G-3'

\section{SecY R357H}

Fwd 5'-GCA TTT GTA CCA GGA ATT CAT CCG GGA GAG CAA AC -3'

Rev 5'- GTT TGC TCT CCC GGA TGA ATT CCT GGT ACA AAT GC-3'

\subsubsection{Heat shock transformation}

DH5 $\alpha$ competent cells were used for routing cloning work. BL21(DE3) and BL21(DE3)pLys competent cells were used for expressing Ffh and FtsY proteins.

1-10 ng of plasmid DNA was mixed with $50 \mu \mathrm{l}$ of competent cells. After 5 min of incubation on ice, cells were incubated at $42^{\circ} \mathrm{C}$ for 45 seconds and then placed back on ice. The transformed cells were mixed with $500 \mu \mathrm{l}$ of LB medium and incubated at $37^{\circ} \mathrm{C}$ for 30 min with agitation. Cells were spread on LB agar plate with the respective antibiotics and grown at $37^{\circ} \mathrm{C}$ overnight.

\subsubsection{Plasmid DNA preparation}

A single colony was used to inoculate $3 \mathrm{~mL}$ (mini-prep) or $200 \mathrm{ml}$ (midi-prep) of LB medium with the respective antibiotics and was grown overnight at $37^{\circ} \mathrm{C}$. Plasmid DNA was purified according to the manufacturer's protocol (Machery-Nagel) and verified by sequencing (SeqLab, sequence laboratories, Göttingen). 


\subsection{Preparation of labeled 4.5S RNA}

\subsubsection{Deletion and insertion mutagenesis of 4.5S RNA}

For the construction of 4.5S RNA9-91 (83mer) lacking the loop E, deletion and insertion mutagenesis PCR was used. 4.5S RNA $21-88$ (68mer) lacking loop D and E as a template was mixed with a pair primers complementary to the sequence of the template including a desired insert for insertion or missing nucleotides for deletion. To insert more than 7 bases the insertion mutagenesis by PCR requires long primers which have unusually high melting temperature. To avoid high melting temperature, a pair of primers (3) was prepared, which contain the bases to be inserted and either side of template sequences. During PCR reaction, the pair of primers extends to either side with the overlap region of the inserted nucleotides.

(1) Insertion of ACC at 3' end of 4.5S RNA $21-88$

Fwd 5'-AGA TGA CGC GTG TGC CGA CCG GAT GTA GCT GGC AG-3'

Rev 5'- CTG CCA GCT ACA TCC GGT CGG CAC ACG CGT CAT CT-3'

(2) Deletion of GGGCG at 5' end of 4.5S RNA $21-91$

Fwd 5'-ATA CGA CTC ACT ATA CGC TAC TCT GTT TAC CA-3'

Rev 5'-TGG TAA ACA GAG TAG CGT ATA GTG AGT CGT AT-3'

(3) Insertion of CAU UUU GGU CGC AA at 5' end of 4.5S RNA26-91

Fwd 5'-ATA CGA CTC ACT ATA CAT TTT GGT CGC AA-3'

Rev 5'-TGG TAA ACA GAG TAG CGT TGC GAC CAA AAT G-3'

(4) Insertion of GGG at 5' end of 4.5S RNA $12-91$

Fwd 5'-AAT ACG ACT CAC TAT AGG GCA TTT TGG TCG CAA-3'

Rev 5'-TTG CGA CCA AAA TGC CCT ATA GTG AGT CGT ATT-3' 


\subsubsection{In vitro transcription of 4.5S RNA}

Using T7 RNA polymerase which specifically transcribes only DNA downstream of a T7 promoter, 4.5S RNA was transcribed in vitro. For large-scale RNA preparations, the respective DNA was amplified by PCR for different lengths of RNAs. The PCR product was used as a template in the transcription reaction without further purification. Transcription was performed by mixing the materials as shown below followed by incubation for $4 \mathrm{~h}$ at $37^{\circ} \mathrm{C}$.

\begin{tabular}{l|l}
\hline \multicolumn{1}{c|}{ Materials } & \multicolumn{1}{c}{ Concentration } \\
\hline 5X Transcription Buffer B & $1 \mathrm{X}$ \\
DTT & $10 \mathrm{mM}$ \\
NTPs & $3 \mathrm{mM}$ \\
GMP & $5 \mathrm{mM}$ \\
Template DNA from PCR & $1 \mathrm{~mL}$ \\
T7 polymerase (Fermentas) & $200 \mathrm{U} / \mathrm{ml}$ \\
RNase Inhibitor & $40 \mathrm{U} / \mathrm{ml}$ \\
Inorganic pyrophosphatase & $0.01 \mathrm{U} / \mu \mathrm{l}$ \\
ddH2O & up to $10 \mathrm{ml}$ \\
\hline
\end{tabular}

The reaction was stopped by adding $1 / 5$ vol of $20 \%$ potassium acetate ( $\mathrm{pH}$ 5.0). Transcribed RNAs were precipitated by adding 2.5-3 vol of a cold ethanol and incubation at $-20{ }^{\circ} \mathrm{C}$ for $30 \mathrm{~min}$. The RNAs were pelletted by centrifugation at $14,000 \mathrm{rpm}$ for $20 \mathrm{~min}$. The pellet was washed with $70 \%$ ethanol, dried, and dissolved in water. This process was repeated once. Then, the pellet was purified by ion exchange chromatography on a HiTrap-Q column using a linear gradient of $20-100 \%$ of Buffer C. The purified RNAs were precipitated by adding 1 volume of isopropanol and incubated at $-20^{\circ} \mathrm{C}$ for $30 \mathrm{~min}$. After centrifugation at $14,000 \mathrm{rpm}$ for $20 \mathrm{~min}$, the pellet was washed with $70 \%$ ethanol. Washed and dried pellets were dissolved in water. The concentration of $4.5 \mathrm{~S}$ RNA was determined by measuring absorbance at $260 \mathrm{~nm}$ and using the extinction coefficient of $1,063,700 \mathrm{M}^{-1} \mathrm{~cm}^{-1}$ for full length 4.5S RNA. 
To label RNA with fluorophore, the 3'-terminal ribose was oxidized to the bi-aldehyde by adding $0.1 \mathrm{M}$ potassium acetate $(\mathrm{pH} 5.3)$ and $4 \mathrm{mM} \mathrm{KIO}_{4}$ in incubation on ice for $30 \mathrm{~min}$. The reaction was stopped by adding $1 / 20 \mathrm{vol}$ of $200 \mathrm{mM}$ ethylenglycol and incubating on ice for $10 \mathrm{~min}$. Oxidized RNAs were precipitated by adding 1/10 vol of potassium acetate and $3 \mathrm{vol}$ of ethanol and incubating at $-20{ }^{\circ} \mathrm{C}$ at least for $1 \mathrm{~h}$. After centrifugation at 14,000 rpm for $30 \mathrm{~min}$ at $4{ }^{\circ} \mathrm{C}$, the pellet was washed with $70 \%$ ethanol and dissolved in distilled water. The precipitation was repeated. Oxidized and purified RNAs were incubated with 1/20 vol of $3 \mathrm{M}$ potassium acetate and labeled by adding 10fold excess amount of Alexa555hydrazide at $4{ }^{\circ} \mathrm{C}$ overnight.

\subsubsection{Purification of labeled 4.5S RNA}

Purification of labeled RNAs was performed in three steps. First, labeled RNAs were ethanol precipitated. This was repeated until the supernatant after pellet is clean and colorless. Next, the RNA was subjected to S200 gel filtration column (GE Healthcare) using FPLC. Gel filtration separates labeled RNAs, non-labeled RNAs, and the remaining dye. The mobile phase was water. The fractions containing labeled RNAs were collected and concentrated by ethanol precipitation. Last, labeled RNAs were purified by reverse phase on a WP300 RP-18 column using linear gradient of 10-100 \% of Buffer D. Fractions containing Alexa555 labeled RNAs were collected, concentrated by ethanol precipitation, and dissolved in water. The purified and labeled RNA was stored at $-20^{\circ} \mathrm{C}$.

\subsubsection{Determination of nucleic acid concentration}

Plasmid DNA concentration was estimated by measuring the absorbance at $260 \mathrm{~nm}$ and using the constant $50 \mu \mathrm{g} / \mathrm{ml}$ of pure dsDNA. The absorbance was measured on a Nanodrop photometer. 4.5S RNA concentration was estimated by measuring the absorbance at $260 \mathrm{~nm}$ and using the constant $40 \mu \mathrm{g} / \mathrm{ml}$ of pure RNA. 


\subsection{Preparation of fluorescence-labeled Ffh and FtsY}

\subsubsection{Protein expression}

A single colony containing the plasmid with the gene of interest was transferred into $200 \mathrm{ml}$ of LB medium with the respective antibiotics. Cells were grown in LB medium overnight at $37^{\circ} \mathrm{C}$ with shaking. $1 \%$ of glucose was supplemented to control basal expression of Ffh. Overnight cultures were diluted in LB medium to an $\mathrm{OD}_{600}$ of $\sim 0.1$. When cultures were grown up to an $\mathrm{OD}_{600}$ of 0.6 , the expression of the desired protein was induced with $5 \mathrm{mM}$ of IPTG for Ffh or $1 \mathrm{mM}$ of IPTG for FtsY and incubated for $2 \mathrm{~h}$ at $37^{\circ} \mathrm{C}$ with shaking. Cells were harvested by centrifugation at 5,000 rpm for $20 \mathrm{~min}$ (Beckman JLA8.1). In average 12 $\mathrm{g}$ of cells were obtained from $6 \mathrm{~L}$ of cell culture.

\subsubsection{Ffh(His6) purification}

Cells (12 g) were resuspended in $50 \mathrm{~mL}$ of Buffer Ffh-A by using a dounce homogenizer. The resupended cells were disrupted using an Emulsiflex at 1,500 $\mathrm{Pa}$ (Emulsiflex, Avestin). Lysed cells were centrifuged at 15,000 rpm in JA25.5 rotor for 45 minutes. The supernatant was loaded onto $5 \mathrm{ml}$ of Ni-NTA agarose resin and incubated at $4{ }^{\circ} \mathrm{C}$ for 60 minutes with gently inverting. The resin was washed with $150 \mathrm{ml}$ (30 ml X 5 times) of Buffer Ffh-B and settled by low speed centrifugation at $700 \mathrm{x} \mathrm{g}$ for $2 \mathrm{~min}$. Ffh protein was eluted by incubating with $20 \mathrm{ml}$ of. The elute was diluted into Buffer Ffh-A and further purified by cation exchange chromatography ( $5 \mathrm{ml}$ Hitrap HP SP, GE Healthcare Life science) using a 20 column volume (CV) linear gradient of 5-100\% of Buffer Ffh-D. At 40-65\% of Buffer Ffh-D Ffh eluted. $3 \mathrm{ml}$ fractions were collected and analyzed by SDS-PAGE. The fractions containing Ffh were pooled and concentrated to $100 \mu \mathrm{M}$ concentration and re-buffered into Buffer A using Vivaspin (GE Healthcare) 10 kD MW.

\subsubsection{FtsY(His6) purification}

Cells (12 g) were resuspended in $40 \mathrm{ml}$ of Buffer Fts Y- A using a dounce homogenizer. The resuspended cells were lysed by a high-pressure homogenizer (Emulsiflex, Avestin). The lysate was centrifuged at 20,000 rpm in JA25.5 rotor for 45 minutes. The supernatant was loaded onto Ni-NTA agarose resin and incubated at $4{ }^{\circ} \mathrm{C}$ for 60 minutes. The resin was washed 5 times with $30 \mathrm{ml}$ of Buffer Fts Y- C. FtsY was eluted in $20 \mathrm{ml}$ of Buffer FtsY- D. The buffer was exchanged by dialysis in Buffer FtsY-A The protein was further purified by 
anion exchange chromatography ( $5 \mathrm{ml}$ Hitrap HP Q, GE Healthcare Life science) using a 20 CV linear gradient of 30 -100\% of Buffer FtsY- E. FtsY protein eluted at 55-70 \% of Buffer FtsY- E. $3 \mathrm{ml}$ fractions were collected and analyzed by SDS-PAGE. The fractions containing pure FtsY were pooled, concentrated, and re-buffered into Buffer A using Vivaspin (GE Healthcare) $10 \mathrm{kD}$ MW.

\subsubsection{Labeling proteins with fluorescent dyes}

To introduce specific fluorescent label, first the native Cys residue was exchanged to Ser, and then a single Cys was engineered by site-directed mutagenesis. To attach fluorescent dyes specifically at Cys residue, thiol-reactive maleimide derivative of the dyes were used. Fluorescent dyes such as Alexa555, Bodipy-FL, and QSY were dissolved in Buffer A. The same concentration of MDCC dye was dissolved in DMSO before use. According to the molecular weight of dyes, the appropriate volume of solvent was added to prepare 20-50 $\mathrm{mM}$ solutions of the dyes in solution containing less than $1 \%$ DMSO final.

To label Ffh with fluorescent dyes, purified Ffh proteins were incubated with a 20 fold excess of an appropriate dyes for 2 hours at room temperature. The reaction was stopped by the addition of $10 \mathrm{mM}$ 2-mercaptoethanol. To remove free dye, the reaction was loaded onto desalting column (GE Healthcare). The labeled proteins were collected and concentrated up to $20 \mu \mathrm{M}$ using Vivaspin (GE Healthcare).

To label FtsY, $0.5 \mathrm{mg}$ of the respective fluorescent dye was incubated with the lysed Fts Y cells by loading to Ni-NTA resins and incubating at $4{ }^{\circ} \mathrm{C}$ for $2 \mathrm{~h}$. The reaction was quenched by the addition of $10 \mathrm{mM}$ 2-mercaptoethanol. Free dye was washed 10 times with $30 \mathrm{~mL}$ Buffer FtsY- B and Buffer FtsY- C. Labeled FtsY was eluted in $20 \mathrm{~mL}$ of Buffer FtsY- D. The labeled FtsY was further purified by anion exchange chromatography as wild-type FtsY. Finally, labeled Fts Y was concentrated and re-buffered by using Vivaspin (GE Healthcare).

\subsubsection{Determination of fluorophore labeling efficiency}

Labeling efficiency was determined by dividing fluorescence concentration by protein concentration. Ffh and FtsY protein concentration was estimated by measuring absorbance at $205 \mathrm{~nm}$. In addition concentration gel (SDS-PAGE) was used to determine the 
concentration of proteins of interest by comparing gel bands to the protein bands whose concentration is already known.

$$
\begin{aligned}
& \text { Ffh concentration }(\mathrm{cm} \cdot \mathrm{M})=\frac{\text { Absorbance at } 205 \mathrm{~nm}}{\text { extinction coefficient }(1,674,000)} \\
& \text { FtsY concentration }(\mathrm{cm} \cdot \mathrm{M})=\frac{\text { Absorbance at } 205 \mathrm{~nm}}{31 * \text { Molecular weight }(48 \mathrm{kD})}
\end{aligned}
$$

Fluorescent dye concentration which is labeled on protein was determined at appropriate wavelength following manufacturer's instruction (Molecular probes, Invitrogen) in Buffer A.

$$
\text { Labeling efficiency }(\%)=\frac{\text { Fluorescent dye concentration }(\mu M)}{\text { Protein concentration }(\mu M)} * 100(\%)
$$

Usually $80 \%$ of proteins were labeled.

\subsection{Preparation of SecYEG embedded in nanodiscs}

\subsubsection{Cell preparation}

pTRC99a plasmid with SecYEG gene was transformed into Lemo21(DE3) cell (New England Biolabs) in which T7 RNA polymerase activity is regulated by its inhibitor T7 lysozyme whose expression is titrated by L-rhamnose promoter. A single colony containing the gene of SecYEG in pTRC99a plasmid was inoculated into $200 \mathrm{ml}$ of LB medium supplemented with $100 \mathrm{mg} / \mathrm{ml}$ of Ampicillin and $30 \mathrm{mg} / \mathrm{ml}$ of Chloramphenicol and grown overnight at $37{ }^{\circ} \mathrm{C}$ with shaking. Overnight cultures were diluted in LB medium to an $\mathrm{OD}_{600}$ of $\sim 0.1$ and supplemented with $2 \mathrm{mM}$ of L-rhamnose. When cultures were grown up to an OD600 of 0.6-0.7, the expression of the desired protein was induced with $400 \mu \mathrm{M}$ of IPTG for $4 \mathrm{~h}$ at $37^{\circ} \mathrm{C}$ with shaking. Cells were harvested by centrifugation at 5,000 rpm for $20 \mathrm{~min}$ (Beckman JLA8.1). The cell pellets were washed by 1X PBS solution and centrifuged at the same speed for $20 \mathrm{~min}$. In average $12 \mathrm{~g}$ of cells were obtained from $6 \mathrm{~L}$ of cell culture. The expression of SecYEG protein was confirmed by running western blot with antibodies against 6XHis tag downstream of SecE. The same process was used to prepare cells of

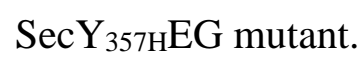




\subsubsection{Preparation of the SecYEG translocon in nanodisc}

Cells (12 g) containing the overexpressed SecYEG proteins His-tagged at SecE were purified following the published protocol with modification (Kusters et al., 2010). Cells were resuspended in $50 \mathrm{ml}$ Buffer SecYEG- A with DNase I. The resuspended cells were opened with high pressure in an EmulsiFlex-C3 High Pressure Homogenizer. The cell lysate was separated from the debris by centrifugation at 30,000 $\mathrm{g}$ for $10 \mathrm{~min}$ in a JA-25.00 fixedangle rotor in an Avanti J-26 XP Beckman coulter. Membranes were separated from the supernatant by the centrifugation at $150,000 \mathrm{~g}$ for $120 \mathrm{~min}$ in the Ti 50.20. The pellet was resuspended in 5-10 ml of Buffer SecYEG-A. $40 \mathrm{~mL}$ of Buffer SecYEG- B was added to the pellet and the suspension was incubated for $1 \mathrm{~h}$ at $4 \mathrm{C}$. SecYEG proteins were separated by centrifugation at $75,000 \mathrm{~g}$ for $25 \mathrm{~min}$ in a Ti 50.2 rotor. The supernatant containing the SecYEG proteins were loaded onto $10 \mathrm{ml}$ Ni-NTA resin which was pre-equilibrated inBuffer SecYEG- B. The resin was then washed with $200 \mathrm{ml}$ Buffer SecYEG- C. For elution, the Ni-NTA resin was incubated 3 times for 15 min with $10 \mathrm{ml}$ Buffer SecYEG- D. SecYEG was further purified by cation exchange chromatography on SP-Sepharose Fast Flow resin (GE Healthcare) in Buffer SecYEG- D, using a gradient of 50-600mM NaCl. Eluted SecYEG was concentrated and re-buffered into buffer A supplemented with $0.03 \%$ DDM. Concentrations of SecYEG were determined by absorbance at $205 \mathrm{~nm}$.

The assembly of nanodiscs containing SecYEG was performed following a published procedure (Alami et al., 2007; Ritchie et al., 2009) with modifications. Purified scaffold protein MSP1D1 was dissolved in buffer F. Phospholipids from E. coli in chloroform solution (Avanti Polar Lipids) were dried under a stream of nitrogen. The lipids were resuspended in buffer A without glycerol and containing 0.5 M DDM. A typical reconstitution experiment involved mixing SecYEG, MSP1D1, and lipids at a molar ratio of 1:2:30. For the reconstitution of empty nanodiscs, the ratio of MSP1D1:lipids was increased to $1: 60$. After $1 \mathrm{~h}$ incubation on ice, self-assembly of nanodiscs was initiated by adding BioBeads (Bio-Rad) followed by gentle rocking overnight at $4^{\circ} \mathrm{C}$. Beads were removed by sedimentation and the resulting mixture was centrifuged for $30 \mathrm{~min}$ at 15,000 rpm and then injected onto a gel filtration column (Superdex 200 PG16/100) equilibrated with buffer A. Fractions containing nanodiscs were combined, concentrated (Vivaspin20, cut-off 100,000; 
Sartorius), and stored at $-80^{\circ} \mathrm{C}$. The protocol for the preparation of the SecYEG translocon and the reconstitution in nanodisc was optimized by Albena Draycheva in our group.

\subsection{Preparation of RNCs}

$70 \mathrm{~S}$ ribosomes from E. coli MRE 600 and purified components of the translation system were prepared as described (Gu et al., 2005; Gu et al., 2003; Matassova et al., 1999; Rodnina et al., 1999; Rodnina and Wintermeyer, 1995). RNCs were prepared as follows. $70 \mathrm{~S}$ ribosomes $(1 \mu \mathrm{M})$ were programmed with truncated Lep-mRNA $(4 \mu \mathrm{M})$ coding for the first 35 to 94 amino acids of leader peptidase (de Gier et al., 1996) in the presence of purified initiation factors $1,2,3\left(1.5 \mu \mathrm{M}\right.$ each), f[ $\left.{ }^{3} \mathrm{H}\right]$ Met-tRNA-fMet $(2 \mu \mathrm{M})$, and GTP (1 $\mathrm{mM}$ ) in Buffer $\mathrm{M}$ for $60 \mathrm{~min}$ at $37^{\circ} \mathrm{C}$. Translation was started by mixing $70 \mathrm{~S}$ initiation complexes $(0.2 \mu \mathrm{M}$ after mixing) with a preincubated mixture of EF-Tu $(40 \mu \mathrm{M})$, EF-G (1 $\mu \mathrm{M})$, purified aminoacyl-tRNA containing $\left[{ }^{14} \mathrm{C}\right]$ Leu-tRNA $(20 \mu \mathrm{M})$, DTT $(1 \mathrm{mM})$, GTP (1 $\mathrm{mM})$, phosphoenolpyruvate $(3 \mathrm{mM})$, pyruvate kinase $(0.01 \mathrm{U} / \mu \mathrm{L})$, and putrescein $(8 \mathrm{mM})$ in Buffer M. After translation for $45 \mathrm{~min}$ at $37^{\circ} \mathrm{C}$, RNCs were purified by ultracentrifugation through $400 \mu \mathrm{L} 1.1 \mathrm{M}$ sucrose in Buffer M containing $20 \mathrm{mM} \mathrm{MgCl}_{2}$ for $1.5 \mathrm{~h}$ at 55,000 rpm in a TLA-55 swing-out rotor in Beckman centrifuge. Pellets were dissolved in Buffer A, shock-frozen, and stored at $-80^{\circ} \mathrm{C}$. The preparation of Lep-RNCs were performed by Anna Bursy (our group).

To measure the efficiency of the $70 \mathrm{~S}$ initiation complex formation, $\mathrm{f}\left[{ }^{3} \mathrm{H}\right] \mathrm{Met}-\mathrm{tRNA}-\mathrm{fMet}$ bound to ribosome was rapidly washed through nitrocellulose filter (Satorius) and the filters were washed extensively with the same buffer. Filters were dissolved in scintillation cocktail. ${ }^{3} \mathrm{H}$ radioactivity was measured in a Packard 2500 scintillation counter. For peptide analysis, the translation reaction was stopped by adding $0.5 \mu \mathrm{M}$ Potassium hydroxide. The samples were incubated for $30 \mathrm{~min}$ at $37{ }^{\circ} \mathrm{C}$ and precipitated by addition with trichloroacetic acid (TCA), which were then rapidly washed through nitrocellulose filter (Satorius) and filters rinsed with TCA and washed with $30 \%$ isopropanol. Filters were dissolved in scintillation cocktail (Quickszint 361, Zinsser Analytic). ${ }^{3} \mathrm{H}$ and ${ }^{14} \mathrm{C}$ radioactivity was measured in a Packard 2500 scintillation counter using a double label program. Lep-peptide in this work was more than $70 \%$ homogenous. 


\subsection{Gel electrophoresis}

\subsubsection{Agarose gel electrophoresis}

To assess the PCR and restriction enzyme reaction results, $0.5 \sim 2 \%$ agarose gel was used. The greater concentration of agarose, the smaller DNA can be resolved. DNA samples were mixed with DNA loading dye and loaded into wells. Gel electrophoresis was run at $120 \mathrm{~V}$ for $45 \mathrm{~min}$ in $1 \mathrm{X}$ TAE buffer (Buffer D). The gel was stained with Stain-G either before or after running. The gel was visualized by UV-lamp (Geldoc, Peqlab).

6X DNA loading dye

\begin{tabular}{c|c}
\hline Materials & Concentration \\
\hline Bromophenol blue & $0.25 \%$ \\
Xylene cyanol & $0.25 \%$ \\
Glycerol & $30 \%$ \\
in Water & $\mathrm{pH} 8.0$ \\
\hline
\end{tabular}

\subsubsection{Urea-PAGE}

Urea at high concentration $(7 \mathrm{M})$ is able to denature RNA secondary structure in polyacrylamide gels. For 4.5S RNA analysis, urea-PAGE was made as below. RNA samples were mixed in $1 \mathrm{X}$ RNA loading dye (2X RNA loading dye, Fermatas). After pre-running the gel for $5 \mathrm{~min}$, it was run with RNAs at $180 \mathrm{~V}$ for $5 \mathrm{~min}$ and then run at $300 \mathrm{~V}$ until bromophenol blue dye migrates to the bottom of the gel.

\section{Urea-PAGE composition}

\begin{tabular}{c|c|c}
\hline Materials & Stock concentration & Final concentration \\
\hline Polyacrylamide & $40 \%$ & $15 \%$ \\
(acrylamide:bis = 19:1) & - & $7 \mathrm{M}$ \\
Urea & $0.5 \mathrm{M}(\mathrm{pH} 8.0)$ & $4 \mathrm{mM}$ \\
EDTA & $50 \mathrm{X}$ & $1 \mathrm{X}$ \\
TAE buffer & $10 \%$ & $0.01 \%(\mathrm{vol})$ \\
APS & - & $0.1 \%(\mathrm{vol})$ \\
TEMED &
\end{tabular}


Gel was stained in solution containing 50\% methanol, $10 \%$ acetic acid, $40 \%$ water, and $0.25 \%$ coomassie blue (R-250) for $2 \mathrm{~h}$ and destained in solution containing 5\% methanol, $7.5 \%$ acetic acid, and $87.5 \%$ water.

\subsubsection{SDS-PAGE}

All the proteins were separated in polyacrylamide (Acrylamide/Bisacrylamide) gels according to their electrophoretic mobility. Gels were composed of two layers, separating gels on the bottom and stacking gels on top. Protein samples were prepared by incubating with $1 \mathrm{X}$ SDS-sample loading dye at $100{ }^{\circ} \mathrm{C}$ for $10 \mathrm{~min}$. The gels were run at a constant current of $20 \mathrm{~mA}$ at approximately $80-200 \mathrm{~V}$ for $1 \mathrm{~h}$ in $0.1 \%$ SDS-Tris running buffer.

\section{Separating gels}

\begin{tabular}{c|c|c}
\hline Materials & Stock concentration & Final concentration \\
\hline Polyacrylamide & $40 \%$ & $12-15 \%$ \\
(acrylamide:bis = 29:1) & & \\
Separating gel buffer & $4 \mathrm{X}$ & $1 \mathrm{X}$ \\
APS & $10 \%$ & $0.01 \%$ \\
TEMED & - & $0.1 \%$ \\
\hline
\end{tabular}

Stacking gels

\begin{tabular}{c|c|c}
\hline Materials & Stock concentration & Final concentration \\
\hline Polyacrylamide (29:1) & $40 \%$ & $4 \%$ \\
Stacking gel buffer & $4 \mathrm{X}$ & $1 \mathrm{X}$ \\
APS & $10 \%$ & $0.01 \%$ \\
TEMED & - & $0.1 \%$ \\
\hline
\end{tabular}


6X SDS-Sample Loading dye

\begin{tabular}{c|c}
\hline Materials & Concentrations \\
\hline Tris-HCl (pH 6.8) & $50 \mathrm{mM}$ \\
SDS & $1.1 \%$ \\
Glycerol & $10 \%$ \\
B-mercaptoethanol & $1 \%$ \\
Bromophenol blue & $0.03 \%$ \\
\hline
\end{tabular}

The gel was stained in a coomassie blue solution and destained with destaining solution.

\begin{tabular}{c|l}
\hline & $0.02 \%$ w/v Coomassie brilliant blue G 250 \\
5 Staining solution (colloid) & $\begin{array}{l}10 \% \text { Ethanol } \\
2 \% \text { orthophosphoacid } \\
\text { in water }\end{array}$ \\
\hline Destaining solution & $10 \%$ Ethanol \\
& $2 \%$ ortho-phosphoacid \\
$88 \%$ water
\end{tabular}

\subsubsection{Gel-shift analysis}

To form SRP Ffh and 1.2 fold excess of 4.5S RNA were incubated with the GTP analog GMPPNP and the SRP was incubated with FtsY in Gel-shift buffer at $25^{\circ} \mathrm{C}$ for $10 \mathrm{~min} .2$ uM 4.5S RNA, 2 uM Ffh, 2-4 uM FtsY, and 400 uM GMPPNP were used. The gel was cooled down after polymerization and it run at $80 \mathrm{~V}$ (constant voltage) at $4^{\circ} \mathrm{C}$ in $1 \mathrm{X}$ Gel shift buffer containing $5 \mu \mathrm{M}$ GMPPNP. The cathode buffer was exchanged every $45 \mathrm{~min}$ for four times. The RNA was detected by staining with Stain-G and protein bands were detected by staining with coomassie blue protein staining solution. 


\subsection{Western blot}

To detect specific proteins, SDS-PAGE and Western blot was used. His- or Strep-tags at the termini of respective proteins were detected by antibodies. In order to make proteins accessible to antibodies, proteins were transferred from SDS-PAGE gels to membranes by blotting. Given as downward blotting, the blot was assembled as follows: first filter papers (Whatman) in Buffer H, second a gel and nitrocellulose membrane in Buffer I, and last filter papers (Whatman) in Buffer I. The protein was transferred at $100 \mathrm{~mA}$ for $60 \mathrm{~min}$ at room temperature. The transfer of proteins from the gel to the membrane was checked by staining with Ponceau S in $3 \%$ TCA solution.

The membrane was then washed in 1X PBS buffer (Buffer K)containing $0.1 \%$ Tween (PBS-Tween Buffer). To prevent nonspecific binding, the membrane was incubated in blocking solution which contains $5 \%$ Bovine serum albumin (BSA-blocking solution)) or $10 \%$ of milk powder in PBS-Tween buffer (Milk-blocking solution) followed by washing with PBS-Tween buffer.

To probe His6-tagged Ffh and FtsY proteins, the membrane was incubated for $1 \mathrm{~h}$ with the first antibody, Rabbit-immunized 6X-His Epitope tag (Thermo Scientific), with a ratio of 1:2,000 in blocking solution. The membrane was then washed three times with PBS-Tween buffer. After washing it was incubated with the blocking solution containing the secondary antibody, Peroxidase-conjugated AffiniPure Goat Anti-Rabbit IgG (Jackson Immuno Research), with the ratio 1 to 10,000 followed by washing with PBS-Tween buffer.

To visualize antibody-conjugated proteins, the Chemiluminescent reagent (Thermo Scientific) was added to the membrane. The peroxidase-conjugated second antibody is used to cleave chemiluminescence reagent, and the reaction product produces luminescence. The luminescence was detected on a Amersham Hyperfilm ECL (GE Healthcare) by autoradiography. 


\subsection{Biochemical assays}

\subsubsection{Förster resonance energy transfer (FRET)}

FRET is so sensitive method to observe interacting molecules. Equilibrium dynamics and pre-steady-state kinetics were studied employing the FRET. FRET occurs due to energycoupling between two chromophores (Förster, 1948). Two chromophores which are close enough can undergo dipole-dipole coupling. One chromophore which is excited and transfers non-radiative energy to the other is called donor. The other which absorbs the energy and gets excited by it is called acceptor. FRET strongly depends on the distance between donor and acceptor. The FRET efficiency is inversely proportional to the sixth power of the distance between the donor and the acceptor.

\subsubsection{Equilibrium titrations}

To determine the $\mathrm{K}_{\mathrm{d}}$ of FtsY binding to SRP and to SRP bound to ribosomes, FRET change between Ffh(ALX) and FtsY(QSY) were monitored. SRP (ALX) was prepared in Buffer A in glass cuvette and fluorescence emission was measured at $570 \mathrm{~nm}$ upon excitation at 520 $\mathrm{nm}$ at $25{ }^{\circ} \mathrm{C}$. Small volumes of FtsY(QSY) solution was added into cuvette which contain the solution of ALX labeled SRP only or SRP bound to ribosome complexes $(0.3 \mathrm{ml})$. Each point of titration was measured after 3 minutes of incubation. To prevent dilution of the fluorescence of SRP at each titration point, the same concentration of fluorescent SRP(ALX) was added to the solution of FtsY(QSY). To saturate SRP with the vacant ribosome or the RNC, the vacant ribosome or the RNC five-to seven-fold higher concentration of $K_{d}$ (Bornemann, 2008) were pre-incubated with SRP. The titration data were fit by a quadratic equation assuming 1:1 stoichiometry.

To study the effect of translocon, the FRET pair, SRP(MDCC) and FtsY(BPY), was used. In this system donor fluorescence (MDCC) emission was monitored at $460 \mathrm{~nm}$ upon excitation at $420 \mathrm{~nm}$. In the absence of the translocon, the fluorescence titration was performed under the same condition as above. To see the effect of the translocon, SecYEG translocon embedded in nanodisc $(0.3 \mu \mathrm{M})$ or empty nanodisc $(0.5 \mu \mathrm{M})$ were added to the solution in the cuvette and to the titrant solution. 
To monitor the interaction of the distal end of 4.5S RNA and proteins Ffh and FtsY, the fluorescence emission of 3'-labeld 4.5S RNA(ALX) was measured at $570 \mathrm{~nm}$ upon excitation at $520 \mathrm{~nm}$ upon binding of FtsY(QSY). Fluorescence titration was performed in the same condition as above.

\subsubsection{Pre-steady-state kinetics}

To determine a rate, equal volumes ( $55 \mu \mathrm{l}$ each) of two solutions were rapidly mixed in the a stopped-flow apparatus (SX-18MV spectrometer, Applied Photophysics), and fluorescence changes were monitored over time.

To determine rate constants of SRP-FtsY complex formation, SRP(ALX) was rapidly mixed with increasing concentrations of Fts Y(QSY). To determine dissociation rate constants, SRP (ALX) and FtsY(QSY) were incubated and rapidly mixed with a 5-10 fold excess of nonlabeled FtsY. To determine binding and dissociation of FtsY to SRP bound to ribosome in different functional states, SRP(ALX) preformed a complex with non-translating ribosome or translating ribosomes by adding seven-fold excess amount of $\mathrm{K}_{\mathrm{d}}$ and upon binding of FtsY(QSY) fluorescence changes were monitored under the same condition. For determine the second step rate of FtsY on SRP or SRP-ribosome complexes, SRP or ribosome-bound SRP binding to FtsY was monitored by using Fts Y(342BPY) fluorescence.

\subsubsection{GTP hydrolysis}

To determine the effect of 4.5S RNA on the GTPase activity of the Ffh-FtsY heterodimer, $100 \mu \mathrm{M}$ GTP and a trace amount of $\left[\gamma^{-32} \mathrm{P}\right] \mathrm{GTP}$ were incubated with $1 \mu \mathrm{M}$ Ffh alone or with $5 \mu \mathrm{M}$ Fts $\mathrm{Y}$ in the presence and absence of 4.5S RNAs of different lengths (61mer, 83mer, and full-length) in Buffer $\mathrm{A}$ at $25^{\circ} \mathrm{C}$. The reaction samples were taken from the start for 10 min. The reaction was stopped with one volume of $45 \%$ formic acid. Samples were analyzed by TLC using $0.5 \mathrm{M}$ potassium phosphate ( $\mathrm{pH}$ 3.5) as running buffer. Radioactivity was detected using a phosphoimager system (FLA-7000). The amount of hydrolyzed GTP was quantified by Multi Gauge software and plotted against time. Initial velocities were determined by linear fits and plotted as hydrolyzed GTP per minute, taking into account the amount of enzyme present in the assay. 


\subsection{Data analysis}

\subsection{1 $K_{d}$ calculation}

Affinities of the SRP-FtsY complex in the presence and absence of ribosome complexes or the translocon were calculated by using a quadratic equation. The equation takes into account the uptake of the added ligand into the complex, which may be significant especially for the early points of the titrations. The equation is as below.

$\left[\mathrm{P}_{\text {total }}\right]$ is the initial concentration of SRP or the SRP-ribosome complex.

$[\mathrm{X}]$ is the concentration of ligand, FtsY.

$\mathrm{F} 0$ is the initial fluorescence level.

$$
\operatorname{Fluorescence}(Y)=\mathrm{F} 0+\frac{(\Delta \mathrm{F})\left(\left[\mathrm{P}_{\text {total }}\right]+[\mathrm{X}]+\mathrm{Kd}\right)-\sqrt{\left(\left[\mathrm{P}_{\text {total }}\right]+[\mathrm{X}]+\mathrm{Kd}\right)^{2}-4\left[\mathrm{P}_{\text {total }}\right][X]}}{2\left[\mathrm{P}_{\text {total }}\right]}
$$

\subsubsection{Partial-competitive or non-competitive binding model}

To decide if the effect of the translocon on the targeting complex is partial-competitive or non-competitive, apparent $\mathrm{K}_{\mathrm{d}}$ values were determined by titrations with the translocon. The plots of apparent $K_{d}$ versus concentration of competing translocon (Figure 19 and Figure 20) were evaluated by the model and the equation below. The model below is the generalized model which describes partial competitive or non-competitive binding.

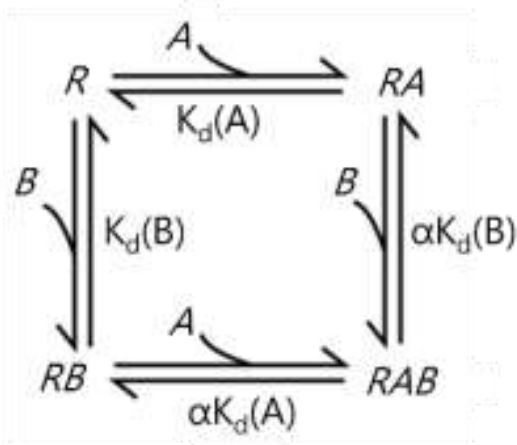

$$
\text { app. } K_{d}(A)=K_{d}(A) * \frac{1+\frac{[B]}{K_{d}(B)}}{1+\frac{[B]}{\alpha * K_{d}(B)}}
$$

$\mathrm{R}$ denotes ribosome complexes, which bind both ligand $\mathrm{A}(\mathrm{Fts} \mathrm{Y})$ and $\mathrm{B}$ (the translocon) and form a complex. $\mathrm{K}_{\mathrm{d}}(\mathrm{A})$ and $\mathrm{K}_{\mathrm{d}}(\mathrm{B})$ are the intrinsic affinities of $\mathrm{A}$ or $\mathrm{B}$ binding to $\mathrm{R}$. Apparent $K_{d}$ determined by equilibrium titration at saturation with the competitor differs 
from the intrinsic $\mathrm{K}_{\mathrm{d}}$ by a factor of $\alpha$. According to the model, partial competitive binding is achieved when $\alpha>>1$ and so apparent $K_{d}$ of competing ligand $B$ is increased by the same factor $\alpha$. Noncompetitive binding occurs when $\alpha=1$, and A (or B) binds R and RB (or RA) with equal affinities, which is, however, not the case here.

\subsubsection{Evaluation of stopped-flow data}

To obtain elemental rate constants, stopped-flow traces (consisting of up to 4000 data points each) were first evaluated by one-, two- or three-exponential fitting, as appropriate, using the TableCurve software (Jandel Scientific, San Rafael, USA), yielding up to three kapp

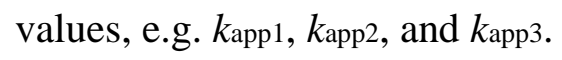

$$
\begin{aligned}
& F_{t(\text { Final })}=F_{0(\text { Initial })}+F_{\Delta 1} \cdot e^{-k_{\text {app } 1} \cdot t} \\
& F_{t(\text { Final })}=F_{0(\text { Initial })}+F_{\Delta 1} \cdot e^{-k_{\text {app } 1} \cdot t}+F_{\Delta 2} \cdot e^{-k_{\text {app } 2} \cdot t} \\
& F_{t(\text { Final })}=F_{0 \text { (Initial })}+F_{\Delta 1} \cdot e^{-k_{\text {app } 1} \cdot t}+F_{\Delta 2} \cdot e^{-k_{\text {app } 2} \cdot t}+F_{\Delta 3} \cdot e^{-k_{\text {app } 3} \cdot t}
\end{aligned}
$$

As the results of fitting the fluorescence time courses, FtsY binding to SRP alone and SRP bound to ribosomes in different functional states are described by two step model.

The $k_{\text {apps }}$ were plotted against the concentration of FtsY. Initial estimates for the values of the elemental rate constants, $k_{1}, k-1, k 2, k-2, k_{3}$, and $k-3$, were obtained from the concentration dependencies of the apparent rate constants. In general the first step equilibrates faster than the second step. Thereby rate constants are obtained as below (Bernasconi, 1976).

$$
\begin{aligned}
& k_{a p p 1}=k_{1}([A]+[B])+k_{-1} \\
& k_{a p p 2}=k_{2}+k_{-2} \\
& k_{o f f 1}=k_{-1} \\
& k_{o f f 2}=k_{-2}
\end{aligned}
$$




\subsubsection{Global fitting}

Elemental rate constants obtained from the evaluation of stopped-flow data (4.13.3) were used as initial guesses for global fitting of the combined datasets of association and dissociation for a given ligand combination (Bernasconi, 1976; Wienken et al., 2010). The data were fitted by numerical integration (Matlab; Mathworks Inc., Ismaning, Germany), using one set of differential equations for the time courses of binding and dissociation for each complex. For FtsY-SRP complex formation, the kinetic scheme of Figure 13 was used, with the fluorescence parameters for the free ligand $(\mathrm{Fa})$, the complex Rib-SRP-FtsY $(\mathrm{Fb})$, and the complex Rib-SRP-Fts $Y^{*}(\mathrm{Fc})$, and an additional rearrangement which was observed upon prolonged incubations. The latter rearrangement was very slow (minutes); it probably represents idling of the complexes due to the lack of the following targeting steps and was therefore not considered as an on-pathway intermediate. The slow step had no influence on $K \mathrm{~d}$ values calculated from rate constants, as forward and backward rate constants of that step were equal. In all cases, global fitting yielded unique solutions for the rate constants as well as for the fluorescence factors. The respective $K \mathrm{~d}$ values of the complexes, as determined by equilibrium titrations (Figure 9), were included in the global fits as fixed values. For the chase data sets, initial concentrations of intermediates were calculated using the initial guesses of the elemental rate constants and varied in each iteration cycle together with the fitted values. R2 values of the global fits were between 0.995 and 0.999 .

The following differential equations were used for the model depicted in Figure 13.

A, B, C, and D represent initial concentrations of each state: A (ribosome-SRP), B(FtsY), C(ribosome-SRP-FtsY), and D(ribosome-SRP-FtsY*).

$$
\begin{aligned}
\mathrm{F}=\mathrm{Fa} * \mathrm{~A} & +\mathrm{Fb}^{*} \mathrm{~B}+\mathrm{Fc}^{*} \mathrm{D} \\
\frac{d A}{d t} & =-k_{1} \cdot A \cdot B+k_{-1} \cdot C \\
\frac{d B}{d t} & =\frac{d A}{d t} \\
\frac{d C}{d t} & =k_{1} \cdot A \cdot B-k_{-1} \cdot C-k_{2} \cdot C+k_{-2} \cdot D \\
\frac{d D}{d t} & =k_{2} \cdot C-k_{-2} \cdot D
\end{aligned}
$$




\section{Bibliography}

Akopian, D., Dalal, K., Shen, K., Duong, F. and Shan, S. O. (2013). SecYEG activates GTPases to drive the completion of cotranslational protein targeting. J Cell Biol 200, 397405.

Alami, M., Dalal, K., Lelj-Garolla, B., Sligar, S. G. and Duong, F. (2007). Nanodiscs unravel the interaction between the SecYEG channel and its cytosolic partner SecA. EMBO J 26, 1995-2004.

Angelini, S., Boy, D., Schiltz, E. and Koch, H. G. (2006). Membrane binding of the bacterial signal recognition particle receptor involves two distinct binding sites. J Cell Biol 174, 71524.

Angelini, S., Deitermann, S. and Koch, H. G. (2005). FtsY, the bacterial signal-recognition particle receptor, interacts functionally and physically with the SecYEG translocon. EMBO Rep 6, 476-81.

Ataide, S. F., Schmitz, N., Shen, K., Ke, A., Shan, S. O., Doudna, J. A. and Ban, N. (2011). The crystal structure of the signal recognition particle in complex with its receptor. Science $331,881-6$.

Baba, T., Jacq, A., Brickman, E., Beckwith, J., Taura, T., Ueguchi, C., Akiyama, Y. and Ito, K. (1990). Characterization of cold-sensitive secY mutants of Escherichia coli. J Bacteriol $172,7005-10$.

Bahari, L., Parlitz, R., Eitan, A., Stjepanovic, G., Bochkareva, E. S., Sinning, I. and Bibi, E. (2007). Membrane targeting of ribosomes and their release require distinct and separable functions of FtsY. J Biol Chem 282, 32168-75.

Ban, N., Beckmann, R., Cate, J. H., Dinman, J. D., Dragon, F., Ellis, S. R., Lafontaine, D. L., Lindahl, L., Liljas, A., Lipton, J. M. et al. (2014). A new system for naming ribosomal proteins. Curr Opin Struct Biol.

Batey, R. T., Rambo, R. P., Lucast, L., Rha, B. and Doudna, J. A. (2000). Crystal structure of the ribonucleoprotein core of the signal recognition particle. Science 287, 1232-9. 
Bayburt, T. H. and Sligar, S. G. (2002). Single-molecule height measurements on microsomal cytochrome P450 in nanometer-scale phospholipid bilayer disks. Proc Natl Acad Sci U S A 99, 6725-30.

Beck, K., Wu, L. F., Brunner, J. and Muller, M. (2000). Discrimination between SRP- and $\mathrm{Sec} \mathrm{A} / \mathrm{SecB}-\mathrm{dependent}$ substrates involves selective recognition of nascent chains by SRP and trigger factor. EMBO J 19, 134-43.

Becker, T., Bhushan, S., Jarasch, A., Armache, J. P., Funes, S., Jossinet, F., Gumbart, J., Mielke, T., Berninghausen, O., Schulten, K. et al. (2009). Structure of monomeric yeast and mammalian Sec61 complexes interacting with the translating ribosome. Science 326, 136973.

Bernasconi, C. F. (1976). Relaxation Kinetics. Academic press, New York San Francisco London.

Bessonneau, P., Besson, V., Collinson, I. and Duong, F. (2002). The SecYEG preprotein translocation channel is a conformationally dynamic and dimeric structure. EMBO J 21, 995-1003.

Bibi, E. (2011). Early targeting events during membrane protein biogenesis in Escherichia coli. Biochim Biophys Acta 1808, 841-50.

Blobel, G., Walter, P., Chang, C. N., Goldman, B. M., Erickson, A. H. and Lingappa, V. R. (1979). Translocation of proteins across membranes: the signal hypothesis and beyond. Symp Soc Exp Biol 33, 9-36.

Bonardi, F., London, G., Nouwen, N., Feringa, B. L. and Driessen, A. J. (2010). Lightinduced control of protein translocation by the SecYEG complex. Angew Chem Int Ed Engl $49,7234-8$

Bornemann, T., Jockel, J., Rodnina, M. V. and Wintermeyer, W. (2008). Signal sequenceindependent membrane targeting of ribosomes containing short nascent peptides within the exit tunnel. Nat Struct Mol Biol 15, 494-9. 
Braig, D., Mircheva, M., Sachelaru, I., van der Sluis, E. O., Sturm, L., Beckmann, R. and Koch, H. G. (2011). Signal sequence-independent SRP-SR complex formation at the membrane suggests an alternative targeting pathway within the SRP cycle. Mol Biol Cell 22, 2309-23.

Breyton, C., Haase, W., Rapoport, T. A., Kuhlbrandt, W. and Collinson, I. (2002). Threedimensional structure of the bacterial protein-translocation complex SecYEG. Nature 418, $662-5$.

Buskiewicz, I., Deuerling, E., Gu, S. Q., Jockel, J., Rodnina, M. V., Bukau, B. and Wintermeyer, W. (2004). Trigger factor binds to ribosome-signal-recognition particle (SRP) complexes and is excluded by binding of the SRP receptor. Proc Natl Acad Sci U S A 101, 7902-6.

Buskiewicz, I., Kubarenko, A., Peske, F., Rodnina, M. V. and Wintermeyer, W. (2005a). Domain rearrangement of SRP protein Ffh upon binding 4.5S RNA and the SRP receptor FtsY. RNA 11, 947-57.

Buskiewicz, I., Peske, F., Wieden, H. J., Gryczynski, I., Rodnina, M. V. and Wintermeyer, W. (2005b). Conformations of the signal recognition particle protein Ffh from Escherichia coli as determined by FRET. J Mol Biol 351, 417-30.

Buskiewicz, I. A., Jockel, J., Rodnina, M. V. and Wintermeyer, W. (2009). Conformation of the signal recognition particle in ribosomal targeting complexes. RNA 15, 44-54.

Chang, D. Y., Newitt, J. A., Hsu, K., Bernstein, H. D. and Maraia, R. J. (1997). A highly conserved nucleotide in the Alu domain of SRP RNA mediates translation arrest through high affinity binding to SRP9/14. Nucleic Acids Res 25, 1117-22.

Cheng, Z., Jiang, Y., Mandon, E. C. and Gilmore, R. (2005). Identification of cytoplasmic residues of Sec61p involved in ribosome binding and cotranslational translocation. J Cell Biol 168, 67-77.

Cleverley, R. M. and Gierasch, L. M. (2002). Mapping the signal sequence-binding site on SRP reveals a significant role for the NG domain. J Biol Chem 277, 46763-8. 
de Gier, J. W., Mansournia, P., Valent, Q. A., Phillips, G. J., Luirink, J. and von Heijne, G. (1996). Assembly of a cytoplasmic membrane protein in Escherichia coli is dependent on the signal recognition particle. FEBS Lett 399, 307-9.

de Leeuw, E., te Kaat, K., Moser, C., Menestrina, G., Demel, R., de Kruijff, B., Oudega, B., Luirink, J. and Sinning, I. (2000). Anionic phospholipids are involved in membrane association of FtsY and stimulate its GTPase activity. EMBO J 19, 531-41.

Driessen, A. J. and Nouwen, N. (2008). Protein translocation across the bacterial cytoplasmic membrane. Annu Rev Biochem 77, 643-67.

du Plessis, D. J., Berrelkamp, G., Nouwen, N. and Driessen, A. J. (2009). The lateral gate of SecYEG opens during protein translocation. J Biol Chem 284, 15805-14.

Egea, P. F., Shan, S. O., Napetschnig, J., Savage, D. F., Walter, P. and Stroud, R. M. (2004). Substrate twinning activates the signal recognition particle and its receptor. Nature 427, $215-$ 21.

Eitan, A. and Bibi, E. (2004). The core Escherichia coli signal recognition particle receptor contains only the $\mathrm{N}$ and $\mathrm{G}$ domains of Fts Y. J Bacteriol 186, 2492-4.

Estrozi, L. F., Boehringer, D., Shan, S. O., Ban, N. and Schaffitzel, C. (2011). Cryo-EM structure of the E. coli translating ribosome in complex with SRP and its receptor. Nat Struct Mol Biol 18, 88-90.

Förster, T. (1948). Zwischenmoleklare Energiewanderung und Fluoreszenz. Annalen der Physik 437, 55-75.

Ferbitz, L., Maier, T., Patzelt, H., Bukau, B., Deuerling, E. and Ban, N. (2004). Trigger factor in complex with the ribosome forms a molecular cradle for nascent proteins. Nature $431,590-6$.

Flower, A. M. (2001). SecG function and phospholipid metabolism in Escherichia coli. J Bacteriol 183, 2006-12.

Focia, P. J., Shepotinovskaya, I. V., Seidler, J. A. and Freymann, D. M. (2004). Heterodimeric GTPase core of the SRP targeting complex. Science 303, 373-7. 
Frauenfeld, J., Gumbart, J., Sluis, E. O., Funes, S., Gartmann, M., Beatrix, B., Mielke, T., Berninghausen, O., Becker, T., Schulten, K. et al. (2011). Cryo-EM structure of the ribosome-SecYE complex in the membrane environment. Nat Struct Mol Biol 18, 614-21.

Freymann, D. M., Keenan, R. J., Stroud, R. M. and Walter, P. (1997). Structure of the conserved GTPase domain of the signal recognition particle. Nature 385, 361-4.

Gilmore, R., Walter, P. and Blobel, G. (1982). Protein translocation across the endoplasmic reticulum. II. Isolation and characterization of the signal recognition particle receptor. J Cell Biol 95, 470-7.

Grudnik, P., Bange, G. and Sinning, I. (2009). Protein targeting by the signal recognition particle. Biol Chem 390, 775-82.

Gu, S. Q., Jockel, J., Beinker, P., Warnecke, J., Semenkov, Y. P., Rodnina, M. V. and Wintermeyer, W. (2005). Conformation of 4.5S RNA in the signal recognition particle and on the 30 S ribosomal subunit. RNA 11, 1374-84.

Gu, S. Q., Peske, F., Wieden, H. J., Rodnina, M. V. and Wintermeyer, W. (2003). The signal recognition particle binds to protein L23 at the peptide exit of the Escherichia coli ribosome. RNA 9, 566-73.

Hainzl, T., Huang, S., Merilainen, G., Brannstrom, K. and Sauer-Eriksson, A. E. (2011). Structural basis of signal-sequence recognition by the signal recognition particle. Nat Struct Mol Biol 18, 389-91.

Hainzl, T., Huang, S. and Sauer-Eriksson, A. E. (2007). Interaction of signal-recognition particle 54 GTPase domain and signal-recognition particle RNA in the free signalrecognition particle. Proc Natl Acad Sci U S A 104, 14911-6.

Halic, M., Blau, M., Becker, T., Mielke, T., Pool, M. R., Wild, K., Sinning, I. and Beckmann, R. (2006). Following the signal sequence from ribosomal tunnel exit to signal recognition particle. Nature 444, 507-11.

Harris, C. R. and Silhavy, T. J. (1999). Mapping an interface of SecY (PrlA) and SecE (PrlG) by using synthetic phenotypes and in vivo cross-linking. J Bacteriol 181, 3438-44. 
Hartl, F. U. and Hayer-Hartl, M. (2002). Molecular chaperones in the cytosol: from nascent chain to folded protein. Science 295, 1852-8.

Holtkamp, W., Lee, S., Bornemann, T., Senyushkina, T., Rodnina, M. V. and Wintermeyer, W. (2012). Dynamic switch of the signal recognition particle from scanning to targeting. Nat Struct Mol Biol 19, 1332-7.

Huber, D., Rajagopalan, N., Preissler, S., Rocco, M. A., Merz, F., Kramer, G. and Bukau, B. (2011). SecA interacts with ribosomes in order to facilitate posttranslational translocation in bacteria. Mol Cell 41, 343-53.

Jagath, J. R., Rodnina, M. V., Lentzen, G. and Wintermeyer, W. (1998). Interaction of guanine nucleotides with the signal recognition particle from Escherichia coli. Biochemistry 37, 15408-13.

Jagath, J. R., Rodnina, M. V. and Wintermeyer, W. (2000). Conformational changes in the bacterial SRP receptor FtsY upon binding of guanine nucleotides and SRP. J Mol Biol 295, 745-53.

Janda, C. Y., Li, J., Oubridge, C., Hernandez, H., Robinson, C. V. and Nagai, K. (2010). Recognition of a signal peptide by the signal recognition particle. Nature 465, 507-10.

Jensen, C. G. and Pedersen, S. (1994). Concentrations of 4.5S RNA and Ffh protein in Escherichia coli: the stability of Ffh protein is dependent on the concentration of 4.5S RNA. J Bacteriol 176, 7148-54.

Kalmbach, R., Chizhov, I., Schumacher, M. C., Friedrich, T., Bamberg, E. and Engelhard, M. (2007). Functional cell-free synthesis of a seven helix membrane protein: in situ insertion of bacteriorhodopsin into liposomes. J Mol Biol 371, 639-48.

Kedrov, A., Kusters, I., Krasnikov, V. V. and Driessen, A. J. (2011). A single copy of SecYEG is sufficient for preprotein translocation. EMBO J 30, 4387-97.

Keenan, R. J., Freymann, D. M., Stroud, R. M. and Walter, P. (2001). The signal recognition particle. Annu Rev Biochem 70, 755-75. 
Keenan, R. J., Freymann, D. M., Walter, P. and Stroud, R. M. (1998). Crystal structure of the signal sequence binding subunit of the signal recognition particle. Cell 94, 181-91.

Klammt, C., Schwarz, D., Fendler, K., Haase, W., Dotsch, V. and Bernhard, F. (2005). Evaluation of detergents for the soluble expression of alpha-helical and beta-barrel-type integral membrane proteins by a preparative scale individual cell-free expression system. FEBS J 272, 6024-38.

Koch, H. G. and Muller, M. (2000). Dissecting the translocase and integrase functions of the Escherichia coli SecYEG translocon. J Cell Biol 150, 689-94.

Kusters, I., van den Bogaart, G., de Wit, J., Krasnikov, V., Poolman, B. and Driessen, A. (2010). Purification and functional reconstitution of the bacterial protein translocation pore, the SecYEG complex. Methods Mol Biol 619, 131-143.

Lam, V. Q., Akopian, D., Rome, M., Henningsen, D. and Shan, S. O. (2010). Lipid activation of the signal recognition particle receptor provides spatial coordination of protein targeting. J Cell Biol 190, 623-35.

Lentzen, G., Moine, H., Ehresmann, C., Ehresmann, B. and Wintermeyer, W. (1996). Structure of $4.5 \mathrm{~S}$ RNA in the signal recognition particle of Escherichia coli as studied by enzymatic and chemical probing. RNA 2, 244-53.

Lingappa, V. R., Lingappa, J. R. and Blobel, G. (1980). Signal sequences for early events in protein secretion and membrane assembly. Ann N Y Acad Sci 343, 356-61.

Luirink, J., ten Hagen-Jongman, C. M., van der Weijden, C. C., Oudega, B., High, S., Dobberstein, B. and Kusters, R. (1994). An alternative protein targeting pathway in Escherichia coli: studies on the role of FtsY. EMBO J 13, 2289-96.

Luirink, J., von Heijne, G., Houben, E. and de Gier, J. W. (2005). Biogenesis of inner membrane proteins in Escherichia coli. Annu Rev Microbiol 59, 329-55.

Lyukmanova, E. N., Shenkarev, Z. O., Khabibullina, N. F., Kopeina, G. S., Shulepko, M. A., Paramonov, A. S., Mineev, K. S., Tikhonov, R. V., Shingarova, L. N., Petrovskaya, L. E. et al. (2012). Lipid-protein nanodiscs for cell-free production of integral membrane proteins in 
a soluble and folded state: comparison with detergent micelles, bicelles and liposomes. Biochim Biophys Acta 1818, 349-58.

Matassova, N. B., Rodnina, M. V., Endermann, R., Kroll, H. P., Pleiss, U., Wild, H. and Wintermeyer, W. (1999). Ribosomal RNA is the target for oxazolidinones, a novel class of translational inhibitors. RNA 5, 939-46.

Matlack, K. E., Mothes, W. and Rapoport, T. A. (1998). Protein translocation: tunnel vision. Cell 92, 381-90.

Menetret, J. F., Schaletzky, J., Clemons, W. M., Jr., Osborne, A. R., Skanland, S. S., Denison, C., Gygi, S. P., Kirkpatrick, D. S., Park, E., Ludtke, S. J. et al. (2007). Ribosome binding of a single copy of the SecY complex: implications for protein translocation. Mol Cell 28, 1083-92.

Miller, J. D., Tajima, S., Lauffer, L. and Walter, P. (1995). The beta subunit of the signal recognition particle receptor is a transmembrane GTPase that anchors the alpha subunit, a peripheral membrane GTPase, to the endoplasmic reticulum membrane. J Cell Biol 128, 273-82.

Millman, J. S., Qi, H. Y., Vulcu, F., Bernstein, H. D. and Andrews, D. W. (2001). FtsY binds to the Escherichia coli inner membrane via interactions with phosphatidylethanolamine and membrane proteins. J Biol Chem 276, 25982-9.

Mircheva, M., Boy, D., Weiche, B., Hucke, F., Graumann, P. and Koch, H. G. (2009). Predominant membrane localization is an essential feature of the bacterial signal recognition particle receptor. BMC Biol 7, 76.

Mitra, K., Schaffitzel, C., Shaikh, T., Tama, F., Jenni, S., Brooks, C. L., 3rd, Ban, N. and Frank, J. (2005). Structure of the E. coli protein-conducting channel bound to a translating ribosome. Nature 438, 318-24.

Montoya, G., Svensson, C., Luirink, J. and Sinning, I. (1997). Crystal structure of the NG domain from the signal-recognition particle receptor Fts Y. Nature 385, 365-8. 
Mori, H. and Ito, K. (2001). An essential amino acid residue in the protein translocation channel revealed by targeted random mutagenesis of SecY. Proc Natl Acad Sci U S A 98, 5128-33.

Neher, S. B., Bradshaw, N., Floor, S. N., Gross, J. D. and Walter, P. (2008). SRP RNA controls a conformational switch regulating the SRP-SRP receptor interaction. Nat Struct Mol Biol 15, 916-23.

Osborne, A. R. and Rapoport, T. A. (2007). Protein translocation is mediated by oligomers of the SecY complex with one SecY copy forming the channel. Cell 129, 97-110.

Paetzel, M., Dalbey, R. E. and Strynadka, N. C. (2002). Crystal structure of a bacterial signal peptidase apoenzyme: implications for signal peptide binding and the Ser-Lys dyad mechanism. J Biol Chem 277, 9512-9.

Park, E., Menetret, J. F., Gumbart, J. C., Ludtke, S. J., Li, W., Whynot, A., Rapoport, T. A. and Akey, C. W. (2013). Structure of the SecY channel during initiation of protein translocation. Nature.

Parlitz, R., Eitan, A., Stjepanovic, G., Bahari, L., Bange, G., Bibi, E. and Sinning, I. (2007). Escherichia coli signal recognition particle receptor FtsY contains an essential and autonomous membrane-binding amphipathic helix. J Biol Chem 282, 32176-84.

Peluso, P., Herschlag, D., Nock, S., Freymann, D. M., Johnson, A. E. and Walter, P. (2000). Role of 4.5S RNA in assembly of the bacterial signal recognition particle with its receptor. Science 288, 1640-3.

Poritz, M. A., Bernstein, H. D., Strub, K., Zopf, D., Wilhelm, H. and Walter, P. (1990). An E. coli ribonucleoprotein containing 4.5S RNA resembles mammalian signal recognition particle. Science 250, 1111-7.

Powers, T. and Walter, P. (1995). Reciprocal stimulation of GTP hydrolysis by two directly interacting GTPases. Science 269, 1422-4. 
Raine, A., Lovmar, M., Wikberg, J. and Ehrenberg, M. (2006). Trigger factor binding to ribosomes with nascent peptide chains of varying lengths and sequences. J Biol Chem 281, 28033-8.

Rapoport, T. A. (2007). Protein translocation across the eukaryotic endoplasmic reticulum and bacterial plasma membranes. Nature 450, 663-9.

Rapoport, T. A. (2008). Protein transport across the endoplasmic reticulum membrane. FEBS J 275, 4471-8.

Ritchie, T. K., Grinkova, Y. V., Bayburt, T. H., Denisov, I. G., Zolnerciks, J. K., Atkins, W. M. and Sligar, S. G. (2009). Reconstitution of membrane proteins in phospholipid bilayer nanodiscs. Methods Enzymol 464, 211-231.

Robinson, P. J., Findlay, J. E. and Woolhead, C. A. (2012). Compaction of a prokaryotic signal-anchor transmembrane domain begins within the ribosome tunnel and is stabilized by SRP during targeting. J Mol Biol 423, 600-12.

Rodnina, M. V., Savelsbergh, A., Matassova, N. B., Katunin, V. I., Semenkov, Y. P. and Wintermeyer, W. (1999). Thiostrepton inhibits the turnover but not the GTPase of elongation factor G on the ribosome. Proc Natl Acad Sci U S A 96, 9586-90.

Rodnina, M. V. and Wintermeyer, W. (1995). GTP consumption of elongation factor Tu during translation of heteropolymeric mRNAs. Proc Natl Acad Sci U S A 92, 1945-9.

Rutkowska, A., Mayer, M. P., Hoffmann, A., Merz, F., Zachmann-Brand, B., Schaffitzel, C., Ban, N., Deuerling, E. and Bukau, B. (2008). Dynamics of trigger factor interaction with translating ribosomes. J Biol Chem 283, 4124-32.

Sakaguchi, M., Tomiyoshi, R., Kuroiwa, T., Mihara, K. and Omura, T. (1992). Functions of signal and signal-anchor sequences are determined by the balance between the hydrophobic segment and the N-terminal charge. Proc Natl Acad Sci U S A 89, 16-9.

Schaffitzel, C., Oswald, M., Berger, I., Ishikawa, T., Abrahams, J. P., Koerten, H. K., Koning, R. I. and Ban, N. (2006). Structure of the E. coli signal recognition particle bound to a translating ribosome. Nature 444, 503-6. 
Seluanov, A. and Bibi, E. (1997). FtsY, the prokaryotic signal recognition particle receptor homologue, is essential for biogenesis of membrane proteins. J Biol Chem 272, 2053-5.

Shen, K., Arslan, S., Akopian, D., Ha, T. and Shan, S. O. (2012). Activated GTPase movement on an RNA scaffold drives co-translational protein targeting. Nature 492, 271-5.

Shen, K., Wang, Y., Hwang Fu, Y. H., Zhang, Q., Feigon, J. and Shan, S. O. (2013). Molecular mechanism of GTPase activation at the signal recognition particle (SRP) RNA distal end. J Biol Chem 288, 36385-97.

Shen, K., Zhang, X. and Shan, S. O. (2011). Synergistic actions between the SRP RNA and translating ribosome allow efficient delivery of the correct cargos during cotranslational protein targeting. RNA 17, 892-902.

Simon, S. M. and Blobel, G. (1991). A protein-conducting channel in the endoplasmic reticulum. Cell 65, 371-80.

Spanggord, R. J., Siu, F., Ke, A. and Doudna, J. A. (2005). RNA-mediated interaction between the peptide-binding and GTPase domains of the signal recognition particle. Nat Struct Mol Biol 12, 1116-22.

Stjepanovic, G., Kapp, K., Bange, G., Graf, C., Parlitz, R., Wild, K., Mayer, M. P. and Sinning, I. (2011). Lipids trigger a conformational switch that regulates signal recognition particle (SRP)-mediated protein targeting. J Biol Chem 286, 23489-97.

Tam, P. C., Maillard, A. P., Chan, K. K. and Duong, F. (2005). Investigating the SecY plug movement at the SecYEG translocation channel. EMBO J 24, 3380-8.

Ullers, R. S., Houben, E. N., Raine, A., ten Hagen-Jongman, C. M., Ehrenberg, M., Brunner, J., Oudega, B., Harms, N. and Luirink, J. (2003). Interplay of signal recognition particle and trigger factor at L23 near the nascent chain exit site on the Escherichia coli ribosome. J Cell Biol 161, 679-84.

Ulmschneider, M. B. and Sansom, M. S. (2001). Amino acid distributions in integral membrane protein structures. Biochim Biophys Acta 1512, 1-14. 
Valent, Q. A., Scotti, P. A., High, S., de Gier, J. W., von Heijne, G., Lentzen, G., Wintermeyer, W., Oudega, B. and Luirink, J. (1998). The Escherichia coli SRP and SecB targeting pathways converge at the translocon. EMBO J 17, 2504-12.

Van den Berg, B., Clemons, W. M., Jr., Collinson, I., Modis, Y., Hartmann, E., Harrison, S. C. and Rapoport, T. A. (2004). X-ray structure of a protein-conducting channel. Nature 427, $36-44$.

Verstraeten, N., Fauvart, M., Versees, W. and Michiels, J. (2011). The universally conserved prokaryotic GTPases. Microbiol Mol Biol Rev 75, 507-42, second and third pages of table of contents.

Voigts-Hoffmann, F., Schmitz, N., Shen, K., Shan, S. O., Ataide, S. F. and Ban, N. (2013). The Structural Basis of FtsY Recruitment and GTPase Activation by SRP RNA. Mol Cell 52, 643-54.

Walter, P. and Blobel, G. (1981). Translocation of proteins across the endoplasmic reticulum III. Signal recognition protein (SRP) causes signal sequence-dependent and site-specific arrest of chain elongation that is released by microsomal membranes. J Cell Biol 91, 557-61.

Wienken, C. J., Baaske, P., Rothbauer, U., Braun, D. and Duhr, S. (2010). Protein-binding assays in biological liquids using microscale thermophoresis. Nat Commun 1, 100.

Wu, Z. C., de Keyzer, J., Kedrov, A. and Driessen, A. J. (2012). Competitive binding of the SecA ATPase and ribosomes to the SecYEG translocon. J Biol Chem 287, 7885-95.

Zhang, X., Kung, S. and Shan, S. O. (2008). Demonstration of a multistep mechanism for assembly of the SRP x SRP receptor complex: implications for the catalytic role of SRP RNA. J Mol Biol 381, 581-93.

Zhang, X., Schaffitzel, C., Ban, N. and Shan, S. O. (2009). Multiple conformational switches in a GTPase complex control co-translational protein targeting. Proc Natl Acad Sci U S A 106, 1754-9.

Zwieb, C. and Eichler, J. (2002). Getting on target: the archaeal signal recognition particle. rchaea 1, 27-34. 


\section{Acknowledgement}

I would like to express my heartfelt gratitude to my supervisor, Prof. Wolfgang Wintermeyer. This thesis would not have been possible without the help and patience of him, not to mention his advice and creative ideas.

I am also grateful to Prof. Marina V. Rodnina for her support to work in her lab and valuable criticism.

I would like to thank my thesis committee members Prof. Ralf Ficner and Prof. Marina Bennati who provided encouraging and constructive feedback during our meetings.

My particular thanks to Thomas Bornemann for all his help and time. I learned a lot from his brilliant ideas and our stimulating discussions.

I am thankful to Wolf Holtkamp for his encouragement in frustration and helpful discussions. I would like to thank Yan Ge for her help and advices. I would also like to thank Albena Draycheva for organizing joint method course and being a good bench neighbor. Many thanks to Tamara Senyushkina for evaluations in kinetic analysis.

This work would have been very difficult without technical assistance. Special thanks to Anna Bursy and Franziska Hummel who provided me with common stocks of proteins, ribosome complexes, and nanodiscs. I would also like to thank Tanja Wiles, Olaf Geintzer and Sandra Kappler for preparations of RNAs and ribosomes and to Ant Wiles for computer facilities. I would like to acknowledge the office support of Dimitra Papastavrou. Furthermore, I would like to thank all the other members of the Department of Physical Biochemistry for making pleasant environment and creating enthusiasm.

I would also like to thank to the GGNB and its staffs for more learning opportunities and help in administration.

I could not have finished my $\mathrm{PhD}$ study without the support from my friends and family. I thank all my friends for our conversation and being there. The piano in the Max Planck Institute have been one of my best friend. Finally, I thank my parents for love and confidence in me. To my sister who shared joy and suffering with me, thank her. 


\section{Appendix A: Trigger factor and SRP on the ribosome}

Experiments were also performed on trigger factor-ribosome interaction. These experiments are not in the focus of the present thesis and in part are preliminary. Therefore, these results are briefly presented in this Appendix.

\section{A1. Introduction}

The bacterial chaperone trigger factor (TF) is is an early-acting chaperone that binds to the majority of nascent polypeptides when they emerge from the ribosome (Hartl and HayerHartl, 2002). TF forms a cradle-like structure that serves to accommodate the nascent chain (Ferbitz et al., 2004). Longer nascent chains harboring more hydrophobic amino acids contribute to the higher affinity of TF binding to the ribosome (Raine et al., 2006; Rutkowska et al., 2008).

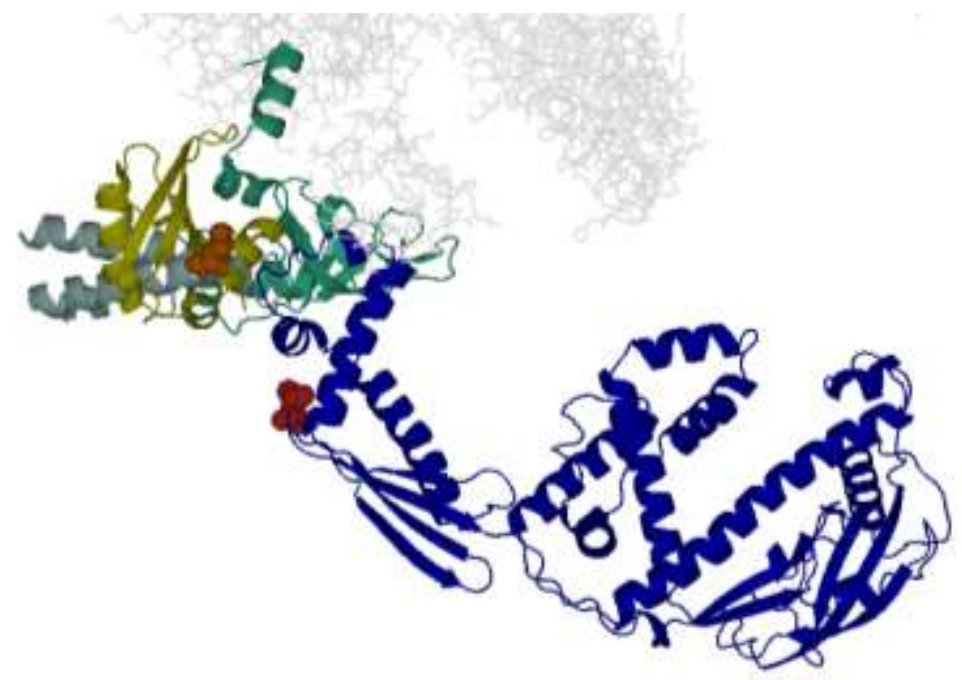

Figure 25 TF bound to the ribosome

$\mathrm{TF}$ bound at the ribosome exit is shown in blue. The labeling position in $\mathrm{TF}(\mathrm{Bpy})$ is shown in red. The labeling position in ribosomal protein L23 (MDCC) is shown in orange. Around the ribosome exit proteins L23 (yellow), L24 (green) and L29 (pale blue) are depicted. The remaining part of the ribosome is shown in light grey. Coordinates were taken from PDB files 1W2B and 1W26 (Ferbitz et al., 2004).

TF acts on nascent chains at the ribosome exit. Thus, TF and SRP share the binding site on the ribosome, L23 (Buskiewicz et al., 2004, Raine et al., 2004)(Ullers et al., 2003). However, TF and SRP do not exclude each other. TF and SRP concurrently bind to the ribosome with decreased propensity (Bornemann, in preparation). TF mainly associates with cytosolic or secretory proteins, while SRP recruits inner-membrane proteins. Chemical crosslinking 
discovered that TF prevents SRP binding to RNCs harboring secretory proteins (Beck et al., 2000). TF showed strong preferences to cytosolic proteins and outer membrane proteins, in contrast to the poor preferences to membrane proteins as indicated by ribosome profiling (Oh et al., 2011). In the context of SRP-dependent targeting, it was observed previously that FtsY weakens the interaction between TF and the SRP-ribosome complex, as indicated by pull-down assay (Buskiewicz et al., 2004). One aim of the present experiemnts with TF was to examine whether the competition between TF and FtsY would also be seen in an equilibrium assay, monitoring FRET. FRET labels were attached to ribosomal protein L23 (MDCC at position 21) and TF (BPY at position 99) (Figure 25).

\section{A2. Materials and Methods}

\section{Plasmid construct and buffers}

\begin{tabular}{|c|c|c|c|}
\hline Protein name & Vector & Resistance & Reference \\
\hline $\begin{array}{l}\text { TF-WT(SUMO) } \\
\text { TF-99C(SUMO) }\end{array}$ & $\begin{array}{l}\text { pSUMO } \\
\text { pSUMO }\end{array}$ & Kanamycin & This study \\
\hline Buffers & Purpose & \multicolumn{2}{|c|}{ Composition } \\
\hline Buffer TF- A & Cell opening & \multicolumn{2}{|c|}{$50 \mathrm{mM}$ Tris- $\mathrm{HCl}(\mathrm{pH}$ 7.6), $100 \mathrm{mM} \mathrm{NaCl}$} \\
\hline Buffer TF- B & Ni-NTA washing & \multicolumn{2}{|c|}{$\begin{array}{l}50 \mathrm{mM} \text { Tris- } \mathrm{HCl}(\mathrm{pH} 7.6), 500 \mathrm{mM} \mathrm{NaCl} \text {, } \\
15 \% \text { glycerol }\end{array}$} \\
\hline Buffer TF- C & Ni-NTA elution & \multicolumn{2}{|c|}{$\begin{array}{l}50 \mathrm{mM} \text { Tris- } \mathrm{HCl} \text { (pH 7.6), } 100 \mathrm{mM} \mathrm{NaCl} \text {, } \\
200 \mathrm{mM} \text { imidazol, } 15 \% \text { glycerol }\end{array}$} \\
\hline
\end{tabular}

\section{Purification of TF}

Cells $(15 \mathrm{~g})$ containing the overexpressed SUMO-tagged TF protein was resuspended in 50 ml Buffer TF- A with DNase I. The resuspended cells were opened with high pressure in EmulsiFlex-C3 High Pressure Homogenizer. The cell lysate was separated from the debris by the centrifugation at $15,000 \mathrm{rpm}$ for $45 \mathrm{~min}$ in the JA-25.50 fixed-angle rotor in Avanti J26 XP Beckman coulter. Supernatant was incubated for $40 \mathrm{~min}$ on $10 \mathrm{ml} \mathrm{Ni-NTA}$ resin which was pre-equilibrated in Buffer TF- A. TF bound to the resin was washed 3 times with $30 \mathrm{ml}$ Buffer TF- A, 3 times with $30 \mathrm{ml}$ Buffer TF- B and again 3 times with $30 \mathrm{ml}$ Buffer TF- A until the supernatant appears clear. For elution, the Ni-NTA resin was incubated 3 
times for $15 \mathrm{~min}$ with $7 \mathrm{ml}$ Buffer TF- C. The eluted TF protein was concentrated and rebuffered by Buffer Avusing Vivaspin MWCO of 10 kD. Purified TF was analyzed by SDSPAGE (12\%). To cleave the SUMO-tag of TF, UlpI enzyme was added into a 80:1 ratio (v/v) and incubated overnight. UlpI digested TF was again loaded on Ni-NTA and incubated for 45 min to remove the SUMO tag. Uncleaved TF as well as the SUMO tag and Ulp1 stay on the resin and untagged TF was eluted by washing Ni-NTA three times with 7 mlBuffer A. The eluates were analyzed by SDS-PAGE (12-15\%). The untagged TF was concentrated using Vivaspin MWKO of $10 \mathrm{kDa}$.

\section{Labeling of TF with fluorescent dye}

Untagged and purified TF was labeled overnight with Bpy dye in a 10-fold excess and labeling was stopped by adding 2-mercaptoethanol. Unreacted dye was removed by gelfiltration on a PD-10 column, and the eluate containing labeled TF was concentrated with Vivaspin MWCO $30 \mathrm{kDa}$ tubes. Protein concentration was measured at $280 \mathrm{~nm}(\varepsilon=17420$ $\left.\mathrm{M}^{-1} \mathrm{~cm}^{-1}\right)$ and dye concentration was measured at $508 \mathrm{~nm}\left(\varepsilon=79000 \mathrm{M}^{-1} \mathrm{~cm}^{-1}\right)$.

\section{Preparation of ribosomes containing fluorescence-labeled L23}

MDCC-labeled ribosomes were prepared following a published procedure (Holtkamp et al., 2012).

\section{A3. Result}

To determine if FtsY can replace TF on the ribosome, a competition experiment was performed by rapidly mixing the TF(BPY) complex with MDCC-labeled ribosomes with excess non-labeled TF, SRP, or FtsY in the stopped-flow apparatus. Upon dissociation of TF(BPY) from the ribosome(MDCC), the BPY fluorescence decreased rapidly (Figure 26). The dissociation of TF from the ribosome was monophasic, and the apparent dissociation rate was about $12 \mathrm{~s}^{-1}$ (Figure 26, grey). When SRP was present, a smaller signal change (10\%) was observed. This indicated that the ribosome complex with both SRP and TF assumes a different conformation, consistent with the obsreved partial competitive binding of the two ligands (Bornemann et al., submitted). Mixing the ribosome-TF complex with FtsY alone had no effect (Figure 26, blue), as expected since FtsY does not bind to the ribosome on its own. When Therefore, the same experiment was performed in the presence 
of SRP. TF(BPY) bound to the ribosome(MDCC)-SRP complex was mixed with TF or FtsY. Upon mixing with FtsY, no signal change was observed, indicating that again FtsY does not diseplace TF on the ribosome. Upon mixing with TF, a biphasic signal in BPY fluorescence was observed, suggesting that TF dissociates from the ribosome-SRP complex but slower than in the absence of SRP by a factor of $50\left(\mathrm{k}_{-2} \sim 0.2 \mathrm{~s}^{-1}\right)$.

a

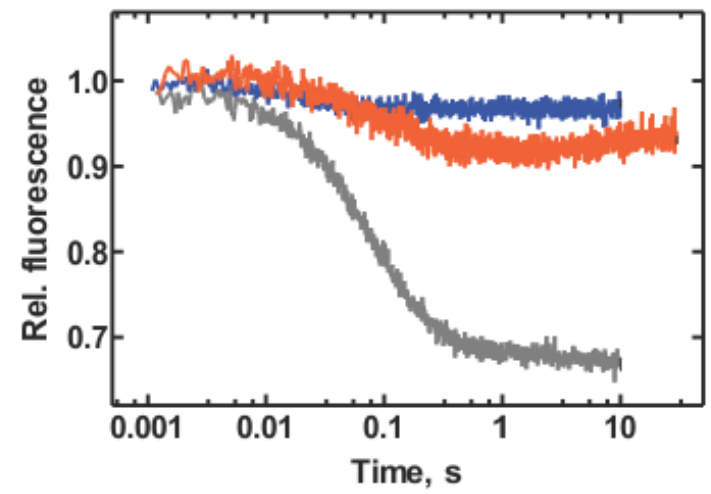

b

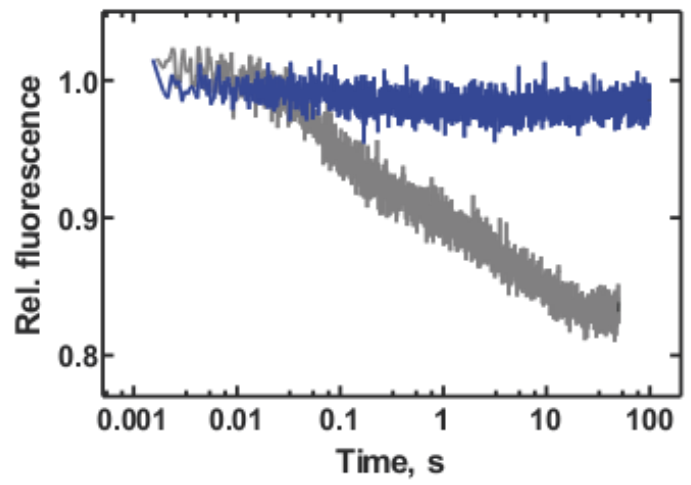

Figure 26 Dissociation of TF from ribosomes and the effect of SRP and FtsY

$25 \mathrm{nM}$ ribosome(MDCC) and $500 \mathrm{nM} \mathrm{TF}(\mathrm{Bpy})$ were rapidly mixed with either $5 \mu \mathrm{M} \mathrm{TF}$ (grey), $4 \mu \mathrm{M}$ SRP (orange) or $2 \mu \mathrm{M}$ Fts Y (blue) in the absence (a) and presence (b) of $1 \mu \mathrm{M}$ SRP. The initial fluorescence is set to 1.0 .

To examine the effect of the SRP-FtsY complex on TF binding to the ribosome in more detail, the dissociation of $\mathrm{TF}(\mathrm{BPY})$ from the ribosome(MDCC) complex with SRP-FtsY was measured. A biphasic time course was observed with a slow second phase (Figure 27a, green). The time course was fitted to a double-exponential term, which yielded elemental rate constant $\mathrm{k}_{-1}$ of $10 \mathrm{~s}^{-1}$ and $\mathrm{k}_{-2}$ of $0.2 \mathrm{~s}^{-1}$. $\mathrm{k}_{\text {off } 1}$ is in the same range with $\mathrm{k}_{\text {off }}$ of $12 \mathrm{~s}^{-1}$ when

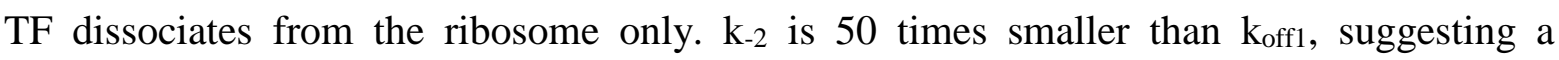
stabilization or a conformational change of TF on the ribosome in the presence of the SRPFtsY complex.

To see if the stabilization is due to SRP or the SRP-FtsY complex, the same set of dissociation was performed in the presence of SRP alone (Figure 27a, orange). The similar time course and elemental rate constants in the presence of SRP ( $\mathrm{k}_{-1}$ of $10 \mathrm{~s}^{-1}$ and $\mathrm{k}_{-2}$ of 0.12 $\mathrm{s}^{-1}$ ) were observed. This indicates that the stabilization of the TF-ribosome complex is mainly due to the presence of SRP, suggesting an interaction between SRP and TF on the ribosome. 

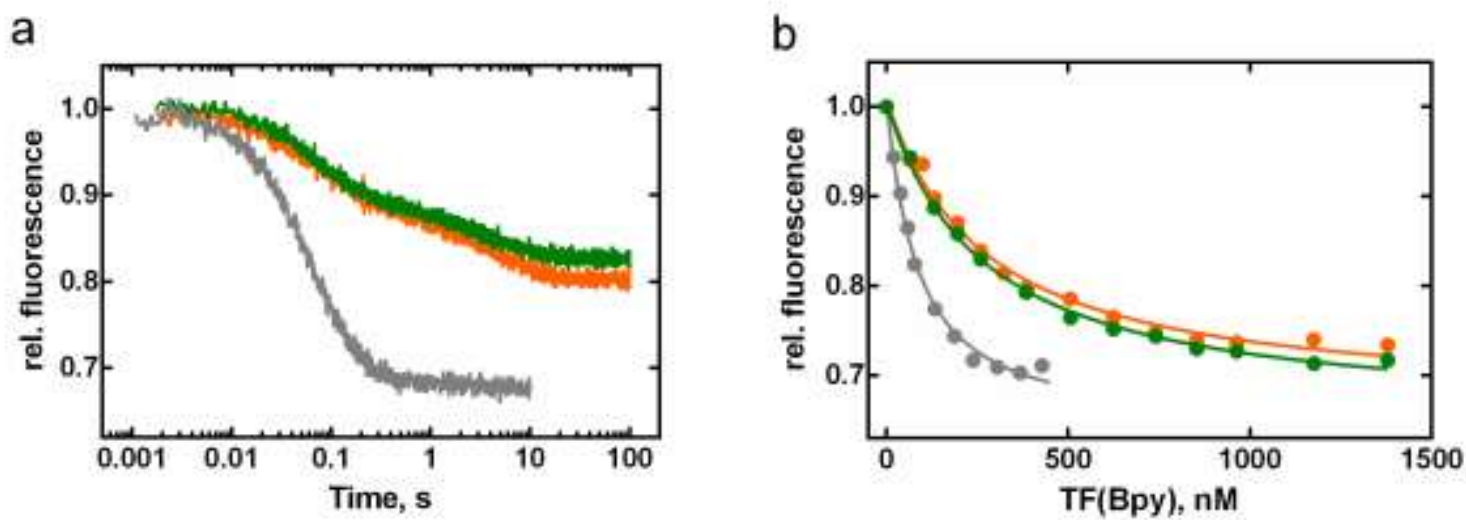

Figure 27 Influence of SRPon TF binding to ribosomes

(a) Time courses of the dissociation of TF from the ribosome in the absence of SRP (grey) and in the presence of $1 \mu \mathrm{M}$ SRP alone (yellow) or $1 \mu \mathrm{M}$ SRP and $3 \mu \mathrm{M}$ FtsY complexes (green). (b) Equilibrium titrations of $\mathrm{TF}(\mathrm{BPY})$ binding to the ribosome(MDCC) (grey), in the presence of $1 \mu \mathrm{M}$ SRP (yellow), and in the presence of $1 \mu \mathrm{M}$ SRP and $3 \mu \mathrm{M}$ FtsY (green).

Equilibrium titration was performed to determine the affinity of TF binding to the ribosome alone or in a complex with SRP (or with FtsY). Since the TF-ribosome complex was more stable in the presence of SRP, it was assumed that the affinity of Fts Y binding to the ribosome is higher in the presence of SRP. The same was expected in the presence of the SRP-FtsY complex. However, the affinity of TF binding to the ribosome decreased four times from $70 \mathrm{nM}$ to $250 \mathrm{nM}$ (Figure 27b). This indicates that the effect of SRP on the TFribosome complex must be more complex.

To determine kinetic parameters of the TF-ribosome complex in the presence of SRP, the influence of SRP on the dissociation of TF from the ribosome was quantified. With varying the concentration of SRP, the dissociation of $\mathrm{TF}(\mathrm{BPY})$ from the ribosome(MDCC) was performed (Figure 28a). Dissociation rate constants decreased on a small scale from $9 \mathrm{~s}^{-1}$ to $5.3 \mathrm{~s}^{-1}\left(\mathrm{k}_{-1}\right)$ and from $0.2 \mathrm{~s}^{-1}$ to $0.14 \mathrm{~s}^{-1}\left(\mathrm{k}_{-2}\right)$ with the increasing concentration of SRP from 1 to $3 \mu \mathrm{M}$. As indicated by the analysis of the amplitudes, the slow step became more prominent with increasing concentration of SRP (Figure 28b), indicating saturation of the second phase at $3 \mu \mathrm{M}$ SRP. At $3 \mu \mathrm{M}$ of SRP, more than $80 \%$ of the dissociation of TF from the ribosome was seen in the second phase with the the apparent rate constant $\left(\mathrm{k}_{\mathrm{app} 2}\right)$ of 0.14 $\mathrm{s}^{-1}$. 

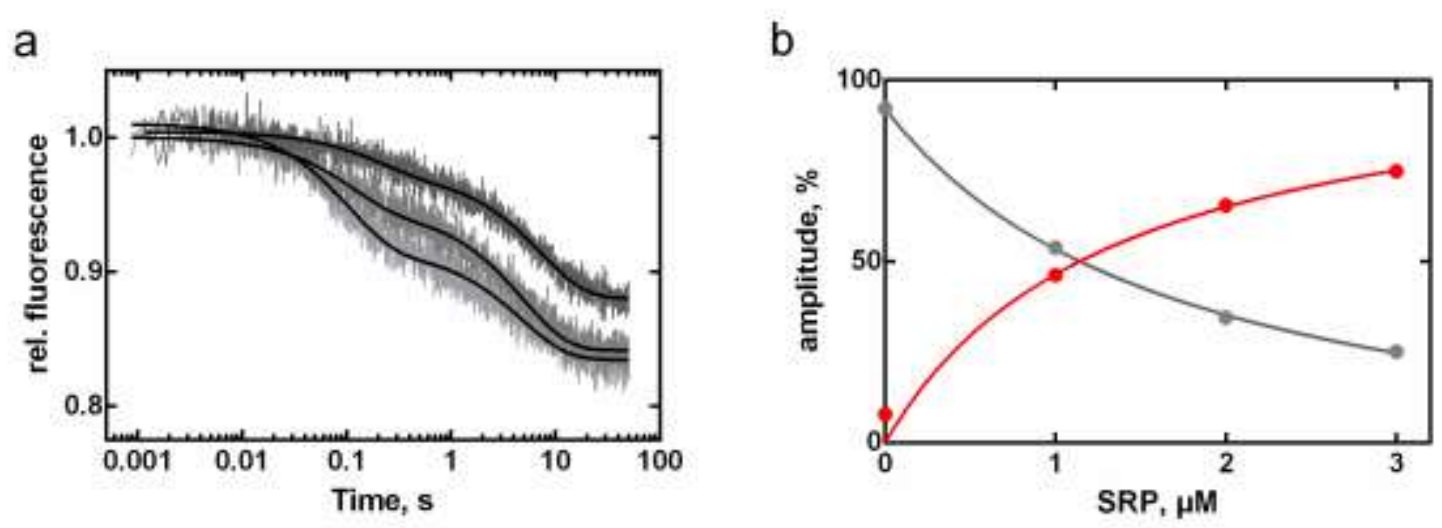

Figure 28 The dissociation of TF from the ribosome in the presence of SRP

(a) Time courses of the dissociation of TF from the ribosome. $25 \mathrm{nM}$ ribosome(MDCC) and $500 \mathrm{nM} \mathrm{TF}(\mathrm{BPY})$ were rapidly mixed with $5 \mu \mathrm{M}$ TF in the presence of 1,2 , and $3 \mu \mathrm{M}$ SRP (from grey to black) (b) The relative signal change of the first phase (grey) and the second phase (red).

The inconsistency of kinetic stability and affinity indicates that SRP affected not only the rate of TF dissociation from, but also the rate of TF association with the ribosome. Therefore, the association kinetics were examined in the presence and absence of $3 \mu \mathrm{M}$ SRP, again monitoring FRET. The time course observed in the absence of SRP could be fitted to a single exponential term, indicating a single binding step with $\mathrm{k}_{\text {app }}$ of $100 \mathrm{~s}^{-1}$ (Figure 29, grey). In the presence of SRP, the time course had to be fitted by a double-exponential term, indicating a two-step binding scheme with decreased rate constants $\left(\mathrm{k}_{\mathrm{app} 1} \sim 7 \mathrm{~s}^{-1}\right.$ and $\mathrm{k}_{\mathrm{app} 2}$ $\sim 0.12 \mathrm{~s}^{-1}$ ) (Figure 29, red).

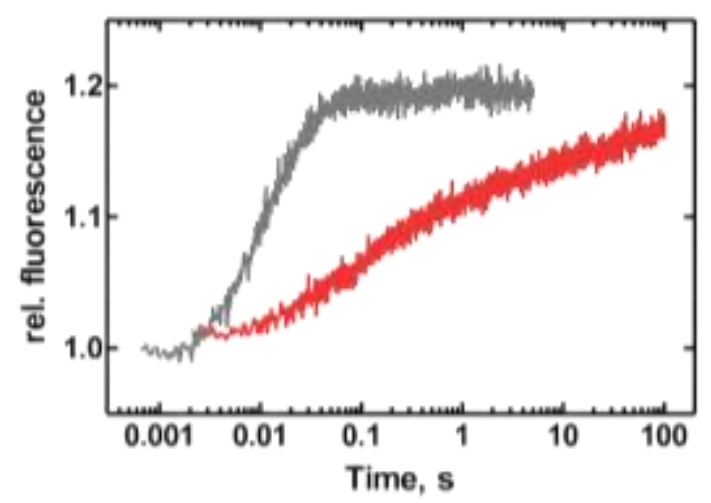

Figure 29 Effect of SRP on the kinetics of TF binding to ribosomes

Time courses of $1 \mu \mathrm{M}$ TF(BPY) binding to $25 \mathrm{nM}$ ribosome(MDCC) in the absence (grey) and in the presence of $3 \mu \mathrm{M}$ SRP (red). 
To determine kinetic parameters of TF-SRP-ribosome complexes, the ribosome(MDCC) saturated with SRP were titrated with $\mathrm{TF}(\mathrm{BPY})$. Of the two apparent rate constants, $\mathrm{k}_{\mathrm{app} 1}$ showed linear concentration dependency and $\mathrm{k}_{\mathrm{app} 2}$ was independent on the concentration of TF (Figure 30). Global fitting of association traces and dissociation time courses based on elemental rate constants (at $3 \mu \mathrm{M}$ SRP) resulted in rate constants (Table 4). Compared to the binding of TF to the ribosome ( $\mathrm{k}_{\text {on }}$ of $85 \mu \mathrm{M}^{-1} \mathrm{~s}^{-1}$, (Bornemann et al., submitted)), much slower binding $\left(\mathrm{k}_{1} \sim 8 \mu \mathrm{M}^{-1} \mathrm{~s}^{-1}\right)$ was observed as well as slow dissociation.

a

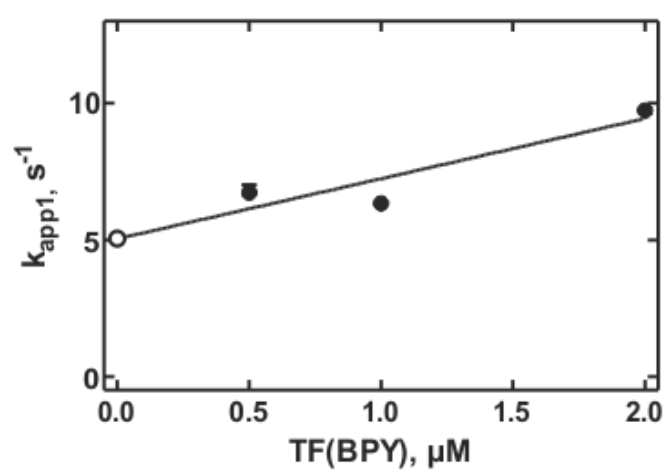

b

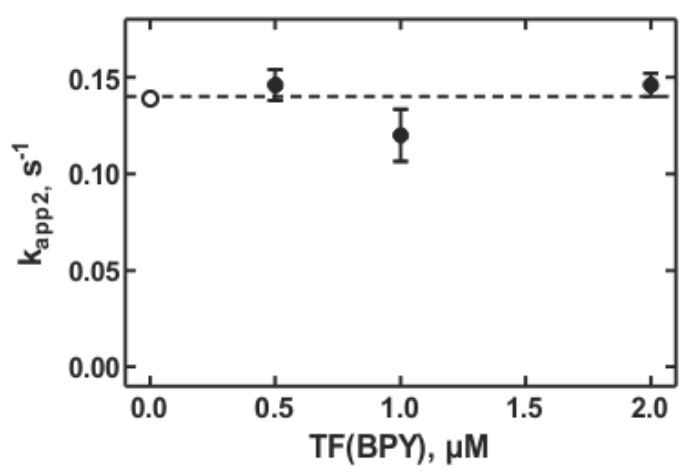

Figure 30 Kinetics of TF binding to ribosomes in the presence of SRP

Concentration dependence of TF binding to the ribosome in the presence of $3 \mu \mathrm{M}$ SRP. Empty circles in graphs are apparent values of $\mathrm{k}_{-1}$ and $\mathrm{k}_{-2}$ from the dissociation experiment.

Table 4 Rate constants of TF binding to ribosome in the presence of SRP

\begin{tabular}{|l|c|l|c|}
\hline \multicolumn{2}{|c|}{ Forward rate constants } & \multicolumn{2}{c|}{ Backward rate constants } \\
\hline $\mathrm{k}_{1}, \mu \mathrm{M}^{-1} \mathrm{~s}^{-1}$ & $8.6 \pm 0.2$ & $\mathrm{k}_{-1}, \mathrm{~s}^{-1}$ & 5.3 \\
\hline $\mathrm{k}_{2}, \mathrm{~s}^{-1}$ & $0.11 \pm 0.07$ & $\mathrm{k}_{-2}, \mathrm{~s}^{-1}$ & 0.14 \\
\hline $\mathrm{Kd}, \mathrm{nM}$ & $780 *(350)$ & \multicolumn{2}{|}{} \\
\cline { 1 - 3 } & &
\end{tabular}

* Kd calculated from rate constants; $(\mathrm{Kd})$ determined by equilibrium titration

The $K_{d}$ value calculated from the preliminary kinetic parameters was comparable with the $\mathrm{K}_{\mathrm{d}}$ value determined by titration within a factor of two, suggesting that the model was suitable to describe the interplay between SRP and TF on the ribosome. An extended kinetic analysis is required, however, to validate the model. In particular, further kinetic experiments examining RNCs exposing TF-specific and SRP-specific nascent chains will have to be carried out to arrive at a model that is relevant for the situation in vivo. 